\title{
Cognitive function in patients with cerebral small vessel disease : a study on vascular and brain imaging markers
}

Citation for published version (APA):

Huijts, M. (2014). Cognitive function in patients with cerebral small vessel disease : a study on vascular and brain imaging markers. [Doctoral Thesis, Maastricht University]. Maastricht University. https://doi.org/10.26481/dis.20140124mh

Document status and date:

Published: 01/01/2014

DOI:

10.26481/dis.20140124mh

Document Version:

Publisher's PDF, also known as Version of record

Please check the document version of this publication:

- A submitted manuscript is the version of the article upon submission and before peer-review. There can be important differences between the submitted version and the official published version of record.

People interested in the research are advised to contact the author for the final version of the publication, or visit the DOI to the publisher's website.

- The final author version and the galley proof are versions of the publication after peer review.

- The final published version features the final layout of the paper including the volume, issue and page numbers.

Link to publication

\footnotetext{
General rights rights.

- You may freely distribute the URL identifying the publication in the public portal. please follow below link for the End User Agreement:

www.umlib.nl/taverne-license

Take down policy

If you believe that this document breaches copyright please contact us at:

repository@maastrichtuniversity.nl

providing details and we will investigate your claim.
}

Copyright and moral rights for the publications made accessible in the public portal are retained by the authors and/or other copyright owners and it is a condition of accessing publications that users recognise and abide by the legal requirements associated with these

- Users may download and print one copy of any publication from the public portal for the purpose of private study or research.

- You may not further distribute the material or use it for any profit-making activity or commercial gain

If the publication is distributed under the terms of Article $25 \mathrm{fa}$ of the Dutch Copyright Act, indicated by the "Taverne" license above, 


\section{Cognitive function in patients with cerebral small vessel disease}

A study on vascular and brain imaging markers 
Cognitive function in patients with cerebral small vessel disease - A study on vascular and brain imaging markers, by Marjolein Huijts

ISBN: 978-90-5335-785-9

Financial support for printing of this thesis was kindly provided by Boehringer Ingelheim BV, Science Plus Group BV, Servier Nederland Farma and Internationale Stichting Alzheimer Onderzoek.

Lay-out: Marjolein Huijts

Cover and image design: Alex Uyttendaele

Cover photo: "Guardian" by Shana and Robert ParkeHarrison

Printed by: Ridderprint, Ridderkerk (NL)

(C) 2014, Marjolein Huijts

All rights are reserved. Reproduction in whole or in part is prohibited without prior written consent of the copyright owner. 


\section{Cognitive function in patients with cerebral small vessel disease}

A study on vascular and brain imaging markers

PROEFSCHRIFT

ter verkrijging van de graad van doctor

aan de Universiteit Maastricht,

op gezag van de Rector Magnificus, Prof. dr. L.L.G. Soete,

volgens het besluit van het College van Decanen,

in het openbaar te verdedigen

op vrijdag 24 januari 2014 om 14.00 uur

door

Marjolein Huijts 


\section{Promotor}

Prof. dr. R.J. van Oostenbrugge

\section{Copromotores}

Dr. A.A. Duits

Dr. J. Staals

\section{Beoordelingscommissie}

Prof. dr. R.W.H.M. Ponds

Dr. P.A.M. Hofman

Dr. R.J.M.W. Rennenberg

Prof. dr. F.R.J. Verhey

Prof. dr. H.C. Weinstein, st. Lucas Andreas Ziekenhuis Amsterdam

The research described in this thesis was performed at the Department of Neurology, Maastricht University Medical Centre, and within the School for Mental Health and Neuroscience (MHeNS) and Cardiovascular Research Institute Maastricht (CARIM) of Maastricht University.

Financial support by the Dutch Heart Foundation for the publication of this thesis is gratefully acknowledged. 
voor oma

"Some us think holding on makes us strong but sometimes it is letting go"

Herman Hesse 



\section{TABLE OF CONTENTS}

\section{INTRODUCTION}

Chapter 1. General introduction 9

Chapter 2. The relation of cerebral small vessel disease and cognition in patients with or at risk for cardiovascular disease

\section{PART I - HYPERTENSION}

Chapter 3. Arterial stiffness and cognitive function in essential hypertensive patients

Chapter 4. Progression of cerebral small vessel disease predicts cognitive function at follow-up in hypertensive patients

\section{PART II - CONGESTIVE HEART FAILURE}

Chapter 5. Cognitive impairment in heart failure: results from the Trial of Intensified vs standard Medical therapy in Elderly patients with Congestive Heart Failure (TIME-CHF) trial

\section{PART III - LACUNAR STROKE}

Chapter 6. Association of vitamin B12 deficiency with fatigue and depression after lacunar stroke

Chapter 7. Effects of vitamine B12 supplementation on cognition, depression and fatigue in patients with lacunar stroke

Chapter 8. Brain microbleeds do not independently relate to cognition in patients with cerebral small vessel disease

Chapter 9. Cognitive function and enlarged perivascular spaces in patients with cerebral small vessel disease

Chapter 10. Accumulation of MRI markers of cerebral small vessel disease is associated with decreased cognitive function. A study in first-ever lacunar stroke and hypertensive patients

\section{SUMMARY}

Chapter 11. General discussion and future perspectives

Dankwoord

Publications 
8 


\section{Chapter}


$10 \mid$ Chapter 1 


\section{Cerebral small vessel disease and cognitive function}

Cerebral small vessel disease (cSVD) refers to a cluster of pathological mechanisms with varying etiologies that affects the small perforating end-arteries, arterioles, venules and capillaries in the brain ${ }^{1}$. Manifestations of cSVD can be seen on magnetic resonance imaging (figure 1-4) and may include small focal areas of infarction (lacunar infarcts), hyperintense areas on T2- weighted and FLAIR images (white matter lesions [WMLs]), small dot-like hemosiderin deposits (brain microbleeds [BMBs]) and enlarged cerebrospinal fluid-filled cavities surrounding the perforating arteries of the brain (enlarged perivascular spaces [EPVS] $)^{1-4}$.

Clinical symptoms of cSVD can be divided in acute symptoms, such as a lacunar stroke syndrome, and subacute symptoms such as cognitive impairment ${ }^{5}$, mood disorders ${ }^{6}$, gait disturbances ${ }^{7}$ and urinary symptoms ${ }^{8}$. Most of these subacute symptoms have been explained by a disconnection of prefrontal-subcortical circuits ${ }^{9}$. Regarding cognition this may result in executive dysfunction and slowing of psychomotor speed, but also, though less prominent, memory problems.

Cerebral small vessel disease is associated with increasing age and vascular risk factors. Its MRI markers may be present in the healthy elderly population, but can also be expected in patients with vascular risk factors that affect the microvasculature, such as hypertension ${ }^{10}$ and diabetes ${ }^{11}$, and in patients with clinical manifestations of cSVD, such as lacunar stroke patients. However, patients with large vessel occlusion (cortical stroke) and other cardiovascular diseases, such as coronary artery disease and congestive heart failure (CHF), may also show MRI expressions of cSVD due to cerebral hypoperfusion. Consequently, associations between markers of cSVD and cognitive function have been found in population as well as hospital-based studies ${ }^{12-15}$.

\section{OUTLINE OF THIS THESIS - CHAPTER 2}

The aim of this chapter was to review the literature for associations between structural cerebrovascular lesions related to cSVD and cognitive function in patient groups with or at risk for cardiovascular disease.

In this thesis, we describe three hospital-based populations with an increased risk for cSVD and cognitive impairment: patients with essential hypertension, patients with congestive heart failure and patients with lacunar stroke.

\section{PART I - Hypertension}

Hypertension is a major risk factor for $\mathrm{cSVD}^{16}$ and cognitive decline, but the mechanisms underlying hypertension-related cognitive decline are complex and not yet fully understood. Earlier we found that $20 \%$ of hypertensive patients showed advanced WMLs and that silent 


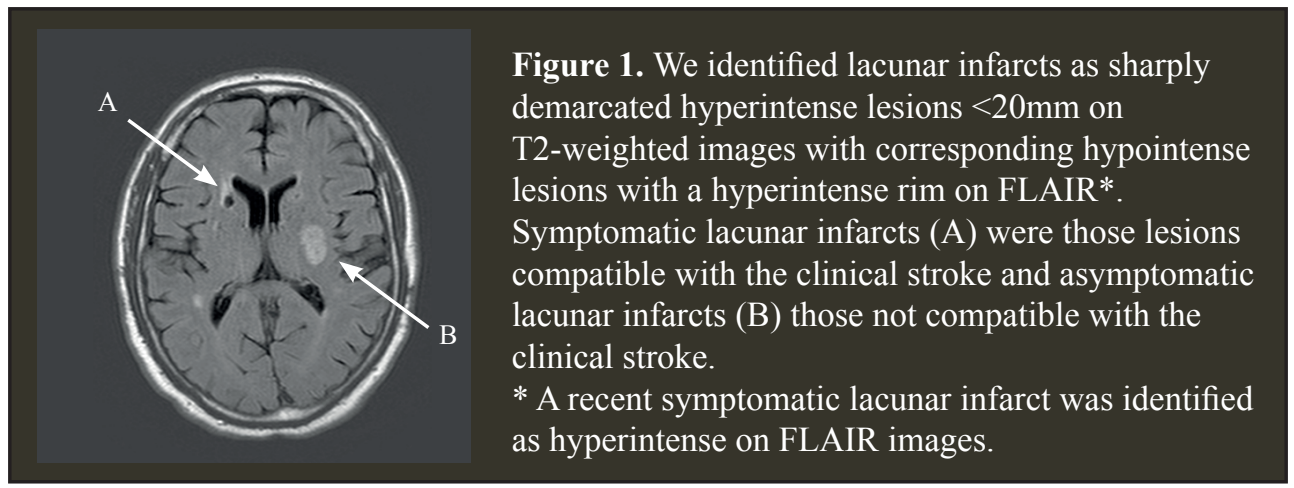

Figure 2. White matter lesions were identified as hyperintense areas on T2-weighted images. WMLs connected to the lateral ventricles were rated as periventricular, otherwise we considered them as deep.

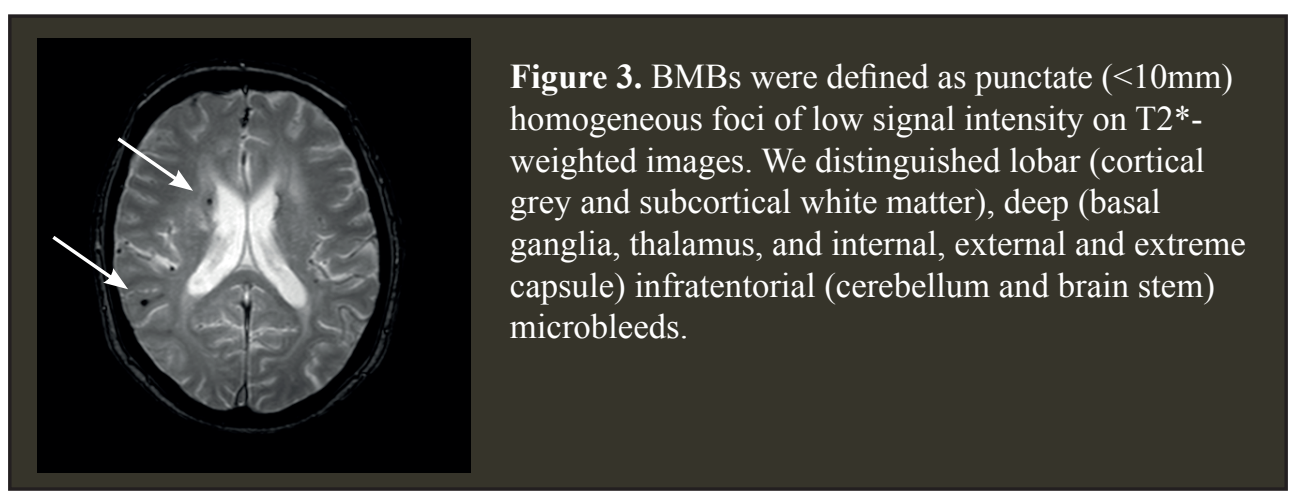

Figure 4. EPVS were defined as round, oval or linear shaped lesions with a smooth margin, absence of mass effect and with signal intensity equal to cerebrospinal fluid on T2-weighted images and (if visible) hypointense on FLAIR images without hyperintense rim to distinguish them from old lacunar infarcts.

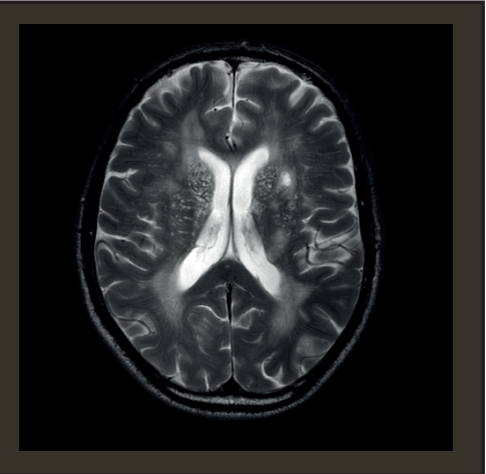


brain infarcts were present in $29 \%$ and BMBs in about $15 \%{ }^{17}$. Although hypertension constitutes a major risk factor for cSVD, it cannot account for all the risk of cognitive decline ${ }^{3}$. Therefore, other risk factors need to be investigated in order to disentangle the complex model of the pathogenesis of cSVD-mediated cognitive decline.

Recent evidence suggests a role for arterial stiffness ${ }^{18}$. Arterial stiffness gradually increases due to the effects of age and hypertension. Previous research into the relationship between arterial stiffness and cognitive functioning revealed a negative association ${ }^{19-29}$, in particular with memory performance ${ }^{18,30,31}$. Others investigated relationships between arterial stiffness and cSVD and found that increased arterial stiffness was positively associated with severity or volume of white matter lesions $(\mathrm{WMLs})^{30,32-34}$, presence or number of lacunar infarcts $(\mathrm{LACs})^{32,34,35}$, but not with number of $\mathrm{BMBs}^{32,33}$. Only a few studies ${ }^{18,25,31}$ explored associations with specific cognitive domains, and a "cerebral microvascular mechanism" for decreased cognitive performance in patients with arterial stiffness ${ }^{36}$ has not yet been investigated.

Numerous studies investigated the relation between hypertension and cognitive function, but only a few took the mediating factor cSVD into account. Additionally, those who did, mainly focused on the interrelationship with WMLs. Associations between WMLs and executive function and attention were most often found in hypertensive patients. The interrelationship with lacunar infarcts or BMBs were rarely studied, although it was recently found that these manifestations were present in $20 \%$ and $16 \%$ of the hypertensive patients respectively ${ }^{37,38}$.

\section{OUTLINE OF THIS THESIS - CHAPTER 3 \& 4}

The aim of chapter 3 was to explore a "cerebral microvascular mechanism" for decreased cognitive performance in hypertensive patients with arterial stiffness. The aim of chapter 4 was to study the association of progression of cSVD with cognitive function in patients with essential hypertension.

\section{PART II - Congestive heart failure}

Evidence regarding an association between CHF and cognitive impairment is increasing ${ }^{39}$ and may include up to $50 \%$ of patients with $\mathrm{CHF}^{40}$. Cognitive impairment may have significant influence on health outcome in patients with CHF, since they have to adequately manage their medication and diet, as well as to be alert on CHF symptoms ${ }^{40}$. The exact pathophysiological mechanism of cognitive deficits associated with CHF is still unclear.

Regarding a direct relationship between CHF severity and cognitive impairment, it was recently found that most CHF patients (83\%) with normal scores on a cognitive screening test were classified in New York Heart Association (NYHA) class I or II, whereas 66\% of those patients with abnormal scores were classified in NYHA class III or IV ${ }^{41}$. Additionally, pa- 
tients in the lowest and highest quintile left ventricular ejection fraction (LVEF), as compared to the middle ones, performed worse on cognitive measures ${ }^{42}$. A decline in cognitive function could not be explained by $\mathrm{LVEF}^{43}$. However, no longitudinal data are available regarding changes in CHF severity and changes in cognitive function.

Regarding the mechanisms through which CHF may act on cognitive function, it has been proposed that chronic or intermittent cerebral hypoperfusion due to low cardiac output or impaired cerebrovascular reactivity could result in cerebral hypoxia and ischemic brain damage $^{44}$. As shown on brain MR, CHF patients presented with increased frequencies of small vessel disease consisting of lacunar infarcts and white matter lesions ${ }^{45}$, most probably due to hypoperfusion and impaired flow regulation. Vogels et $\mathrm{al}^{46}$ investigated the relation between cognitive function and cerebral abnormalities in patients with CHF, but failed to find an association of WMLs with cognitive function. Another mechanism suggested by Jefferson et $\mathrm{al}^{47}$ is the influence of environmental and genetic risk factors on both reduced cardiac output and abnormal brain aging (cSVD and cognitive impairments).

It is not clear whether treatments to improve cardiac and vascular function also translate in improvement of cognitive function. The finding that cerebral blood flow in patients with CHF was restored and cognitive function improved ${ }^{48}$ after heart transplantation ${ }^{49}, 50$, supposedly due to improved cardiac function, suggests that some mechanisms might be reversible. However, longitudinal studies on cognitive impairment in CHF patients are sparse $\mathrm{e}^{40}$ and whether changes in cognitive impairment occur when CHF severity changes is unknown ${ }^{51}$.

\section{OUTLINE OF THIS THESIS - CHAPTER 5}

The aim of this chapter was to assess the prevalence of severe cognitive impairment in elderly patients with CHF, its correlates with CHF severity, and its effect on morbidity and mortality. In addition, we tested if changes in measures of CHF severity would result in changes of cognitive function.

\section{PART III - Lacunar stroke}

We recently found that around $30 \%$ of lacunar stroke patients are vitamin B12 deficient ${ }^{52}$ while in the normal elderly population this is only $10-15 \% 0^{53}$. This deficiency was related to the degree of periventricular white matter lesions (pWMLs) ${ }^{52}$. WMLs in turn are known to be related to depression ${ }^{54}$, while post-stroke depressive symptoms have been associated with an increased risk of post-stroke fatigue ${ }^{55}$. The prevalence of depression in lacunar stroke patients was found to be $35 \%{ }^{56}$. The prevalence of fatigue in these patients is $38 \%^{57}$. So far, there are no data available on the relationship between vitamin B12 deficiency and either depression or fatigue in lacunar stroke patients. Besides fatigue and depression, vitamin B12 deficiency was also found to be related to decreased cognitive functioning ${ }^{58}$. 59 . Since vitamin B12 de- 
ficiency is easily treatable with supplementation, possible effects on cognitive function and post-stroke fatigue and depression may have significant effects on quality of life after lacunar stroke.

\section{OUTLINE OF THIS THESIS - CHAPTER 6 \& 7}

In chapter 6 we aimed to compare levels of fatigue and depression in first-ever lacunar stroke patients with and without vitamin B12 deficiency. Consequently, in chapter 7, we were interested whether vitamin B12 supplementation would affect cognitive function or improve fatigue and depressive symptoms in lacunar stroke patients with vitamin B12 deficiency.

The relation between lacunar stroke and cognitive function has been well established in the present literature and risk factors for decreased cognitive performance or cognitive decline have been widely studied. Chronic kidney disease ${ }^{60}$, brain atrophy ${ }^{61,62}$, and cSVD markers as WMLs ${ }^{63-65}$ and lacunar infarcts ${ }^{60}$ have been suggested before. More recently, BMBs and EPVS have also been recognized as markers of $\mathrm{cSVD}^{66,67}$.

The presence of BMBs has been mainly studied in the healthy elderly population and prevalences ranged from $4 \%$ to $15 \%{ }^{14,68-70}$. Evidence for an association between BMBs and cognitive function is increasing, but study populations vary from healthy elderly populations to stroke or TIA patients $^{71}$ or patients from the memory clinic ${ }^{72,73}$. Patients with cerebrovascular disease however have not been studied that extensively yet, which is surprising, since BMBs are expected in these populations. Additionally, it is not yet clear whether the association of BMBs with cognitive function is independent of other markers of cSVD.

EPVS are now also being recognized as a feature of $\mathrm{cSVD}^{2}$ and have been related to cSVD severity $^{74}$. In general, patients with EPVS remain asymptomatic ${ }^{75}$ and therefore EPVS are considered benign. However, MacLullich et $\mathrm{al}^{13}$ found that increased EPVS were related to decreased cognitive function in healthy elderly men. This relationship however, was not independent from WMLs, which were already known to be correlated to EPVS ${ }^{76,77}$. Although EPVS have been related to CSVD, their presence has not been studied in relation to cognitive function in patients with cSVD.

The markers of cSVD have all been individually linked to cognitive functioning ${ }^{71,78-80}$, often adjusted for each of the other manifestations. When investigated together, studies mainly focused on the combination of lacunar infarcts and WMLs. Others ${ }^{15,81}$ suggested that the combined occurrence was associated with stronger reductions in cognitive function and decline than each of the two lesion types alone. However, no data are available on the clinical consequences of the total burden of cSVD, thus the co-occurrence of two or more markers of cSVD. 


\section{OUTLINE OF THIS THESIS - CHAPTER $8,9 \& 10$}

The aim of chapter 8 was to assess the preence of BMBs in patients with a high risk for cSVD (essential hypertenisve and first-ever lacunar stroke patients) as well as to study associations of presence, number and location of BMBs with cognitive function, independent of other markers of cSVD. The objective of chapter 9 was to assess the relationship between EPVS and cogniitve function in the same population. No data are available on the clinical consequences of the total burden of cSVD, expressed by the co-occurrence of several different markers of cSVD. In chapter 10 we aimed to investigate whether an accumulation of MRI markers of cSVD was associated with a decreased performance in cognitive function.

\section{Aim of this thesis}

The general aim of this thesis was to explore the association of vascular and brain imaging markers with cognitive function in patients with or at risk for cerebral small vessel disease. Therefore, we studied three hospital-based populations with an increased risk for cSVD and cognitive impairment: patients with essential hypertension, patients with congestive heart failure and patients with lacunar stroke.

\section{OUTLINE OF THIS THESIS - CHAPTER $11 \& 12$}

Chapter 11 presents a general discussion of our findings with implications for future research and interventions. In chapter 12 we summarized our findings in English and Dutch. 


\section{References}

1. Pantoni L. Cerebral small vessel disease: from pathogenesis and clinical characteristics to therapeutic challenges. Lancet Neurol. 2010;9:689-701

2. Doubal FN, MacLullich AM, Ferguson KJ, Dennis MS, Wardlaw JM. Enlarged perivascular spaces on MRI are a feature of cerebral small vessel disease. Stroke. 2010;41:450-454

3. Vermeer SE, Longstreth WT, Jr., Koudstaal PJ. Silent brain infarcts: a systematic review. Lancet Neurol. 2007;6:611-619

4. Wardlaw JM, Lewis SC, Keir SL, Dennis MS, Shenkin S. Cerebral microbleeds are associated with lacunar stroke defined clinically and radiologically, independently of white matter lesions. Stroke. 2006;37:26332636

5. van der Flier WM, van Straaten EC, Barkhof F, Verdelho A, Madureira S, Pantoni L, et al. Small vessel disease and general cognitive function in nondisabled elderly: the LADIS study. Stroke. 2005;36:2116-2120

6. White CL, McClure LA, Wallace PM, Braimah J, Liskay A, Roldan A, et al. The correlates and course of depression in patients with lacunar stroke: results from the Secondary Prevention of Small Subcortical Strokes (SPS3) study. Cerebrovasc Dis. 2011;32:354-360

7. de Laat KF, van Norden AG, Gons RA, van Oudheusden LJ, van Uden IW, Bloem BR, et al. Gait in elderly with cerebral small vessel disease. Stroke. 2010;41:1652-1658

8. Poggesi A, Pracucci G, Chabriat H, Erkinjuntti T, Fazekas F, Verdelho A, et al. Urinary complaints in nondisabled elderly people with age-related white matter changes: the Leukoaraiosis And DISability (LADIS) Study. J Am Geriatr Soc. 2008;56:1638-1643

9. Wolfe N, Linn R, Babikian VL, Knoefel JE, Albert ML. Frontal systems impairment following multiple lacunar infarcts. Arch Neurol. 1990;47:129-132

10. Sierra C, De La Sierra A, Salamero M, Sobrino J, Gomez-Angelats E, Coca A. Silent cerebral white matter lesions and cognitive function in middle-aged essential hypertensive patients. Am J Hypertens. 2004; 17:529-534

11. Saczynski JS, Jonsdottir MK, Garcia ME, Jonsson PV, Peila R, Eiriksdottir G, et al. Cognitive impairment: an increasingly important complication of type 2 diabetes: the age, gene/environment susceptibility--Reykjavik study. Am J Eepidem. 2008;168:1132-1139

12. Pantoni L, Poggesi A, Inzitari D. The relation between white-matter lesions and cognition. Curr Opin Neurol. 2007;20:390-397

13. Maclullich AM, Wardlaw JM, Ferguson KJ, Starr JM, Seckl JR, Deary IJ. Enlarged perivascular spaces are associated with cognitive function in healthy elderly men. J Neurol, Neurosurg Psychiatry. 2004;75:1519-1523 14. Poels MM, Ikram MA, van der Lugt A, Hofman A, Niessen WJ, Krestin GP, et al. Cerebral microbleeds are associated with worse cognitive function: the Rotterdam Scan Study. Neurology. 2012;78:326-333

15. Jokinen H, Gouw AA, Madureira S, Ylikoski R, van Straaten EC, van der Flier WM, et al. Incident lacunes influence cognitive decline: the LADIS study. Neurology. 2011;76:1872-1878

16. Spence JD. Cerebral consequences of hypertension: where do they lead? J hypertens. 1996;14:S139145

17. Henskens LH, van Oostenbrugge RJ, Kroon AA, Hofman PA, Lodder J, de Leeuw PW. Detection of silent cerebrovascular disease refines risk stratification of hypertensive patients. J Hypertens. 2009;27:846-853 18. Waldstein SR, Rice SC, Thayer JF, Najjar SS, Scuteri A, Zonderman AB. Pulse pressure and pulse wave velocity are related to cognitive decline in the Baltimore Longitudinal Study of Aging. Hypertension. 2008;51:99-104

19. Hanon O, Haulon S, Lenoir H, Seux ML, Rigaud AS, Safar M, et al. Relationship between arterial stiffness and cognitive function in elderly subjects with complaints of memory loss. Stroke. 2005;36:2193-2197 20. Scuteri A, Brancati AM, Gianni W, Assisi A, Volpe M. Arterial stiffness is an independent risk factor 
for cognitive impairment in the elderly: a pilot study. J Hypertens. 2005;23:1211-1216

21. Muller M, Grobbee DE, Aleman A, Bots M, van der Schouw YT. Cardiovascular disease and cognitive performance in middle-aged and elderly men. Atherosclerosis. 2007;190:143-149

22. Triantafyllidi H, Arvaniti C, Lekakis J, Ikonomidis I, Siafakas N, Tzortzis S, et al. Cognitive impairment is related to increased arterial stiffness and microvascular damage in patients with never-treated essential hypertension. Am J Hypertens. 2009;22:525-530

23. Abbatecola AM, Barbieri M, Rizzo MR, Grella R, Laieta MT, Quaranta E, et al. Arterial stiffness and cognition in elderly persons with impaired glucose tolerance and microalbuminuria. J Gerontol A Biol Sci Med Sci. 2008;63:991-996

24. Kim YS, Kim DH, Choi BH, Sohn EH, Lee AY. Relationship between brachial-ankle pulse wave velocity and cognitive function in an elderly community-dwelling population with metabolic syndrome. Arch Gerontol Geriatr. 2009;49:176-179

25. Elias MF, Robbins MA, Budge MM, Abhayaratna WP, Dore GA, Elias PK. Arterial pulse wave velocity and cognition with advancing age. Hypertension. 2009;53:668-673

26. Sugawara N, Yasui-Furukori N, Umeda T, Kaneda A, Sato Y, Takahashi I, et al. Comparison of anklebrachial pressure index and pulse wave velocity as markers of cognitive function in a community-dwelling population. BMC Psychiatry. 2010;10:46

27. Scuteri A, Tesauro M, Appolloni S, Preziosi F, Brancati AM, Volpe M. Arterial stiffness as an independent predictor of longitudinal changes in cognitive function in the older individual. J Hypertens. 2007;25:1035-1040 28. Poels MM, van Oijen M, Mattace-Raso FU, Hofman A, Koudstaal PJ, Witteman JC, et al. Arterial stiffness, cognitive decline, and risk of dementia: the Rotterdam study. Stroke. 2007;38:888-892

29. Fujiwara Y, Chaves PH, Takahashi R, Amano H, Yoshida H, Kumagai S, et al. Arterial pulse wave velocity as a marker of poor cognitive function in an elderly community-dwelling population. J Gerontol A Biol Sci Med Sci. 2005;60:607-612

30. Kearney-Schwartz A, Rossignol P, Bracard S, Felblinger J, Fay R, Boivin JM, et al. Vascular structure and function is correlated to cognitive performance and white matter hyperintensities in older hypertensive patients with subjective memory complaints. Stroke. 2009;40:1229-1236

31. Pase MP, Pipingas A, Kras M, Nolidin K, Gibbs AL, Wesnes KA, et al. Healthy middle-aged individuals are vulnerable to cognitive deficits as a result of increased arterial stiffness. J Hypertens. 2010;28:1724-1729 32. Henskens LH, Kroon AA, van Oostenbrugge RJ, Gronenschild EH, Fuss-Lejeune MM, Hofman PA, et al. Increased aortic pulse wave velocity is associated with silent cerebral small-vessel disease in hypertensive patients. Hypertension. 2008;52:1120-1126

33. van Elderen SG, Brandts A, Westenberg JJ, van der Grond J, Tamsma JT, van Buchem MA, et al. Aortic stiffness is associated with cardiac function and cerebral small vessel disease in patients with type 1 diabetes mellitus: assessment by magnetic resonance imaging. Eur Radiol. 2010;20:1132-1138

34. Hatanaka R, Obara T, Watabe D, Ishikawa T, Kondo T, Ishikura K, et al. Association of Arterial Stiffness with Silent Cerebrovascular Lesions: The Ohasama Study. Cerebrovasc Dis. 2011;31:329-337

35. Kim DH, Kim J, Kim JM, Lee AY. Increased brachial-ankle pulse wave velocity is independently associated with risk of cerebral ischemic small vessel disease in elderly hypertensive patients. Clin Neurol Neurosurg. 2008;110:599-604

36. O'Rourke MF. Brain microbleeds, amyloid plaques, intellectual deterioration, and arterial stiffness. Hypertension. 2008;51:e20; author reply e21

37. Henskens LH, van Oostenbrugge RJ, Kroon AA, de Leeuw PW, Lodder J. Brain microbleeds are associated with ambulatory blood pressure levels in a hypertensive population. Hypertension. 2008;51:62-68

38. Henskens LH. High blood pressure and target-organ damage of the brain. 2008;Unpublished doctoral dissertation

39. Kindermann I, Fischer D, Karbach J, Link A, Walenta K, Barth C, et al. Cognitive function in patients 
with decompensated heart failure: the Cognitive Impairment in Heart Failure (CogImpair-HF) study. Eur J Heart Fail. 2012;14:404-413

40. Pressler SJ. Cognitive functioning and chronic heart failure: a review of the literature (2002-July 2007). J Cardiovasc Nurs. 2008;23:239-249

41. Harkness K, Demers C, Heckman GA, McKelvie RS. Screening for cognitive deficits using the Montreal cognitive assessment tool in outpatients $>/=65$ years of age with heart failure. Am J Cardiol. 2011;107:12031207

42. Jefferson AL, Himali JJ, Au R, Seshadri S, Decarli C, O’Donnell CJ, et al. Relation of left ventricular ejection fraction to cognitive aging (from the Framingham Heart Study). Am J Cardiol. 2011;108:1346-1351

43. Almeida OP, Beer C, Lautenschlager NT, Arnolda L, Alfonso H, Flicker L. Two-year course of cognitive function and mood in adults with congestive heart failure and coronary artery disease: the Heart-Mind Study. Int Psychogeriatr. 2012;24:38-47

44. Jefferson AL, Tate DF, Poppas A, Brickman AM, Paul RH, Gunstad J, et al. Lower cardiac output is associated with greater white matter hyperintensities in older adults with cardiovascular disease. J Am Geriatr Soc. 2007;55:1044-1048

45. Sila CA. Cognitive impairment in chronic heart failure. Cleve Clin J Med. 2007;74 Suppl 1:S132-137

46. Vogels RL, Oosterman JM, van Harten B, Gouw AA, Schroeder-Tanka JM, Scheltens P, et al. Neuroimaging and correlates of cognitive function among patients with heart failure. Dement Geriatr Cogn Disord. $2007 ; 24: 418-423$

47. Jefferson AL. Cardiac output as a potential risk factor for abnormal brain aging. J Alzheimers Dis. 2010;20:813-821

48. Deshields TL, McDonough EM, Mannen RK, Miller LW. Psychological and cognitive status before and after heart transplantation. Gen Hosp Psychiatry. 1996;18:62S-69S

49. Gruhn N, Larsen FS, Boesgaard S, Knudsen GM, Mortensen SA, Thomsen G, et al. Cerebral blood flow in patients with chronic heart failure before and after heart transplantation. Stroke. 2001;32:2530-2533 50. Massaro AR, Dutra AP, Almeida DR, Diniz RV, Malheiros SM. Transcranial Doppler assessment of cerebral blood flow: effect of cardiac transplantation. Neurology. 2006;66:124-126

51. Gaviria M, Pliskin N, Kney A. Cognitive impairment in patients with advanced heart failure and its implications on decision-making capacity. Congest Heart Fail. 2011;17:175-179

52. Pieters B, Staals J, Knottnerus I, Rouhl R, Menheere P, Kessels A, et al. Periventricular white matter lucencies relate to low vitamin B12 levels in patients with small vessel stroke. Stroke. 2009;40:1623-1626

53. Baik HW, Russell RM. Vitamin B12 deficiency in the elderly. Annu Rev Nutr. 1999;19:357-377 54. O'Brien J, Desmond P, Ames D, Schweitzer I, Harrigan S, Tress B. A magnetic resonance imaging study of white matter lesions in depression and Alzheimer's disease. Br J Psychiatry. 1996;168:477-485

55. Snaphaan L, van der Werf S, de Leeuw FE. Time course and risk factors of post-stroke fatigue: a prospective cohort study. Eur J Neurol. 2011;18:611-617

56. Tang WK, Chen YK, Lu JY, Chu WC, Mok VC, Ungvari GS, et al. Cerebral Microbleeds and Depression in Lacunar Stroke. Stroke. 2011;42:2443-2446

57. Van Zandvoort MJ, Kappelle LJ, Algra A, De Haan EH. Decreased capacity for mental effort after single supratentorial lacunar infarct may affect performance in everyday life. J Neurol Neurosurg Psychiatry. 1998;65:697-702

58. Riggs KM, Spiro A, 3rd, Tucker K, Rush D. Relations of vitamin B-12, vitamin B-6, folate, and homocysteine to cognitive performance in the Normative Aging Study. Am J Clin Nutr. 1996;63:306-314

59. Wang HX, Wahlin A, Basun H, Fastbom J, Winblad B, Fratiglioni L. Vitamin B(12) and folate in relation to the development of Alzheimer's disease. Neurology. 2001;56:1188-1194

60. Yamamoto Y, Ohara T, Nagakane Y, Tanaka E, Morii F, Koizumi T, et al. Chronic kidney disease, 24-h blood pressure and small vessel diseases are independently associated with cognitive impairment in lacunar infarct 
patients. Hypertens Res. 2011;34:1276-1282

61. Nitkunan A, Lanfranconi S, Charlton RA, Barrick TR, Markus HS. Brain atrophy and cerebral small vessel disease: a prospective follow-up study. Stroke. 2011;42:133-138

62. Grau-Olivares M, Arboix A, Junque C, Arenaza-Urquijo EM, Rovira M, Bartres-Faz D. Progressive gray matter atrophy in lacunar patients with vascular mild cognitive impairment. Cerebrovasc Dis. 2010;30:157166

63. Wen HM, Mok VC, Fan YH, Lam WW, Tang WK, Wong A, et al. Effect of white matter changes on cognitive impairment in patients with lacunar infarcts. Stroke. 2004;35:1826-1830

64. Mok VC, Liu T, Lam WW, Wong A, Hu X, Guo L, et al. Neuroimaging predictors of cognitive impairment in confluent white matter lesion: volumetric analyses of 99 brain regions. Dement Geriatr Cogn Disord. 2008;25:67-73

65. McMurtray AM, Liao A, Haider J, Licht E, Mendez MF. Cognitive performance after lacunar stroke correlates with leukoaraiosis severity. Cerebrovasc Dis. 2007;24:271-276

66. Vernooij MW, van der Lugt A, Ikram MA, Wielopolski PA, Niessen WJ, Hofman A, et al. Prevalence and risk factors of cerebral microbleeds: the Rotterdam Scan Study. Neurology. 2008;70:1208-1214

67. Doubal FN, MacLullich AM, Ferguson KJ, Dennis MS, Wardlaw JM. Enlarged perivascular spaces on MRI are a feature of cerebral small vessel disease. Stroke. 2010;41:450-454

68. Takashima Y, Mori T, Hashimoto M, Kinukawa N, Uchino A, Yuzuriha T, et al. Clinical correlating factors and cognitive function in community-dwelling healthy subjects with cerebral microbleeds. J Stroke Cerebrovasc Dis. 2011;20:105-110

69. Qiu C, Cotch MF, Sigurdsson S, Jonsson PV, Jonsdottir MK, Sveinbjrnsdottir S, et al. Cerebral microbleeds, retinopathy, and dementia: the AGES-Reykjavik Study. Neurology. 2010;75:2221-2228

70. Yakushiji Y, Nishiyama M, Yakushiji S, Hirotsu T, Uchino A, Nakajima J, et al. Brain microbleeds and global cognitive function in adults without neurological disorder. Stroke. 2008;39:3323-3328

71. Werring DJ, Frazer DW, Coward LJ, Losseff NA, Watt H, Cipolotti L, et al. Cognitive dysfunction in patients with cerebral microbleeds on T2*-weighted gradient-echo MRI. Brain. 2004;127:2265-2275

72. Cordonnier C, van der Flier WM, Sluimer JD, Leys D, Barkhof F, Scheltens P. Prevalence and severity of microbleeds in a memory clinic setting. Neurology. 2006;66:1356-1360

73. Goos JD, Henneman WJ, Sluimer JD, Vrenken H, Sluimer IC, Barkhof F, et al. Incidence of cerebral microbleeds: a longitudinal study in a memory clinic population. Neurology. 2010;74:1954-1960

74. Rouhl RP, van Oostenbrugge RJ, Knottnerus IL, Staals JE, Lodder J. Virchow-Robin spaces relate to cerebral small vessel disease severity. J Neurol. 2008;255:692-696

75. Mathias J, Koessler L, Brissart H, Foscolo S, Schmitt E, Bracard S, et al. Giant cystic widening of Virchow-Robin spaces: an anatomofunctional study. AJNR Am J Neuroradiol. 2007;28:1523-1525

76. Heier LA, Bauer CJ, Schwartz L, Zimmerman RD, Morgello S, Deck MD. Large Virchow-Robin spaces: MR-clinical correlation. AJNR Am J Neuroradiol. 1989;10:929-936

77. Udaka F, Sawada H, Kameyama M. White matter lesions and dementia: MRI-pathological correlation. Ann N Y Acad Sci. 2002;977:411-415

78. van den Heuvel DM, ten Dam VH, de Craen AJ, Admiraal-Behloul F, Olofsen H, Bollen EL, et al. Increase in periventricular white matter hyperintensities parallels decline in mental processing speed in a nondemented elderly population. J Neurol Neurosurg Psychiatry. 2006;77:149-153

79. Zhu YC, Dufouil C, Soumare A, Mazoyer B, Chabriat H, Tzourio C. High degree of dilated VirchowRobin spaces on MRI is associated with increased risk of dementia. J Alzheimers Dis. 2010;22:663-672

80. Carey CL, Kramer JH, Josephson SA, Mungas D, Reed BR, Schuff N, et al. Subcortical lacunes are associated with executive dysfunction in cognitively normal elderly. Stroke. 2008;39:397-402 
Introduction and outline of this thesis $\mid 21$

81. Baune BT, Roesler A, Knecht S, Berger K. Single and combined effects of cerebral white matter lesions and lacunar infarctions on cognitive function in an elderly population. J Geront A Biol Sci Med Sci. 2009;64:118-

124 
22 



\begin{abstract}
Cognitive impairment due to vascular disease is frequently found. White matter lesions (WMLs) and lacunar infarcts, both markers of cerebral small vessel disease (cSVD), appear to be the most common forms of cerebrovascular damage, and a frequent cause of cognitive impairment. Many studies examined cognition in relation to cardiovascular risk factors and symptomatic cardiovascular disease. However, most of these studies did not integrate evidence of cerebrovascular damage based on neuroimaging. In the present review we searched the literature for associations between cerebrovascular damage in terms of cSVD and cognitive function in patient groups with or at risk for cardiovascular disease. We included 50 studies. Results showed negative associations between WMLs and cognitive status in all patient groups, affecting executive function, information processing speed and memory. Progression of cerebrovascular damage paralleled by cognitive decline was found by some. An increased risk for dementia in those with WMLs was confined to those with symptomatic cardiovascular disease. Standardization of neuroimaging and neuropsychological assessment might be helpful to compare CSVD and cognitive status across the cardiovascular spectrum.
\end{abstract}

\title{
Chapter 2
}

\section{The relation of cerebral small vessel disease and cognition in patients with or at risk for cardiovascular disease}

\author{
Marjolein Huijts, Annelien Duits, Robert van Oostenbrugge
}




\section{Introduction}

Cognitive impairment associated with cerebrovascular disease is frequently found and vascular dementia $(\mathrm{VaD})$ is the second most common form of dementia ${ }^{1}$. Hachinski et $\mathrm{al}^{2}$ introduced the construct of vascular cognitive impairment (VCI) to capture the entire spectrum of cognitive disorders ranging from mild cognitive impairment to fully developed dementia. Gorelick et al ${ }^{3}$ recently stated that a diagnosis of VCI should be based on 2 factors: 1) demonstration of cognitive impairment by neuropsychological assessment and 2) history of clinical stroke or presence of cerebrovascular disease by neuroimaging. This second factor refers to a relationship between cognitive impairment and cerebrovascular damage, regardless of the underlying pathology. Cerebral small vessel disease (cSVD) is the most frequent cause of $\mathrm{VCI}^{4}$ and $\mathrm{VaD}^{5}$. cSVD causes deep and periventricular white matter lesions (WMLs) and lacunar infarcts ${ }^{6-8}$. WMLs and lacunar infarcts, both markers of cSVD, have been mentioned as the most common forms of cerebrovascular damage ${ }^{3}$.

Cerebrovascular damage is expected in patients with vascular risk factors that affect the microvasculature, such as hypertension ${ }^{9}$ and diabetes ${ }^{10}$, but also in patients with clinical manifestations of cSVD, such as lacunar stroke patients. However, patients with large vessel occlusion (cortical stroke) and other cardiovascular disease, such as peripheral artery disease and coronary artery disease, may also show expressions of cSVD. Many studies have been published on the relationship between cardiovascular risk factors or symptomatic cardiovascular disease and cognitive function and refer to VCI. However, most of these studies did not integrate evidence of cerebrovascular damage based on neuroimaging, as suggested by Gorelick et $\mathrm{al}^{3}$. In the present review, we searched the literature for associations between structural cerebrovascular lesions related to CSVD and cognitive function in patient groups with or at risk for cardiovascular disease. Additionally, we were interested in the relationship between the total burden of structural lesions due to CSVD and the course of cognitive function. Although microbleeds are also recognized as imaging markers for $\mathrm{cSVD}^{11}$ with increasing evidence for an association with cognitive function ${ }^{12}$, we focused on WMLs and lacunar infarcts.

\section{Methods}

We searched the literature from January 1994 to June 2012 (PUBMED). In line with Gorelick et $\mathrm{al}^{3}$, cerebrovascular lesions were defined as the presence of WMLs and lacunar infarcts. Studies with the following patient groups were selected: 1) patients with vascular risk factors, a) diabetes, b) hypertension, c) hypercholesterolemia, d) metabolic syndrome; and 2) patients with symptomatic cardiovascular disease, a) peripheral artery disease, b) cardiac disease, c) stroke. Case-control, as well as case series, and cohort studies were included. Using the advanced search option the following terms were combined:

1) Diabetes: "diabetes".

2) Hypertension: "hypertens", "blood pressure" using Boolean operator "OR".

3) Hypercholesterolemia: "hypercholesterolemia", "cholesterol" using Boolean opera- 
tor "OR".

4) Metabolic syndrome: "metabolic syndrome".

5) Peripheral Artery Disease: "peripheral artery disease", "peripheral vascular disease" using Boolean operator "OR".

6) Cardiac Disease: "heart failure", "coronary artery disease", "coronary heart disease", "myocard* infarct*", "angina pectoris" using Boolean operator "OR".

7) Stroke: "stroke", "infarct*", "cerebral hemorrhage" using Boolean operator "OR". Boolean operator "AND" was then used to link the above terms to "MRI" or "magnetic resonance imaging" in abstract/title and "cognit*" in abstract/title. Inclusion and exclusion criteria were as follows:

Inclusion criteria:

1) English language is used

2) Cognition is (one of) the outcome measure(s) and associations with WMLs and lacunar infarcts are investigated

Exclusion criteria:

1) Studies with patients suffering from genetically determined cSVD, such as cerebral autosomal dominant arteriopathy with subcortical infarcts and leucoencephalopathy (CADASIL)

2) Studies on patients undergoing surgery for coronary artery bypass grafting (CABG)

The selected studies were classified in accordance to the groups described above. Within the groups the studies were organised based on their design (cross-sectional versus longitudinal) and neuropsychological assessment (cognitive screening instrument versus extensive neuropsychological battery).

\section{Results}

The search method yielded 902 papers. After applying the above-mentioned inclusion and exclusion criteria, 50 papers were suitable for further analysis. Study characteristics and results are explained below.

\section{Patients with cardiovascular risk factors}

We restricted to the most well-established cardiovascular risk factors including diabetes, hypertension, hypercholesterolemia and metabolic syndrome. Twenty studies examined the effects of either diabetes or hypertension on cognitive function ${ }^{9,13-31}$. We were unable to detect studies that reported on the relationship between hypercholesterolemia and cognition. We found two studies on the relationship between metabolic syndrome and cognitive function ${ }^{32}$, ${ }^{33}$, but no specific associations between cSVD and cognitive functions were reported. All studies, except seven ${ }^{13,20,21,28-31}$, had a cross-sectional design, and all, except one ${ }^{21}$, included extensive neuropsychological assessment. 


\section{Diabetes}

We included twelve papers on both type 1 diabetes and type 2 diabetes patients ${ }^{13-19,25,28-31}$. All studies investigated cognition with extensive neuropsychological testing. Five studies had a longitudinal design ${ }^{13,28-31}$. In the cross-sectional studies, the association between WMLs and cognition was most prominent for information processing speed, with diabetics performing worse on cognitive measures than non-diabetic controls ${ }^{14,15}$.

The number of silent brain infarcts (SBI) was significantly correlated to decline in speed and executive function with stronger associations at follow-up than at baseline ${ }^{28}$. Patients with either WMLs or SBI progression showed a more rapid decline in speed ${ }^{28,31}$ and executive function $^{31}$ than those without progression. Accelerated cognitive decline was also found in patients with greater increase in $\mathrm{WMLs}^{13}$. Umegaki and Van Elderen ${ }^{29,30}$ however, found no association between change scores in executive function and baseline MRI parameters, such as WMLs and silent cerebral infarcts.

\section{Hypertension}

Eight papers were included that studied the relationship between hypertension, cerebrovascular lesions and cognition ${ }^{9}$,20-24, 26, 27. Treated as well as non-treated hypertensive patients were investigated and hypertension duration ranged from two to nine years at baseline. Cross-sectional studies most often found an association between WMLs and executive function and attention, with hypertensive patients performing worse on cognitive measures than normotensive controls ${ }^{23,24}$.

In the longitudinal study by Swan et $\mathrm{al}^{20}$, subjects with a high midlife systolic blood pressure (SBP) appeared to have greater cognitive decline (particularly information processing speed) and larger white matter hyperintensities (WMH) volumes at follow-up than those with low midlife SBP. Kitagawa et $\mathrm{al}^{21}$ found that six patients $(22.2 \%)$ showed a decline of more than 3 points on the Mini Mental State Examination (MMSE) ${ }^{34}$ after 3 years. Baseline MMSE, WMLs and lacunes were similar in decliners and non-decliners. However, patients with lower cerebral blood flow at baseline developed cognitive decline and dementia, whereas cognitive function remained intact in patients with higher cerebral blood flow.

\section{Patients with cardiovascular disease}

The relationship between cardiovascular disease, cerebrovascular lesions and cognition was investigated in 29 studies ( 2 on cardiac disease ${ }^{35,36}$ and 27 on stroke ${ }^{37-63}$ ). We were unable to detect studies that reported on the relationship between peripheral artery disease or myocardial infarction, neuroimaging and cognition.

\section{Cardiac disease}

Vogels et $\mathrm{al}^{36}$ investigated cognition, together with the expressions of cSVD in patients with heart failure (HF). The design was cross-sectional, and cognitive domains were investigated with several tests in patients with HF and healthy controls. The result showed no correlation of WMLs with any of the cognitive measures, but medial temporal lobe atrophy was cor- 
related with memory and executive functioning. However, it was demonstrated that $24 \%$ of the HF patients was cognitively impaired as opposed to $4 \%$ of the healthy controls. In a same patient population, Beer et $\mathrm{al}^{35}$ however, found an association of global cognitive function with deep white matter lesions and medial temporal lobe atrophy.

\section{Stroke}

The relationship between stroke, cSVD and cognition was examined by 27 studies. Some studies examined stroke in general without subdividing $(\mathrm{N}=7)$, others studied ischemic stroke patients $(\mathrm{N}=8)$ and others specified to lacunar stroke patients $(\mathrm{N}=12)$. None of the included studies reported specifically on hemorrhagic stroke.

\section{Stroke}

The relationship between stroke, cSVD and cognition was examined by 4 cross-sectional ${ }^{37-39}$, 48 and 3 longitudinal studies ${ }^{45,46,51}$. All of the studies, except five ${ }^{37,45,46,48,51}$ conducted extensive neuropsychological assessment. The majority of cross-sectional studies reported an association between WMLs and executive functioning.

Conversion to dementia was recorded by Firbank ${ }^{45}$ and Dufouil ${ }^{46}$. Firbank et $\mathrm{al}^{45}$ weren't able to find differences in brain volumetric measures, baseline scores or slopes of decline between converters and non-converters. However, Dufouil ${ }^{46}$ observed that, 4 years after stroke, around $10 \%$ of patients developed dementia, and that this dementia risk was 7.7 times higher in subjects with severe WMLs compared to those without WMLs. Firbank et al ${ }^{51}$ recently found that volume of WMLs was a significant neuroimaging predictor of shorter time to dementia onset in a sample of stroke patients.

\section{Ischemic stroke}

The relationship between stroke, cSVD and cognition was examined by 6 cross-sectional ${ }^{40-42,}$ $47,49,50$ and 2 longitudinal studies ${ }^{43,44}$. All of the studies, except one ${ }^{50}$ conducted extensive neuropsychological assessment. The majority of cross-sectional studies reported an association between WMLs and general cognitive function. The studies by Sachdev et $\mathrm{al}^{40-42}$ represent the same population and we included the article with the highest number of patients ${ }^{42}$.

In the longitudinal study by Ross et $\mathrm{al}^{43}$ it was noticed that in stroke patients and controls, the change in cognition, based on overall Z-score correlated with WMLs after a follow-up period of 12 months. This correlation however, disappeared for stroke patients after a follow-up of 3 years, possibly due to reduced power ${ }^{43}$. Sachdev et $\mathrm{al}^{44}$ divided stroke patients in a vascular mild cognitive impairment (vMCI; 43.3\%) group and a group with no cognitive impairment (56.7\%) and compared both groups with healthy controls. Stroke patients, either with or without cognitive deficits, had more WMLs than the control group. At baseline, the vMCI group performed worse than the other groups on all cognitive tests, except verbal memory. Follow-up analyses revealed that this group declined significantly on word naming (Boston Naming Task) and word fluency, but only marginally on memory. Sachdev et $\mathrm{al}^{44}$ also recorded conversion to dementia, but weren't able to find differences in brain volumetric 
measures, baseline scores or slopes of decline between converters and non-converters.

\section{Lacunar stroke}

Twelve studies $^{52-63}$, of which 5 longitudinal ${ }^{52,57-59,62}$, investigated cognition and cSVD in lacunar stroke patients. Two studies used the dichotomous variable vMCI or cognitive impairment as outcome variable ${ }^{53,63}$. Baseline assessment ranged from less than a month to 3 months after stroke onset and follow-up assessment from 1 to 9 years. Cross-sectional studies most often found an association between lacunar infarcts and executive function and attention.

Longitudinal studies found no change in cognition after 1 to 3 years $^{52,58}$. WMLs were correlated with cognitive impairment, whereas no relationship was found between increase in WMLs and decline in cognition at follow-up ${ }^{57,58}$. Yamamoto ${ }^{62}$ however, found that extensive WMLs were an independent predictor for the development of dementia. No differences concerning WMLs increases at follow-up were found between patients with vMCI and those without cognitive impairment ${ }^{59}$.

\section{Discussion}

Based on the diagnostic criteria for VCI by Gorelick et $\mathrm{al}^{3}$, we reviewed studies that aimed to investigate the relationship between cerebrovascular damage, in terms of cSVD, and cognitive function in patients with cardiovascular risk factors and patients with manifest cardiovascular disease. The focus of this review was on WMLs and lacunar infarcts in relation to both cognitive status and cognitive decline.

Most studies were based on a cross-sectional design, generally exploring associations between WMLs and performance in different cognitive domains. In all groups, negative associations between WMLs and cognitive status were reported. Most studies reported decreased executive function, information processing speed and memory, which is in line with the suggested disconnection of frontosubcortical structures ${ }^{64}$. Memory impairment on the other hand, might be related to smaller hippocampal volumes, which have been observed in patients with $\mathrm{cSVD}^{65}$. Since none of the included studies compared (at) risk groups, we cannot speculate about differences in either the severity of cSVD and cognitive impairment or differences in their interrelationships. In symptomatic groups and in particular stroke patients, it has been found that those with cognitive impairment showed more cerebrovascular damage in terms of cSVD and/or damage related to their stroke than those without cognitive impairment ${ }^{44,66}$. One third of the included studies had a longitudinal design, with some observing progression of WMLs paralleled by a decline in cognition and others reporting no such association. These equivocal outcomes were found in patients at risk for, as well as in patients with symptomatic cardiovascular disease. However, an increased risk for dementia in those with WMLs was confined to patients with symptomatic cardiovascular disease. This finding is in line with the absence of an association between WMLs and incident dementia in patients at risk for cardiovascular disease ${ }^{67}$ and the presence of an association between clinical stroke, WMLs and generalized brain atrophy and an increased risk of dementia ${ }^{68,69}$. Generalized brain atrophy on MRI is a characteristic finding in Alzheimer's Disease ${ }^{70,71}$, but is also associated 
with vascular risk factors and $\mathrm{cSVD}^{72}$. Overall, the investigated studies in this review did not adjust for generalized atrophy in their analyses. Since brain atrophy and WMLs seem to be independently related to longitudinal cognitive decline in patients with $\mathrm{cSVD}^{73}$, the abovementioned equivocal results might be explained by differences in (sub)cortical atrophy.

When we put these results into perspective with the criteria of Gorelick et $\mathrm{al}^{3}$, we found associations between cSVD and cognitive function in patients with or without symptomatic cardiovascular disease, but only patients with symptomatic cardiovascular disease had an increased risk of dementia. This may indicate that clinical stroke, either lacunar or cortical, plays an intermediate role in the relationship between cSVD and cognitive impairment. Besides clinical stroke, the structural integrity of the normal-appearing white matter (NAWM) should also be taken into account when investigating the relationship between cSVD and cognitive function ${ }^{74}$. Conventional FLAIR imaging is however not able to detect microstructural pathology extending into the NAWM and the studies described in this review could not adjust for this factor. Microstructural differences in NAWM might explain why some subjects suffer from severe cognitive impairment and cognitive decline and others not. It is therefore suggested to use DTI-imaging, which explores white matter tracts, instead of the conventional T2 and FLAIR images, especially in longitudinal studies ${ }^{75}$.

Other possible mediating factors might be socioeconomic status and age. Low socioeconomic status is known to be related to a greater burden of vascular risk factors ${ }^{76-78}$ and consequently might be related to a lower cognitive reserve with the presence of cSVD. Whereas the mean age in most studies was about ${ }^{70}$, the mean age of the hypertensive patients was approximately 55 years. Although most studies adjusted their results for age, as well as educational level, there might have been an advantage in cognitive performance for the hypertensive patients. As such, younger age may compensate the impact of WMLs on cognition.

In the reviewed studies, visual as well as volumetric measures were used to assess the severity of WMLs and both methods have their advantages and disadvantages ${ }^{79}$. A uniform method is necessary to compare the selected patient groups. Another and more complicated methodological issue is the problem of comorbidity in vascular disease, including the risk factors as reviewed here. This comorbidity, in either the at risk or the symptomatic patients, complicates discerning independent associations.

Overall, the selection of studies is very heterogeneous with differences in the procedures of inclusion, design and times frames. For example, some lacunar stroke patients were included based on only their clinical syndrome, whereas other studies based their inclusion on MR imaging or a combination of these two. Furthermore, the longitudinal studies used different time frames of follow-up, varying from 1 to 10 years. To determine the relationship between cognition and imaging variables, it is important to plan baseline assessment of cognitive function 3 months after a symptomatic vascular event to reduce the effect of signal distortion caused by the acute phase. Most studies respected this time frame, but some studies planned their baseline assessment within 1 month or even within one week after the event ${ }^{44}$. Considering the patients with vascular risk factors, time from diagnosis to baseline assessment varied 
from 1 year to more than 10 years. Those patients with longer exposure might probably have performed worse than those with less time between diagnosis and baseline assessment.

Finally, the MMSE was frequently used as the only cognitive test. It is however known that the MMSE is biased towards orientation and language, whereas executive and right-hemisphere functions are not fully represented ${ }^{56,57,80}$. Given the impact on executive function and information processing speed, the MMSE is insensitive to assess cognition in cSVD patients. Preferably, cognition is assessed by an extensive neuropsychological battery, but at least by standard neuropsychological tests related to executive function, information processing speed and memory.

In conclusion, cSVD seems to be related to cognitive status in patients with or at risk for cardiovascular disease, specifically affecting executive function, information processing speed and memory. Brain atrophy and clinical stroke may play an intermediate role in this relationship, especially in case of cognitive decline. These results refer to the complex interrelationships between vascular and degenerative pathology leading to cognitive impairment and decline, but the underlying structure of these relationships still remains unsolved. Overall standardization of assessment might be helpful to unmask this structure. 


\section{References}

1. Korczyn AD, Vakhapova V, Grinberg LT. Vascular dementia. J Neurol Sci. 2012;15:2-10

2. Hachinski V, Iadecola C, Petersen RC, Breteler MM, Nyenhuis DL, Black SE, et al. National Institute of Neurological Disorders and Stroke-Canadian Stroke Network vascular cognitive impairment harmonization standards. Stroke. 2006;37:2220-2241

3. Gorelick PB, Scuteri A, Black SE, Decarli C, Greenberg SM, Iadecola C, et al. Vascular contributions to cognitive impairment and dementia: a statement for healthcare professionals from the american heart association/american stroke association. Stroke. 2011;42:2672-2713

4. Ross GW, Petrovitch H, White LR, Masaki KH, Li CY, Curb JD, et al. Characterization of risk factors for vascular dementia: the Honolulu-Asia Aging Study. Neurology. 1999;53:337-343

5. Visser MC, Scheltens, Ph. Vasculaire cognitieve achteruitgang en dementie. In: Franke CL, Limburg, M., ed. Handboek Cerebrovasculaire Aandoeningen. Utrecht: De Tijdstroom; 2006.

6. $\quad$ Schmidtke K, Hull M. Cerebral small vessel disease: how does it progress? J Neurol Sci. 2005;229230:13-20

7. Boiten J, Lodder J. Lacunar infarcts. Pathogenesis and validity of the clinical syndromes. Stroke. $1991 ; 22: 1374-1378$

8. Pantoni L. Cerebral small vessel disease: from pathogenesis and clinical characteristics to therapeutic challenges. Lancet Neurol. 2010;9:689-701

9. Sierra C, De La Sierra A, Salamero M, Sobrino J, Gomez-Angelats E, Coca A. Silent cerebral white matter lesions and cognitive function in middle-aged essential hypertensive patients. Am J Hypertens. 2004; $17: 529-534$

10. Saczynski JS, Jonsdottir MK, Garcia ME, Jonsson PV, Peila R, Eiriksdottir G, et al. Cognitive impairment: an increasingly important complication of type 2 diabetes: the age, gene/environment susceptibility--Reykjavik study. Am J Epidemiol. 2008;168:1132-1139

11. Werring DJ, Gregoire SM, Cipolotti L. Cerebral microbleeds and vascular cognitive impairment. J Neurol Sci. 2010;299:131-135

12. Poels MM, Ikram MA, van der Lugt A, Hofman A, Niessen WJ, Krestin GP, et al. Cerebral microbleeds are associated with worse cognitive function: the Rotterdam Scan Study. Neurology. 2012;78:326-333

13. Reijmer YD, van den Berg E, de Bresser J, Kessels RP, Kappelle LJ, Algra A, et al. Accelerated cognitive decline in patients with type 2 diabetes: MRI correlates and risk factors. Diabetes Metab Res Rev. 2011;27:195-202

14. Brands AM, Kessels RP, Hoogma RP, Henselmans JM, van der Beek Boter JW, Kappelle LJ, et al. Cognitive performance, psychological well-being, and brain magnetic resonance imaging in older patients with type 1 diabetes. Diabetes. 2006;55:1800-1806

15. Manschot SM, Brands AM, van der Grond J, Kessels RP, Algra A, Kappelle LJ, et al. Brain magnetic resonance imaging correlates of impaired cognition in patients with type 2 diabetes. Diabetes. 2006;55:1106-1113 16. Akisaki T, Sakurai T, Takata T, Umegaki H, Araki A, Mizuno S, et al. Cognitive dysfunction associates with white matter hyperintensities and subcortical atrophy on magnetic resonance imaging of the elderly diabetes mellitus Japanese elderly diabetes intervention trial (J-EDIT). Diabetes Metab Res Rev. 2006;22:376-384 17. Ferguson SC, Blane A, Wardlaw J, Frier BM, Perros P, McCrimmon RJ, et al. Influence of an earlyonset age of type 1 diabetes on cerebral structure and cognitive function. Diabetes Care. 2005;28:1431-1437 18. van Harten B, Oosterman J, Muslimovic D, van Loon BJ, Scheltens P, Weinstein HC. Cognitive impairment and MRI correlates in the elderly patients with type 2 diabetes mellitus. Age Ageing. 2007;36:164-170 19. Wessels AM, Rombouts SA, Remijnse PL, Boom Y, Scheltens P, Barkhof F, et al. Cognitive performance in type 1 diabetes patients is associated with cerebral white matter volume. Diabetologia. 2007;50:17631769 
20. Swan GE, DeCarli C, Miller BL, Reed T, Wolf PA, Jack LM, et al. Association of midlife blood pressure to late-life cognitive decline and brain morphology. Neurology. 1998;51:986-993

21. Kitagawa K, Oku N, Kimura Y, Yagita Y, Sakaguchi M, Hatazawa J, et al. Relationship between cerebral blood flow and later cognitive decline in hypertensive patients with cerebral small vessel disease. Hypertens Res. 2009;32:816-820

22. van Boxtel MP, Henskens LH, Kroon AA, Hofman PA, Gronenschild EH, Jolles J, et al. Ambulatory blood pressure, asymptomatic cerebrovascular damage and cognitive function in essential hypertension. J Hum Hypertens. 2006;20:5-13

23. Consoli D, Di Carlo A, Inzitari D, De Lucia D, Lamassa M, D’Avino M, et al. Subcortical ischaemic changes in young hypertensive patients: frequency, effect on cognitive performance and relationship with markers of endothelial and haemostatic activation. Eur J Neurol. 2007;14:1222-1229

24. Hannesdottir K, Nitkunan A, Charlton RA, Barrick TR, MacGregor GA, Markus HS. Cognitive impairment and white matter damage in hypertension: a pilot study. Acta Neurol Scand. 2009;119:261-268

25. Kodl CT, Franc DT, Rao JP, Anderson FS, Thomas W, Mueller BA, et al. Diffusion tensor imaging identifies deficits in white matter microstructure in subjects with type 1 diabetes that correlate with reduced neurocognitive function. Diabetes. 2008;57:3083-3089

26. O’Brien JT, Wiseman R, Burton EJ, Barber B, Wesnes K, Saxby B, et al. Cognitive associations of subcortical white matter lesions in older people. Ann N Y Acad Sci. 2002;977:436-444

27. Raz N, Rodrigue KM, Acker JD. Hypertension and the brain: vulnerability of the prefrontal regions and executive functions. Behav Neurosci. 2003;117:1169-1180

28. Imamine R, Kawamura T, Umemura T, Umegaki H, Kawano N, Hotta M, et al. Does cerebral small vessel disease predict future decline of cognitive function in elderly patients with type 2 diabetes? Diabetes Res Clin Pract. 2011;94:91-99

29. van Elderen SG, de Roos A, de Craen AJ, Westendorp RG, Blauw GJ, Jukema JW, et al. Progression of brain atrophy and cognitive decline in diabetes mellitus: a 3-year follow-up. Neurology. 2010;75:997-1002

30. Umegaki H, Kawamura T, Kawano N, Umemura T, Kanai A, Sano T. Factors associated with cognitive decline in elderly diabetics. Dement Geriatr Cogn Dis Extra. 2011;1:1-9

31. Umemura T, Kawamura T, Umegaki H, Mashita S, Kanai A, Sakakibara T, et al. Endothelial and inflammatory markers in relation to progression of ischaemic cerebral small-vessel disease and cognitive impairment: a 6-year longitudinal study in patients with type 2 diabetes mellitus. J Neurol Neurosurg Psychiatry. 2011;82:1186-1194

32. Bokura H, Nagai A, Oguro H, Kobayashi S, Yamaguchi S. The association of metabolic syndrome with executive dysfunction independent of subclinical ischemic brain lesions in Japanese adults. Dement Geriatr Cogn Disord. 2010;30:479-485

33. Cavalieri M, Ropele S, Petrovic K, Pluta-Fuerst A, Homayoon N, Enzinger C, et al. Metabolic syndrome, brain magnetic resonance imaging, and cognition. Diabetes Care. 2010;33:2489-2495

34. Folstein MF, Folstein SE, McHugh PR. "Mini-mental state". A practical method for grading the cognitive state of patients for the clinician. J Psychiatr Res. 1975;12:189-198

35. Beer C, Ebenezer E, Fenner S, Lautenschlager NT, Arnolda L, Flicker L, et al. Contributors to cognitive impairment in congestive heart failure: a pilot case-control study. Intern Med J. 2009;39:600-605

36. Vogels RL, Oosterman JM, van Harten B, Gouw AA, Schroeder-Tanka JM, Scheltens P, et al. Neuroimaging and correlates of cognitive function among patients with heart failure. Dement Geriatr Cogn Disord. 2007;24:418-423

37. Xiong Y, Mok V, Wong A, Chen X, Chu WC, Fan Y, et al. The age-related white matter changes scale correlates with cognitive impairment. Eur J Neurol. 2010;17:1451-1456

38. Burton E, Ballard C, Stephens S, Kenny RA, Kalaria R, Barber R, et al. Hyperintensities and frontosubcortical atrophy on MRI are substrates of mild cognitive deficits after stroke. Dement Geriatr Cogn Disord. 
2003; $16: 113-118$

39. Burton E, Kenny RA, O’Brien J, Stephens S, Bradbury M, Rowan E, et al. White matter hyperintensities are associated with impairment of memory, attention, and global cognitive performance in older stroke patients. Stroke. 2004;35:1270-1275

40. Sachdev PS, Valenzuela MJ, Brodaty H, Wang XL, Looi J, Lorentz L, et al. Homocysteine as a risk factor for cognitive impairment in stroke patients. Dement Geriatr Cogn Disord. 2003;15:155-162

41. Sachdev PS, Brodaty H, Valenzuela MJ, Lorentz L, Looi JC, Wen W, et al. The neuropsychological profile of vascular cognitive impairment in stroke and TIA patients. Neurology. 2004;62:912-919

42. Sachdev PS, Brodaty H, Valenzuela MJ, Lorentz L, Looi JC, Berman K, et al. Clinical determinants of dementia and mild cognitive impairment following ischaemic stroke: the Sydney Stroke Study. Dement Geriatr Cogn Disord. 2006;21:275-283

43. Ross AJ, Sachdev PS, Wen W, Brodaty H, Joscelyne A, Lorentz LM. Prediction of cognitive decline after stroke using proton magnetic resonance spectroscopy. J Neurol Sci. 2006;251:62-69

44. Sachdev PS, Chen X, Brodaty H, Thompson C, Altendorf A, Wen W. The determinants and longitudinal course of post-stroke mild cognitive impairment. J Int Neuropsychol Soc. 2009;15:915-923

45. Firbank MJ, Burton EJ, Barber R, Stephens S, Kenny RA, Ballard C, et al. Medial temporal atrophy rather than white matter hyperintensities predict cognitive decline in stroke survivors. Neurobiol Aging. 2007;28:1664-1669

46. Dufouil C, Godin O, Chalmers J, Coskun O, MacMahon S, Tzourio-Mazoyer N, et al. Severe cerebral white matter hyperintensities predict severe cognitive decline in patients with cerebrovascular disease history. Stroke. 2009;40:2219-2221

47. Pohjasvaara TI, Jokinen H, Ylikoski R, Kalska H, Mantyla R, Kaste M, et al. White matter lesions are related to impaired instrumental activities of daily living poststroke. J Stroke Cerebrovasc Dis. 2007;16:251-258 48. Mok V, Chang C, Wong A, Lam WW, Richards PS, Wong KT, et al. Neuroimaging determinants of cognitive performances in stroke associated with small vessel disease. J Neuroimaging. 2005;15:129-137

49. Williamson J, Nyenhuis D, Stebbins GT, Lamb D, Simkus V, Sripathirathan K, et al. Regional differences in relationships between apparent white matter integrity, cognition and mood in patients with ischemic stroke. J Clin Exp Neuropsychol. 2010;32:673-681

50. Mok V, Wong KK, Xiong Y, Wong A, Schmidt R, Chu W, et al. Cortical and frontal atrophy are associated with cognitive impairment in age-related confluent white-matter lesion. J Neurol Neurosurg Psychiatry. 2011;82:52-57

51. Firbank MJ, Allan LM, Burton EJ, Barber R, O’Brien JT, Kalaria RN. Neuroimaging predictors of death and dementia in a cohort of older stroke survivors. J Neurol Neurosurg Psychiatry. 2012;83:263-267

52. Mok VC, Wong A, Lam WW, Baum LW, Ng HK, Wong L. A case-controlled study of cognitive progression in Chinese lacunar stroke patients. Clin Neurol Neurosurg. 2008;110:649-656

53. Grau-Olivares M, Bartres-Faz D, Arboix A, Soliva JC, Rovira M, Targa C, et al. Mild cognitive impairment after lacunar infarction: voxel-based morphometry and neuropsychological assessment. Cerebrovasc Dis. 2007;23:353-361

54. Mok VC, Liu T, Lam WW, Wong A, Hu X, Guo L, et al. Neuroimaging predictors of cognitive impairment in confluent white matter lesion: volumetric analyses of 99 brain regions. Dement Geriatr Cogn Disord. 2008;25:67-73

55. Yamauchi H, Fukuyama H, Shio H. Corpus callosum atrophy in patients with leukoaraiosis may indicate global cognitive impairment. Stroke. 2000;31:1515-1520

56. Wen HM, Mok VC, Fan YH, Lam WW, Tang WK, Wong A, et al. Effect of white matter changes on cognitive impairment in patients with lacunar infarcts. Stroke. 2004;35:1826-1830

57. Appelros P, Samuelsson M, Lindell D. Lacunar infarcts: functional and cognitive outcomes at five years in relation to MRI findings. Cerebrovasc Dis. 2005;20:34-40 
58. Nitkunan A, Barrick TR, Charlton RA, Clark CA, Markus HS. Multimodal MRI in cerebral small vessel disease: its relationship with cognition and sensitivity to change over time. Stroke. 2008;39:1999-2005

59. Grau-Olivares M, Arboix A, Junque C, Arenaza-Urquijo EM, Rovira M, Bartres-Faz D. Progressive gray matter atrophy in lacunar patients with vascular mild cognitive impairment. Cerebrovasc Dis. 2010;30:157166

60. Kandiah N, Wiryasaputra L, Narasimhalu K, Karandikar A, Marmin M, Chua EV, et al. Frontal subcortical ischemia is crucial for post stroke cognitive impairment. J Neurol Sci. 2011;309:92-95

61. Pavlovic AM, Pekmezovic T, Zidverc-Trajkovic J, Jovanovic Z, Mijajlovic M, Pavlovic D, et al. What are the differences between younger and older patients with symptomatic small vessel disease? Clin Neurol Neurosurg. 2011;113:762-767

62. Yamamoto Y, Akiguchi I, Oiwa K, Hayashi M, Kasai T, Ozasa K. Twenty-four-hour blood pressure and MRI as predictive factors for different outcomes in patients with lacunar infarct. Stroke. 2002;33:297-305

63. Yamamoto Y, Ohara T, Nagakane Y, Tanaka E, Morii F, Koizumi T, et al. Chronic kidney disease, 24-h blood pressure and small vessel diseases are independently associated with cognitive impairment in lacunar infarct patients. Hypertens Res. 2011;34:1276-1282

64. de Groot JC, de Leeuw FE, Oudkerk M, van Gijn J, Hofman A, Jolles J, et al. Cerebral white matter lesions and cognitive function: the Rotterdam Scan Study. Ann Neurol. 2000;47:145-151

65. Kril JJ, Patel S, Harding AJ, Halliday GM. Patients with vascular dementia due to microvascular pathology have significant hippocampal neuronal loss. J Neurol Neurosurg Psychiatry. 2002;72:747-751

66. Grau-Olivares M, Arboix A, Bartres-Faz D, Junque C. Neuropsychological abnormalities associated with lacunar infarction. J Neurol Sci. 2007;257:160-165

67. Debette S, Markus HS. The clinical importance of white matter hyperintensities on brain magnetic resonance imaging: systematic review and meta-analysis. BMJ. 2010;341:c3666

68. Kuller LH, Lopez OL, Newman A, Beauchamp NJ, Burke G, Dulberg C, et al. Risk factors for dementia in the cardiovascular health cognition study. Neuroepidemiology. 2003;22:13-22

69. Vermeer SE, Prins ND, den Heijer T, Hofman A, Koudstaal PJ, Breteler MM. Silent brain infarcts and the risk of dementia and cognitive decline. N Engl J Med. 2003;348:1215-1222

70. Fox NC, Freeborough PA. Brain atrophy progression measured from registered serial MRI: validation and application to Alzheimer's disease. J Magn Reson Imaging. 1997;7:1069-1075

71. Scahill RI, Schott JM, Stevens JM, Rossor MN, Fox NC. Mapping the evolution of regional atrophy in Alzheimer's disease: unbiased analysis of fluid-registered serial MRI. Proc Natl Acad Sci U S A. 2002;99:47034707

72. Walters RJ, Fox NC, Schott JM, Crum WR, Stevens JM, Rossor MN, et al. Transient ischaemic attacks are associated with increased rates of global cerebral atrophy. J Neurol Neurosurg Psychiatry. 2003;74:213-216 73. Jokinen H, Lipsanen J, Schmidt R, Fazekas F, Gouw AA, van der Flier WM, et al. Brain atrophy accelerates cognitive decline in cerebral small vessel disease: The LADIS study. Neurology. 2012;78:1785-1792 74. van Norden AG, de Laat KF, van Dijk EJ, van Uden IW, van Oudheusden LJ, Gons RA, et al. Diffusion tensor imaging and cognition in cerebral small vessel disease: the RUN DMC study. Biochim Biophys Acta. 2012;1822:401-407

75. Patel B, Markus HS. Magnetic resonance imaging in cerebral small vessel disease and its use as a surrogate disease marker. Int J Stroke. 2011;6:47-59

76. Smith GD, Hart C, Watt G, Hole D, Hawthorne V. Individual social class, area-based deprivation, cardiovascular disease risk factors, and mortality: the Renfrew and Paisley Study. J Epidemiol Community Health. 1998;52:399-405

77. Lawlor DA, Davey Smith G, Patel R, Ebrahim S. Life-course socioeconomic position, area deprivation, and coronary heart disease: findings from the British Women's Heart and Health Study. Am J Public Health. 2005;95:91-97 
$36 \mid$ Chapter 2

78. Winkleby MA, Kraemer HC, Ahn DK, Varady AN. Ethnic and socioeconomic differences in cardiovascular disease risk factors: findings for women from the Third National Health and Nutrition Examination Survey, 1988-1994. JAMA. 1998;280:356-362

79. Enzinger C, Fazekas F, Ropele S, Schmidt R. Progression of cerebral white matter lesions -- clinical and radiological considerations. J Neurol Sci. 2007;257:5-10

80. Nys GM, van Zandvoort MJ, de Kort PL, Jansen BP, Kappelle LJ, de Haan EH. Restrictions of the Mini-Mental State Examination in acute stroke. Arch Clin Neuropsychol. 2005;20:623-629 
\begin{tabular}{l|l} 
cSVD and cognition in cardiovascular disease & 37
\end{tabular} 
38 
Chapter

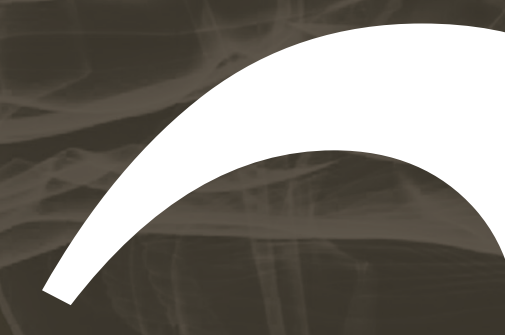




\begin{abstract}
Background - Associations of arterial stiffness with specific cognitive domains have been investigated in some studies, but long term follow-up studies are lacking and therefore no information is available on the predictive value of arterial stiffness on cognitive function. The aim of this study was to explore the association between arterial stiffness and cognitive performance after 5 years in patients with essential hypertension.

Methods - We included 86 essential hypertensive patients. At baseline, patients underwent pulse wave velocity measurements and brain MRI. At 5-year follow-up, patients underwent brain MRI and neuropsychological assessment. We investigated baseline pulse wave velocity in relation to cognitive function as well as cerebral small vessel disease imaging markers (white matter lesion volume, lacunar infarcts and brain microbleeds) at 5-year follow-up. Results - The difference in total WML volume between baseline and follow-up was significant, but only for patients in PWV tertile 2 and 3 ( $p<.001$ and $p=.028$ respectively). Compound scores for all cognitive domains, except executive function, decreased with increasing pulse wave velocity. However, results lost significance when we corrected for age or white matter lesion volume.

Conclusions - We found that increased arterial stiffness is a predictor for WML volume progression and that increased arterial stiffness predicts cognitive function at follow-up, but not independently of age and white matter lesion volume. These findings support the "cerebral microvascular hypothesis" for intellectual deterioration in patients with arterial stiffness.
\end{abstract}

\title{
Chapter 3
}

\section{Arterial stiffness and cognitive function in essential hypertensive patients}

\author{
Marjolein Huijts, Julie Staals, Annelien Duits, Ed Gronenschild, Bram Kroon, \\ Peter de Leeuw, Robert van Oostenbrugge
}

\author{
Submitted
}




\section{Introduction}

Arterial stiffness gradually increases with aging and supposedly is a risk factor for cerebrovascular damage ${ }^{1,2}$ and cognitive dysfunction ${ }^{3}$. Previous research into the relationship between arterial stiffness and cerebral small vessel disease (cSVD) revealed that increased arterial stiffness is positively associated with severity or volume of white matter lesions (WMLs) ${ }^{2,4-8}$, and with the presence or number of lacunar infarcts (LACs) $)^{5,7,9}$, but not with the number of brain microbleeds $(\mathrm{BMBs})^{5,6,8}$. Others found that arterial stiffness also correlates with cogni-

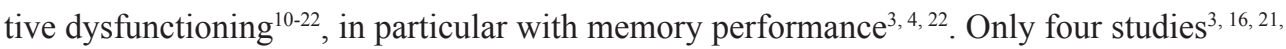
22 explored associations with specific multiple cognitive domains, but long term follow-up studies are lacking. Additionally, adjustments for MRI expressions of cSVD have rarely been made, even though this is needed to test the hypothesis that a "cerebral microvascular mechanism" is responsible for decreased cognitive performance in patients with arterial stiffness ${ }^{23}$. The aim of the present study was to explore the association between incident arterial stiffness, measured by pulse wave velocity, and cognitive performance 5 years later in patients with essential hypertension, taking into account the possible influence of cSVD markers.

\section{Methods \\ Participants}

Subjects were essential hypertensive patients who were referred to the hypertension outpatient clinic of the Department of Internal Medicine of the Maastricht University Medical Centre. Patients were included in a larger longitudinal study on the effects of hypertension on brain damage ${ }^{5}$ and cognitive function. Exclusion criteria were a history of symptomatic cardio- or cerebrovascular disease or contraindications for MRI. At baseline, blood pressure, aortic pulse wave velocity (PWV) measurements and brain MRI were performed. Five years after baseline assessment, MRI of the brain was repeated and an extensive neuropsychological assessment was added. The study was approved by the Medical Ethics Committee of the Maastricht University Medical Centre and all participants gave written informed consent.

\section{Hemodynamic measurements}

Hemodynamic measurements have been described in detail earlier ${ }^{5}$. Briefly, office blood pressure measurements were assessed by sphygmanometry in the sitting position. Three consecutive measurements were taken at the non-dominant arm after $\geq 5$ minutes of rest, for which the mean was calulated. Mean systolic (SBP) and diastolic blood pressure (DBP) were used to calculate the peripheral pulse pressure (PP) and mean arterial pressure (MAP) by using the following formulas: $\mathrm{PP}=\mathrm{SBP}-\mathrm{DBP}$ and $\mathrm{MAP}=\mathrm{DBP}+[(\mathrm{SBP}-\mathrm{DBP}) / 3]$.

Pulse wave velocity (PWV) was assessed noninvasively in the supine position, by applying the foot-to-foot velocity method ${ }^{24}$. The time delay $(\mathrm{t})$ between the rapid upstroke of the feet of simultaneously recorded waveforms, obtained transcutaneously over the right common carotid artery and the right femoral artery, was measured with an automatic device (Complior, Colson). We estimated the distance (D) traveled by the pulse waves by measuring the distance between the 2 recording sites over the body surface with a tape measure. PWV was 
calculated as $\mathrm{D} / \mathrm{t}(\mathrm{m} / \mathrm{s})$.

\section{Brain magnetic resonance imaging}

MRI of the brain (Intera 1.5T, Philips Medical Systems, Best, The Netherlands) was performed to obtain axial T2-weighted, fluid-attenuated inversion recovery and T2*-weighted gradient echo images.

We defined white matter lesions (WMLs) as hyperintense areas in the periventricular and deep white matter on both T2-weighted and FLAIR images. Since visual rating scales apply arbitrary cutoffs to define lesion severity and display ceiling effects ${ }^{25}$, we quantified the WML volumes semi-automatically using the in-house developed (EG) image-processing software package GIANT, version 2V1.26 (General Imaging and Analysis Tools; Department of Psychiatry and Neuropsychology, Maastricht University, Maastricht, The Netherlands) ${ }^{26}$. Additionally, volumetric measurements may be more sensitive in detecting subtle differences $^{25}$. A trained observer $(\mathrm{MH})$ performed the quantitative assessments after reaching satisfactory agreement with an experienced neuroradiologist.

We identified asymptomatic lacunar infarcts as sharply demarcated hyperintense lesions $<20$ $\mathrm{mm}$ on $\mathrm{T} 2$-weighted images with corresponding hypointense lesions with a hyperintense rim on FLAIR. BMBs were defined as punctate $(<10 \mathrm{~mm})$ homogeneous foci of low signal intensity on T2*-weighted images. Symmetrical hypointensities in the globi pallidi were disregarded, since these most likely represent calcification.

\section{Cognitive function}

Cognitive function was assessed by a trained neuropsychologist $(\mathrm{MH})$ during a 2 hour session. The test battery included the Rey Auditory Verbal Learning Test (RAVLT) ${ }^{27}$, Stroop Colour Word Test (SCWT) $)^{28}$, Trailmaking Test A and B (TMT) ${ }^{29}$, category and letter fluency $^{30,31}$, and the following subtests of the Wechsler Adult Intelligence Scale III (WAIS III) ${ }^{32}$, Symbol Substitution, Digit span and Letter Number Sequencing. For the SCWT and TMT, interference scores were computed. Interference score SCWT= time on card 3 - Mean (card $1+$ card 2). Interference score TMT= time card B - time card A.

We compared performances on different cognitive domains by using $\mathrm{Z}$ standard scores. For each domain we computed compound scores. Memory domain= $($ Z/RAVLT immediate recall + Z/RAVLT delayed recall + Z/RAVLT word recognition + Z/digit span forward)/4; Executive functions domain $=(\mathrm{Z} / \mathrm{SCWT}$ interference $+\mathrm{Z} / \mathrm{TMT}$ interference $+\mathrm{Z} /$ category fluency + Z/letter fluency + Z/digit span backward + Z/letter number sequencing)/6; Information processing speed $=(Z /$ symbol substitution $+Z / T M T A+Z /$ mean of Stroop card 1 and 2$) / 3$. A compound score for overall cognitive function was calculated as the mean score of the three compound scores. Z-scores of tests with higher scores representing worse performance were inverted before computing the compound scores. Compound scores for memory, executive function, information processing speed and overall cognition were missing for 2,1,1 and 3 patients respectively. Therefore, analyses on these variables were performed with a different number of subjects. 


\section{Statistical analysis}

PWV was analysed in tertiles. We used analysis of variance to detect differences in baseline characteristics between the three tertiles of PWV. In case of skewed distribution or nominal or ordinal variables, we used Mann-Whitney U-tests, Pearson X2 or Somers' d respectively. In order to detect differences in total WML between baseline and follow-up for the three tertiles of PWV, we used non-parametric T-tests for related samples. Differences in progression of lacunar infarcts or BMBs between the tertiles was analyzed using Somers' d directional measures.

Linear regression models were used to test associations of PWV with cognitive function, adjusted for age and sex. Additionally, we performed linear regression analyses with markers of cSVD as confounding factors. Besides PWV measurements, we also assessed associations of pulse pressure, as a surrogate marker for arterial stiffness, with cognitive function. All analyses were performed using PASW 18.0 (Statistical Package for the Social Sciences; Chicago, IL, USA).

\section{Results}

Out of the 218 hypertensive patients included at baseline, 198 agreed to be contacted for follow-up studies. We included 112 patients with 5-year follow-up MRI and extensive neuropsychological assessment. Reasons for exclusion were: not interested $(\mathrm{N}=69)$, cerebrovascular accident or transient ischemic attack between baseline and follow-up $(\mathrm{N}=7)$, preexistent cognitive problems $(\mathrm{N}=3)$, death $(\mathrm{N}=4)$, or other reasons $(\mathrm{N}=3)$. Of the 112 included patients, 86 patients had PWV measurements at baseline. Age, sex, BMI, SBP, DBP and PP did not differ between the 86 included and 26 excluded patients. Time to follow-up was 5.0 years $(\mathrm{SD}=0.1)$. Characteristics of the study population by tertiles of PWV are shown in table 1. Age, SBP and PP at baseline, and WML volume at follow-up, were significantly different for the three tertiles of PWV.

\section{Arterial stiffness and cerebral small vessel disease}

WML volumes at baseline $(p=.001)$ and follow-up $(p=.006)$ increased significantly with increasing PWV. Although the presence of asymptomatic lacunar infarcts and BMBs at baseline and follow-up increased with increasing arterial stiffness, the overall difference across tertiles was not statistically significant.

The difference in total WML volume between baseline and follow-up was significant, but only for patients in PWV tertile 2 and 3 ( $p<.001$ and $p=.028$ respectively). A trend for a difference in progression of BMBs was found for the three tertiles of PWV (Somers' $d=.141$, $p=.078)$, with the highest prevalence of progression in the third tertile $(3.4 \%, 14.3 \%$ and $17.2 \%$ respectively). 
Table 1. Characteristics of the study population according to PWV tertiles

\begin{tabular}{llllll}
\hline \hline & All $(n=86)$ & $\begin{array}{l}\mathrm{PWV} \leq 10.2 \mathrm{~m} / \mathrm{s} \\
(n=29)\end{array}$ & $\begin{array}{l}\mathrm{PWV} 10.2-12.5 \\
\mathrm{~m} / \mathrm{s}(n=28)\end{array}$ & $\begin{array}{l}\mathrm{PWV} \geq 12.5 \mathrm{~m} / \mathrm{s} \\
(n=29)\end{array}$ & $p^{*}$ \\
\hline Age, years & $55.4 \pm 12.7$ & $47.5 \pm 12.0$ & $55.4 \pm 11.8$ & $63.3 \pm 9.1$ & $<.001$ \\
Male sex & $49(57.0)$ & $15(51.7)$ & $14(50.0)$ & $20(69.0)$ & .275 \\
BMI, kg/m ${ }^{2}$ & $27.3 \pm 4.2$ & $27.1 \pm 3.8$ & $28.1 \pm 5.0$ & $26.6 \pm 3.8$ & .380 \\
Office SBP, mmHg & $166.1 \pm 24.5$ & $155.4 \pm 17.2$ & $166.4 \pm 23.2$ & $176.6 \pm 27.9$ &. $\mathbf{0 0 3}$ \\
Office DBP, mmHg & $101.9 \pm 12.4$ & $99.7 \pm 12.2$ & $103.1 \pm 11.1$ & $103.0 \pm 13.9$ & .502 \\
Office MAP, mmHg & $123.3 \pm 14.9$ & $118.3 \pm 12.6$ & $124.2 \pm 13.8$ & $127.6 \pm 17.0$ & .055 \\
Office PP, mmHg & $64.2 \pm 19.1$ & $55.7 \pm 13.2$ & $63.3 \pm 18.0$ & $73.6 \pm 21.4$ &. $\mathbf{0 0 1}$ \\
Office HR, bpm & $74.3 \pm 11.3$ & $74.6 \pm 10.2$ & $72.1 \pm 10.6$ & $76.1 \pm 12.9$ & .405 \\
Brain MRI at BL & & & & & $1197(650-3749)$ \\
WML volume, mm ${ }^{3}$ & $493(233-1525)$ & $343(215-791)$ & $368(200-1168)$ & .001 \\
Presence of LACs & $17(19.8)$ & $4(13.8)$ & $4(14.2)$ & $9(31.0)$ & .073 \\
Presence of BMBs & $10(11.6)$ & $2(6.9)$ & $3(10.7)$ & $5(17.2)$ & .190
\end{tabular}

Brain MRI at 5 years

WML volume, $\mathrm{mm}^{3}$

$716(211-2621)$

269 (116- 1094)

$659(243-2424)$

$1806(605-6456)$

.006

Presence of LACs

$20(23.3)$

4 (13.8)

7 (25.0)

$9(31.0)$

.093

Presence of BMBs

12 (14.0)

2 (6.9)

4 (14.2)

6 (20.7)

.102

Data are shown as mean $\pm \mathrm{SD}$, number (\%), or median (interquartile range [IQR]). BMI= body mass index; $\mathrm{SBP}=$ systolic blood pressure; $\mathrm{DBP}=$ diastolic blood pressure; $\mathrm{MAP}=$ mean arterial pressure; $\mathrm{PP}=$ pulse pressure; $\mathrm{HR}=$ heart rate; $\mathrm{PWV}=$ pulse wave velocity; $\mathrm{BV}=$ brain volume; $\mathrm{WML}=$ white matter lesion; $\mathrm{LAC}=$ lacunar infarct; $\mathrm{BMB}=$ brain microbleed. * $\mathrm{p}$ values are for overall differences across tertiles.

\section{Arterial stiffness and cognitive function}

With increasing PWV, compound scores for all cognitive domains, except executive function, decreased (table 2). However, results lost significance when we corrected for age (model 1). When we corrected for imaging markers of cSVD (model 3 to 5) in regression analyses, results often remained significant after correction for lacunar infarcts or BMBs, but disappeared completely after correction for WML volume. None of these results remained significant after an additional correction for age.

Compound scores for all cognitive domains, except executive function, were significantly lower for those patients with higher PP. This effect however, disappeared after correction for age (model 1). When we corrected for imaging markers of cSVD (model 3 to 5), results often remained significant after correction for lacunar infarcts or BMBs, but disappeared after correction for WML volume, except for information processing speed. However, none of these results remained significant after an additional correction for age. 
Table 2. Relationship between arterial stiffness measures and cognitive function

\begin{tabular}{|c|c|c|}
\hline Cognitive domain & $\begin{array}{l}\text { Aortic PWV } \\
\text { Unstandardized regression coef- } \\
\text { ficient }(95 \% \mathrm{CI})\end{array}$ & $\begin{array}{l}\text { Office PP } \\
\text { Unstandardized regression coef- } \\
\text { ficient }(95 \% \mathrm{CI})\end{array}$ \\
\hline \multicolumn{3}{|l|}{ Memory } \\
\hline - Unadjusted & $-0.062(-0.113 \text { to }-0.010)^{*}$ & $-0.011(-0.018$ to -0.003$) \dagger$ \\
\hline - Model 1 & $0.015(-0.040$ to 0.071$)$ & $-0.004(-0.012$ to 0.004$)$ \\
\hline - Model 2 & $-0.052(-0.104 \text { to }-0.001)^{*}$ & $-0.013(-0.020$ to -0.005$)+$ \\
\hline - Model 3 & $-0.054(-0.105 \text { to }-0.003)^{*}$ & $-0.007(-0.015$ to 0.001$)$ \\
\hline - Model 4 & $-0.058(-0.110 \text { to }-0.005)^{*}$ & $-0.10(-0.018 \text { to }-0.002)^{*}$ \\
\hline - Model 5 & $-0.052(-0.104$ to 0.001$)$ & $-0.008(-0.016 \text { to } 0.000)^{*}$ \\
\hline \multicolumn{3}{|l|}{ Executive function } \\
\hline - Unadjusted & $-0.033(-0.087$ to 0.022$)$ & $-0.007(-0.015$ to 0.001$)$ \\
\hline - Model 1 & $0.039(-0.020$ to 0.098$)$ & $0.002(-0.007$ to 0.010$)$ \\
\hline - Model 2 & $-0.037(-0.093$ to 0.018$)$ & $-0.007(-0.015$ to 0.001$)$ \\
\hline - Model 3 & $-0.022(-0.074$ to 0.030$)$ & $-0.003(-0.011$ to 0.005$)$ \\
\hline - Model 4 & $-0.025(-0.080$ to 0.031$)$ & $-0.007(-0.015$ to 0.002$)$ \\
\hline - Model 5 & $-0.027(-0.083$ to 0.029$)$ & $-0.007(-0.016$ to 0.002$)$ \\
\hline \multicolumn{3}{|c|}{ Information processing speed } \\
\hline - Unadjusted & $-0.107(-0.169$ to -0.045$) \ddagger$ & $-0.019(-0.028$ to -0.010$)+$ \\
\hline - Model 1 & $-0.002(-0.065$ to 0.061$)$ & $-0.006(-0.015$ to 0.003$)$ \\
\hline - Model 2 & $-0.108(-0.172$ to -0.044$) \ddagger$ & $-0.020(-0.029$ to -0.011$) \ddagger$ \\
\hline - Model 3 & $-0.095(-0.155$ to -0.035$) \dagger$ & $-0.013(-0.022$ to -0.004$) \dagger$ \\
\hline - Model 4 & $-0.093(-0.156$ to -0.030$) \dagger$ & $-0.017(-0.025$ to -0.008$)+$ \\
\hline - Model 5 & $-0.099(-0.163$ to -0.035$) \dagger$ & $-0.019(-0.028$ to -0.009$) \$$ \\
\hline \multicolumn{3}{|c|}{ Overall cognitive function } \\
\hline - Unadjusted & $-0.063(-0.111 \text { to }-0.014)^{*}$ & $-0.011(-0.018$ to -0.004$) \dagger$ \\
\hline - Model 1 & $0.019(-0.030$ to 0.069$)$ & $-0.002(-0.010$ to 0.005$)$ \\
\hline - Model 2 & $-0.061(-0.111 \text { to }-0.011)^{*}$ & $-0.012(-0.019$ to -0.005$) \dagger$ \\
\hline - Model 3 & $-0.053(-0.100 \text { to }-0.007)^{*}$ & $-0.007(-0.014$ to 0.000$)$ \\
\hline - Model 4 & $-0.053(-0.102 \text { to }-0.004)^{*}$ & $-0.010(-0.017$ to -0.003$) \dagger$ \\
\hline - Model 5 & $-0.059(-0.108 \text { to }-0.009)^{*}$ & $-0.011(-0.019$ to -0.003$) \dagger$ \\
\hline
\end{tabular}

Linear regression analyses: arterial stiffness predicting cognitive function. Model 1: adjusted for age. Model 2: adjusted for sex. Model 3: adjusted for total WML volume. Model 4: adjusted for total the presence of lacunar infarcts. Model 5: adjusted for the presence of BMBs. None of the significant results found in models 2 to 5 remained significant after additional correction for age.

$* p \leq .05$

$\uparrow p \leq .01$

$\ddagger p \leq .001$

\section{Discussion}

The aim of this study was to explore the association between arterial stiffness and cognitive performance after 5 years in patients with essential hypertension, corrected for markers of cSVD. We found that increasing arterial stiffness was associated with decreased cognitive functioning, but not independently of age or WML volume. Additionally, we found signifi- 
cant increases of WML volume at follow-up for patients with the highest tertiles of PWV at baseline.

Studies with a comparable study population found a relationship between PWV and MMSE score in younger $(<65 \text { years), but not in elderly hypertensive patients ( }>65 \text { years })^{13}$. MMSE scores however, were lower for the elderly patients than for the younger patients, which implies that besides PWV, age contributed to the MMSE scores. In age-weighted analyses for the total population, PWV appeared to be the only predictor for MMSE scores. KearneySchwartz et $\mathrm{al}^{4}$ studied hypertensive patients with memory complaints and found that PWV was related to memory score in men only. The authors of that study suggested that this was attributable to a strong predictive value of male gender to PWV and a more pronounced cardiovascular risk profile in men. We were not able to replicate the relation between PWV and memory score, as our results lost significance after adjustments for age. Since the study population by Kearney-Schwartz et $\mathrm{al}^{4}$ involved hypertensive patients with memory complaints, variation in memory scores was probably much larger and associations with arterial stiffness easier to detect. Additionally, mean age was significantly lower in our population (55.4 versus 69.3 years) than in their population ${ }^{4}$.

We earlier found that, cross-sectionally, increasing arterial stiffness was independently associated with WMLs and lacunar infarcts in hypertensive patients ${ }^{5}$. Recently, Poels et $\mathrm{al}^{33}$ revealed significant associations between increasing arterial stiffness and higher WML volumes in the elderly general population, especially in those with uncontrolled hypertension. The present semi-longitudinal results showed a significant increase in WMLs at follow-up, but only for these patients in the highest tertiles of PWV at baseline. Patients in the highest tertile also showed a higher prevalence of BMB progression. As far as we know, this study is the first to investigate the effect of arterial stiffness on progression of cSVD.

The finding that the association between increased arterial stiffness and decreased cognitive function disappeared after adjustments for WML volume, is in line with the "cerebral microvascular hypothesis" for intellectual deterioration in patients with arterial stiffness as suggested by O'Rourke and $\mathrm{Safar}^{23}$. This hypothesis states that microvascular damage such as lacunar infarcts, WMLs and BMBs are caused by high pulsatile pressures and flow in the cerebral microvessels. This damage may in turn affect cognitive function. Mitchell et $\mathrm{al}^{21}$ recently found associations of arterial stiffness with several cognitive domains in healthy elderly patients. When they adjusted for imaging markers of cSVD, effects were attenuated or no longer significant. They were the first to present results compatible with the hypothesis mentioned above in healthy elderly persons, and we confirmed this in a hypertensive population which is at particular risk for increased PWV and cSVD.

Besides the confounding effect of WML volume in the relation between arterial stiffness and cognitive function, our results were not independent of age. Although it is generally accepted to adjust for age in cognitive function research, a confounding effect of age was expected in this relationship. Due to the effects of aging, the arterial wall becomes thicker and arterial stiffness increases ${ }^{34}$. Rabkin et $\mathrm{a}^{135}$ recently presented a schematic summary of 
potential mechanisms by which arterial stiffness could be causally related to cognitive impairment. Age was suggested to cause arterial stiffness, but also neuronal damage and, as a consequence of either one of them, cognitive impairment. In a meta-analysis by Rabkin et $\mathrm{al}^{35}$ they report 12 studies with multivariate analyses to study the relation between arterial stiffness and cognition. In $75 \%$ of the studies, a significant effect of arterial stiffness on cognitive function was found after adjusting for factors such as age, gender or body mass index. However, only two studies ${ }^{4,13}$ were based on a hypertensive population, of which only 1 found a significant effect ${ }^{4}$ after age correction.

Apparently, arterial stiffness no longer has a predictive value for cognitive function in patients with obvious end organ damage, such as cSVD. Diffusion Tensor Imaging (DTI) may therefore be suggested to investigate this relationship in more detail. Since DTI is able to detect microstructural changes of the normal appearing white matter (NAWM) at a much earlier stage, this might influence the relationship between arterial stiffness, cerebrovascular damage and cognitive function ${ }^{36,37}$.

Strengths of our study include extensive neuropsychological testing, which enables to assess the effect on several cognitive domains. Additionally, we measured arterial stiffness with carotid-femoral PWV, which is considered to be the golden standard in arterial stiffness measurements ${ }^{38}$. One of the limitations of this study concerns the design with the absence of a neuropsychological assessment at baseline and PWV measurements at follow-up, which prevents statements about causality. Longitudinal studies following increase of arterial stiffness and cognitive decline over time are needed to confirm a causal relationship between the two.

In conclusion, we found that increased arterial stiffness is associated with WML volume progression. Increased arterial stiffness also predicts cognitive function at follow-up, but not independent of age and WMLs. This latter finding supports the "cerebral microvascular hypothesis" for intellectual deterioration in patients with arterial stiffness. Additionally, aging-induced alterations in arterial stiffness also need to be considered as a possible cause for the relation with cognitive impairment. Future studies are therefore suggested to assess PWV, imaging markers of cSVD and cognitive function longitudinally, in order to investigate causality. 


\section{References}

1. O'Rourke MF, Safar ME. Relationship between aortic stiffening and microvascular disease in brain and kidney: cause and logic of therapy. Hypertension. 2005;46:200-204

2. Rosano C, Watson N, Chang Y, Newman AB, Aizenstein HJ, Du Y, et al. Aortic Pulse Wave Velocity Predicts Focal White Matter Hyperintensities in a Biracial Cohort of Older Adults. Hypertension. 2012 3. Waldstein SR, Rice SC, Thayer JF, Najjar SS, Scuteri A, Zonderman AB. Pulse pressure and pulse wave velocity are related to cognitive decline in the Baltimore Longitudinal Study of Aging. Hypertension. 2008;51:99-104

4. Kearney-Schwartz A, Rossignol P, Bracard S, Felblinger J, Fay R, Boivin JM, et al. Vascular structure and function is correlated to cognitive performance and white matter hyperintensities in older hypertensive patients with subjective memory complaints. Stroke. 2009;40:1229-1236

5. Henskens LH, Kroon AA, van Oostenbrugge RJ, Gronenschild EH, Fuss-Lejeune MM, Hofman PA, et al. Increased aortic pulse wave velocity is associated with silent cerebral small-vessel disease in hypertensive patients. Hypertension. 2008;52:1120-1126

6. van Elderen SG, Brandts A, Westenberg JJ, van der Grond J, Tamsma JT, van Buchem MA, et al. Aortic stiffness is associated with cardiac function and cerebral small vessel disease in patients with type 1 diabetes mellitus: assessment by magnetic resonance imaging. Eur Radiol. 2010;20:1132-1138

7. Hatanaka R, Obara T, Watabe D, Ishikawa T, Kondo T, Ishikura K, et al. Association of Arterial Stiffness with Silent Cerebrovascular Lesions: The Ohasama Study. Cerebrovasc Dis. 2011;31:329-337

8. Poels MM, Zaccai K, Verwoert GC, Vernooij MW, Hofman A, van der Lugt A, et al. Arterial stiffness and cerebral small vessel disease: the Rotterdam Scan Study. Stroke. 2012;43:2637-2642

9. Kim DH, Kim J, Kim JM, Lee AY. Increased brachial-ankle pulse wave velocity is independently associated with risk of cerebral ischemic small vessel disease in elderly hypertensive patients. Clin Neurol Neurosurg. 2008;110:599-604

10. Hanon O, Haulon S, Lenoir H, Seux ML, Rigaud AS, Safar M, et al. Relationship between arterial stiffness and cognitive function in elderly subjects with complaints of memory loss. Stroke. 2005;36:2193-2197

11. Scuteri A, Brancati AM, Gianni W, Assisi A, Volpe M. Arterial stiffness is an independent risk factor for cognitive impairment in the elderly: a pilot study. J Hypertens. 2005;23:1211-1216

12. Muller M, Grobbee DE, Aleman A, Bots M, van der Schouw YT. Cardiovascular disease and cognitive performance in middle-aged and elderly men. Atherosclerosis. 2007;190:143-149

13. Triantafyllidi H, Arvaniti C, Lekakis J, Ikonomidis I, Siafakas N, Tzortzis S, et al. Cognitive impairment is related to increased arterial stiffness and microvascular damage in patients with never-treated essential hypertension. Am J Hypertens. 2009;22:525-530

14. Abbatecola AM, Barbieri M, Rizzo MR, Grella R, Laieta MT, Quaranta E, et al. Arterial stiffness and cognition in elderly persons with impaired glucose tolerance and microalbuminuria. J Gerontol A Biol Sci Med Sci. 2008;63:991-996

15. Kim YS, Kim DH, Choi BH, Sohn EH, Lee AY. Relationship between brachial-ankle pulse wave velocity and cognitive function in an elderly community-dwelling population with metabolic syndrome. Arch Gerontol Geriatr. 2009;49:176-179

16. Elias MF, Robbins MA, Budge MM, Abhayaratna WP, Dore GA, Elias PK. Arterial pulse wave velocity and cognition with advancing age. Hypertension. 2009;53:668-673

17. Sugawara N, Yasui-Furukori N, Umeda T, Kaneda A, Sato Y, Takahashi I, et al. Comparison of anklebrachial pressure index and pulse wave velocity as markers of cognitive function in a community-dwelling population. BMC Psychiatry. 2010;10:46

18. Scuteri A, Tesauro M, Appolloni S, Preziosi F, Brancati AM, Volpe M. Arterial stiffness as an independent predictor of longitudinal changes in cognitive function in the older individual. J Hypertens. 2007;25:1035-1040 
19. Poels MM, van Oijen M, Mattace-Raso FU, Hofman A, Koudstaal PJ, Witteman JC, et al. Arterial stiffness, cognitive decline, and risk of dementia: the Rotterdam study. Stroke. 2007;38:888-892

20. Fujiwara Y, Chaves PH, Takahashi R, Amano H, Yoshida H, Kumagai S, et al. Arterial pulse wave velocity as a marker of poor cognitive function in an elderly community-dwelling population. J Gerontol A Biol Sci Med Sci. 2005;60:607-612

21. Mitchell GF, van Buchem MA, Sigurdsson S, Gotal JD, Jonsdottir MK, Kjartansson O, et al. Arterial stiffness, pressure and flow pulsatility and brain structure and function: the Age, Gene/Environment Susceptibility-Reykjavik study. Brain. 2011;134:3398-3407

22. Pase MP, Pipingas A, Kras M, Nolidin K, Gibbs AL, Wesnes KA, et al. Healthy middle-aged individuals are vulnerable to cognitive deficits as a result of increased arterial stiffness. J Hypertens. 2010;28:1724-1729

23. O'Rourke MF. Brain microbleeds, amyloid plaques, intellectual deterioration, and arterial stiffness. Hypertension. 2008;51:e20; author reply e21

24. Asmar R, Benetos A, Topouchian J, Laurent P, Pannier B, Brisac AM, et al. Assessment of arterial distensibility by automatic pulse wave velocity measurement. Validation and clinical application studies. Hypertension. 1995;26:485-490

25. van Straaten EC, Fazekas F, Rostrup E, Scheltens P, Schmidt R, Pantoni L, et al. Impact of white matter hyperintensities scoring method on correlations with clinical data: the LADIS study. Stroke. 2006;37:836-840 26. Henskens LH, Kroon AA, van Oostenbrugge RJ, Gronenschild EH, Hofman PA, Lodder J, et al. Associations of ambulatory blood pressure levels with white matter hyperintensity volumes in hypertensive patients. J Hypertens. 2009;27:1446-1452

27. Brand N, Jolles J. Learning and retrieval rate of words presented auditorily and visually. J Gen Psychol. 1985;112:201-210

28. Golden CJ. Stroop Colour and Word Test. Chicago (Ill): Stoelling; 1978.

29. Reitan R. Trail Making Test: Manual for administration, scoring and interpretation. Bloomington: Indiana University; 1956.

30. Luteyn F. Een nieuwe verkorte GIT. Dutch J Psychol. 1966;2:675-682

31. Lezak M, Howieson, DB, \& Loring, DW. Neuropsychological assessment New York: Oxford University Press; 2004.

32. Wechsler D. WAIS III, nederlandstalige bewerking: technische handleiding. Lisse: Swets Test Publishers; 2001 .

33. Poels MM, Zaccai K, Verwoert GC, Vernooij MW, Hofman A, van der Lugt A, et al. Arterial Stiffness and Cerebral Small Vessel Disease: The Rotterdam Scan Study. Stroke. 2012;43:2637-2642

34. O'Rourke MF, Hashimoto J. Mechanical factors in arterial aging: a clinical perspective. J Am Coll Cardiol. 2007;50:1-13

35. Rabkin SW. Arterial stiffness: detection and consequences in cognitive impairment and dementia of the elderly. J Alzheimers Dis. 2012;32:541-549

36. Vernooij MW, Ikram MA, Vrooman HA, Wielopolski PA, Krestin GP, Hofman A, et al. White matter microstructural integrity and cognitive function in a general elderly population. Arch Gen Psychiatry. 2009;66:545-553

37. Burgmans S, van Boxtel MP, Gronenschild EH, Vuurman EF, Hofman P, Uylings HB, et al. Multiple indicators of age-related differences in cerebral white matter and the modifying effects of hypertension. Neuroimage. 2010;49:2083-2093

38. Laurent S, Cockcroft J, Van Bortel L, Boutouyrie P, Giannattasio C, Hayoz D, et al. Expert consensus document on arterial stiffness: methodological issues and clinical applications. Eur Heart J. 2006;27:2588-2605 
50 
Chapter 


\begin{abstract}
Background - Hypertension is a major risk factor for cerebral small vessel disease (cSVD) and cSVD MRI markers are frequently seen in a hypertension population. Data on the relationship between progression of white matter lesions (WMLs) and cognitive function is increasing, but information on the progression of lacunar infarcts and brain microbleeds (BMBs) in relation to cognition, specifically in a hypertensive population with cSVD, is still sparse.

Methods - We included 112 essential hypertensive patients. At baseline patients had an MRI of the brain. At 5-year follow-up imaging was repeated and an extensive neuropsychological assessment was added. WMLs were investigated with quantitative volume measurements. We studied the CSVD markers (WML volume, lacunar infarcts and BMBs) at baseline and their progression in relation to cognitive function at 5-year follow-up.

Results - Patients with substantive (fourth quartile) of WML progression performed significantly worse than patients with little progression (first quartile) on all cognitive domains, and results remained significant after correction for baseline WML volume and age and sex (all $p<.05$ ). Patients with progression of lacunar infarcts performed worse than those without on all cognitive domains except memory. However, only information processing speed remained significant after additional adjustments for age and sex. Progression of BMBs had no significant effects on cognitive function.

Discussion - We found that progression of cSVD over 5 years predicts cognitive function at follow-up, independently of cSVD damage at baseline. Patients with the largest progression of WMLs and progression of lacunar infarcts over 5 years follow-up had worse cognitive function compared to patients with the least or no progression. Our results imply that even only minimal progression of cSVD has consequences for cognitive functioning. Prevention of progression of cSVD is therefore warranted.
\end{abstract}

\title{
Chapter 4
}

\section{Progression of cerebral small vessel disease predicts cognitive function at follow-up in essential hypertensive patients}

\author{
Marjolein Huijts, Annelien Duits, Julie Staals, Ed Gronenschild, Bram Kroon, \\ Peter de Leeuw, Robert van Oostenbrugge
}

\section{Submitted}




\section{Introduction}

Hypertension is a major risk factor for cerebral small vessel disease (cSVD) ${ }^{1}$, which is characterized by lacunar infarcts, white matter lesions (WMLs) and brain microbleeds (BMBs) ${ }^{2-4}$. We previously found that these cSVD markers are frequently seen in a hypertensive population $^{5}$. Furthermore, cSVD markers have been related to cognitive function in hypertensive patients ${ }^{6,7}$. The Framingham study found that blood pressure was unrelated to cognitive function measured at the same time point ${ }^{8}$. Late-life cognitive function however, did correlate with blood pressure during mid-life ${ }^{9}$. Consequently, we were interested whether this time-dependency is also true for the relationship between cSVD and cognitive function in a hypertensive population.

Cross-sectional associations between cSVD and cognition have been studied extensively. However, data on the progression of cSVD in relation to cognition are only sparse. In a population with only minimal brain damage, it may be the slightest progression of brain damage that could have the most influence on cognitive function. This could be important to know for clinicians in order to make decisions on treatment strategies.

In a general population study, it was found that progression of WMLs was related to high blood pressure and a decline in information processing speed ${ }^{10}$. In an elderly population with any degree of WMLs on MRI, progression of WMLs was found in $74 \%$ over 3 years ${ }^{11}$ and was associated with a decline in executive and general cognitive function ${ }^{12,13}$. TIA or stroke patients who had an increase in WML volume over 4 years had an increased risk for cognitive decline and dementia ${ }^{14}$.

Regarding progression of lacunar infarcts and BMBs, associations with cognitive decline have not been investigated that extensively. Progression of lacunar infarcts appeared to be related to a steeper rate of decline in executive function and speed and motor control in a cohort of patients with WMLs ${ }^{12}$. Regarding BMBs, studies exploring the association between BMBs at baseline and cognitive decline did not take into account the association with actual progression of $\mathrm{BMBs}^{15,16}$.

The aim of this study was to assess whether cSVD-related brain damage at baseline, or its progression over years, can predict cognitive function at 5-year follow-up in a hypertensive population.

\section{Methods \\ Participants}

Subjects were essential hypertensive patients who were referred to the hypertension outpatient clinic of the Department of Internal Medicine of the Maastricht University Medical Centre. Patients were selected from a larger longitudinal study on the effects of hypertension on brain damage ${ }^{17}$ and cognitive function. Exclusion criteria were a history of symptomatic cardio- or cerebrovascular disease, secondary hypertension, chronic renal failure, diabetes, obstructive sleep apnea or contraindications for MRI. At baseline ( $\mathrm{N}=218)$, an MRI of the brain was conducted. Five years after baseline, MRI was repeated and an extensive neuropsychological assessment was added. The study was approved by the Medical Ethics Commit- 
tee of the Maastricht University Medical Centre and all participants gave written informed consent.

Figure 1. Flow of participants

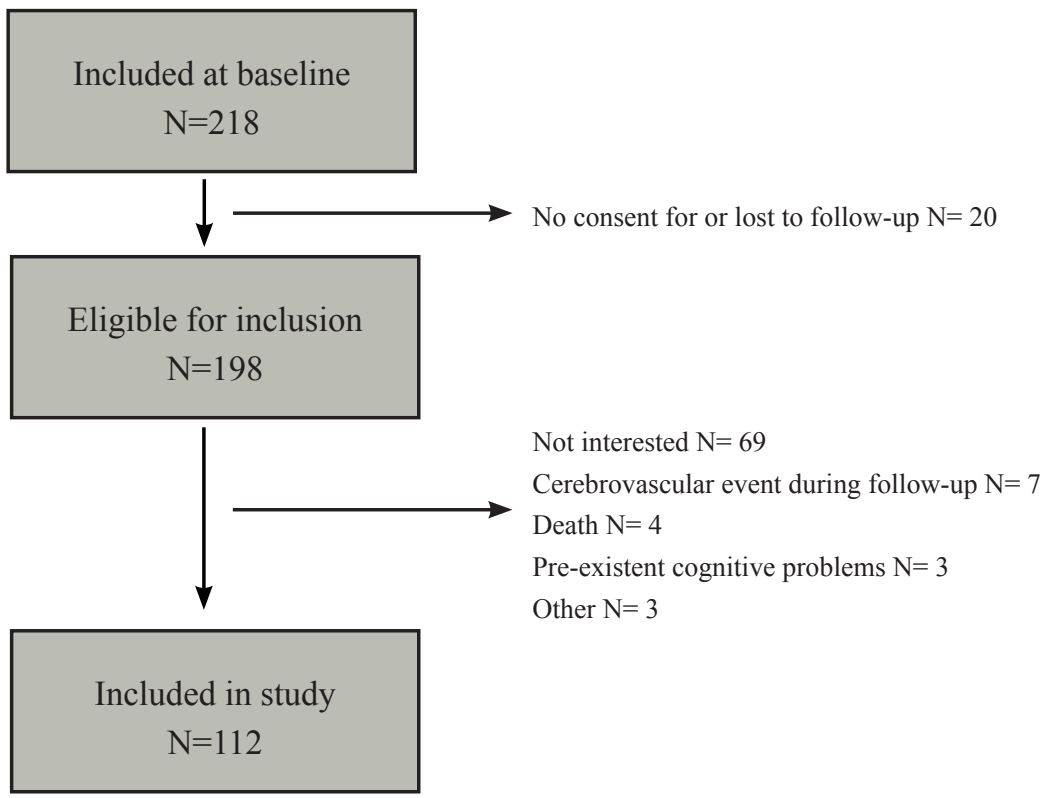

\section{Brain magnetic resonance imaging}

MRI of the brain (Intera 1.5-T, Philips Medical Systems, Best, The Netherlands) was performed to obtain axial T2-weighted, fluid-attenuated inversion recovery (FLAIR) and T2*weighted gradient echo (GE) images. The T2 and FLAIR imaging data were analyzed for WML volumes by using the in-house developed (EG) image-processing software package GIANT (General Imaging and Analysis Tools; Department of Psychiatry and Neuropsychology, Maastricht University, Maastricht, The Netherlands) ${ }^{17}$. Hyperintense areas on T2 as well as FLAIR images were scored semi-automatically as WMLs. WML progression was calculated by follow-up volume minus baseline volume. We identified silent lacunar infarcts as sharply demarcated hyperintense lesions $<20 \mathrm{~mm}$ on T2-weighted images with corresponding hypointense lesions with a hyperintense rim on FLAIR. BMBs were defined as punctate $(<10 \mathrm{~mm})$ homogeneous foci of low signal intensity on T2*-weighted GE images. Follow-up MRI scans were side-by-side compared to baseline MRI. The development of $\geq 1$ new lacunar infarct or BMBs at follow-up was defined as progression.

\section{Cognitive function}

Cognitive function was assessed by a trained neuropsychologist $(\mathrm{MH})$ during a 2 hour session. The test battery included the Rey Auditory Verbal Learning Test (RAVLT) ${ }^{18}$, Stroop Colour Word Test $(\mathrm{SCWT})^{19}$, Trailmaking Test A and B (TMT) ${ }^{20}$, category and letter fluency $^{21,22}$, and the following subtests of the Wechsler Adult Intelligence Scale III (WAIS III) ${ }^{23}$, 
Symbol Substitution, Digit span and Letter Number Sequencing. For the SCWT and TMT, interference scores were computed. Interference score SCWT= time on card 3 - Mean (card $1+$ card 2). Interference score TMT= time card B - time card A.

We compared performances on different cognitive domains by using $\mathrm{Z}$ standard scores. For each domain we computed compound scores. Memory domain $=(Z / R A V L T$ immediate recall + Z/RAVLT delayed recall + Z/RAVLT word recognition + Z/digit span forward)/4; Executive functions domain $=(\mathrm{Z} / \mathrm{SCWT}$ interference $+\mathrm{Z} / \mathrm{TMT}$ interference $+\mathrm{Z} /$ category fluency $+\mathrm{Z} /$ letter fluency $+\mathrm{Z}$ /digit span backward $+\mathrm{Z} /$ letter number sequencing)/6; Information processing speed $=(Z /$ symbol substitution $+Z / T M T A+Z /$ mean of Stroop card 1 and 2)/3. A compound score for overall cognitive function was calculated as the mean score of the three compound scores. Z-scores of tests with higher scores representing worse performance were inverted before computing the compound scores. Compound scores for memory, executive function, information processing speed and overall cognition were missing for 2, 1, 1 and 3 patients respectively. Therefore, analyses on these variables were performed with a different number of subjects.

\section{Statistical analysis}

Differences in baseline characteristics between quartiles of WML volume progression were analyzed using analysis of variance, $\mathrm{X}^{2}$ tests, or non-parametric independent samples median-tests, where appropriate. Differences in baseline characteristics between patients with and without progression of lacunar infarcts and BMBs, were analyzed with independent T-tests, $\mathrm{X}^{2}$ tests or non-parametric independent samples median-tests, where appropriate.

We first analyzed associations of quartiles of total WML volume, presence of asymptomatic lacunar infarcts and presence of BMBs at baseline, with all cognitive domains, using linear regression analyses. We additionally adjusted for age and sex. Secondly, we analyzed associations of progression of WML volume, lacunar infarcts and BMBs during the past 5 years with cognition at follow-up, by using linear regression analyses, additionally adjusting for age, sex and baseline volume or presence of cSVD MRI markers. WML volume progression was analyzed in quartiles. All analyses were performed using PASW 18.0 (Predictive Analytics SoftWare; Chicago, IL, USA).

\section{Results}

Out of 198 patients who consented in being contacted for follow-up studies, we included 112 patients with a follow-up brain MRI and neuropsychological assessment (figure 1). Patients with follow-up assessment did not differ from those without follow-up regarding age or sex. We present baseline characteristics according to quartiles of WML volume progression (table 1) and the presence of progression of lacunar infarcts and BMBs (table 2). Median WML volume at baseline was 485 (IQR $216-1363 \mathrm{~mm}^{3}$ ) and median progression was 82 (IQR $\left.-82-716 \mathrm{~mm}^{3}\right)$. Ten $(8.9 \%)$ patients showed progression of lacunar infarcts and $12(10.7 \%)$ of BMBs over 5 years. Mean Z-scores of cognitive function by quartiles of WML progression are presented in figure 2. 


\section{cSVD at baseline and cognitive function}

Patients in the fourth quartile of total WML volume performed significantly worse than patients in the second quartile on the domains of memory $(\beta=-.403 \pm .185, p=.031)$, information processing speed $(\beta=-.463 \pm .225, p=.042)$ and overall cognitive function $(\beta=-.356 \pm .173$, $p=.042$ ). Patients in the fourth quartile also performed worse than patients in the first quartile on information processing speed $(\beta=-.531 \pm .225, p=.020)$. None of these results remained significant after correction for age and sex.

No significant associations between the presence of asymptomatic lacunar infarcts or the presence of BMBs at baseline were found with any of the cognitive domains.

Table 1. Baseline characteristics according to quartiles of total WML volume progression

\begin{tabular}{llllll}
\hline & Quartile 1 $(n=28)$ & Quartile 2 $(n=28)$ & Quartile 3 $(n=28)$ & Quartile 4 $(n=28)$ & $p$ \\
\hline Age, mean years & $52.6 \pm 12.6$ & $53.7 \pm 12.0$ & $56.6 \pm 12.0$ & $62.9 \pm 9.5$ & .006 \\
Male sex & $19(67.9)$ & $17(60.7)$ & $14(50.0)$ & $15(53.6)$ & .539 \\
Time to follow-up, & $5.0 \pm 0.1$ & $5.0 \pm 0.1$ & $5.0 \pm 0.1$ & $5.0 \pm 0.1$ & .355 \\
years & & & & \\
Diabetes & $1(3.6)$ & $1(3.6)$ & $0(0.0)$ & $0(0.0)$ & .565 \\
BMI, mean kg/m ${ }^{3}$ & $27.2 \pm 4.5$ & $27.5 \pm 4.7$ & $27.6 \pm 3.6$ & $27.2 \pm 4.1$ & .971 \\
Current smoking & $3(11.1)$ & $3(10.7)$ & $6(21.4)$ & $4(14.3)$ & .644 \\
WML volume, me- & $428(238-1294)$ & $202(94-318)$ & $537(339-1247)$ & $1739(709-5426)$ & $\mathbf{. 0 0 0}$ \\
dian (IQR) mm & & & & & $11(39.3)$ \\
Lacunar infarcts & $8(28.6)$ & $1(3.6)$ & $2(7.1)$ & $5(17.9)$ & .001 \\
BMBs & $4(14.3)$ & $2(7.1)$ & $2(7.1)$ & .503 \\
\hline \hline
\end{tabular}

Numbers represent frequencies with their percentage, except where reported otherwise. BMI= body mass index; $\mathrm{WML}=$ white matter lesion; $\mathrm{IQR}=$ interquartile range; $\mathrm{BMBs}=$ brain microbleeds. $\mathrm{WML}$ volume is given in $\mathrm{mm}^{3}$

\section{Progression of cSVD and cognitive function}

Table 3 presents associations between quartiles of WML progression over 5 years and cognitive function after 5 years. Patients in the highest quartile of WML progression performed significantly worse than patients in the first and second quartile on all cognitive domains. Patients in the third quartile also performed significantly worse than patients in the first quartile regarding information processing speed and overall cognition. When we adjusted for baseline WML volume (model 2) and additionally for age and sex (model 3), results remained significant for all cognitive domains for the differences between the first and fourth quartile (model 2 and 3). The differences between quartile 1 and 3 regarding information processing speed and overall cognition also remained significant, after correction for baseline WML volume, age and sex.

Patients with progression of lacunar infarcts performed worse on measures of executive function $(\beta=-.481 \pm .233, p=.041)$, information processing speed $(\beta=-.827 \pm .274, p=.003)$ and overall cognition $(\beta=-.560 \pm .209, p=.009)$. After adjustments for baseline presence of lacunar infarcts results remained significant ( $p=.040, p=.004$ and $p=.014$, respectively). 
Figure 2. Mean Z-scores of cognitive function by quartiles of WML progression
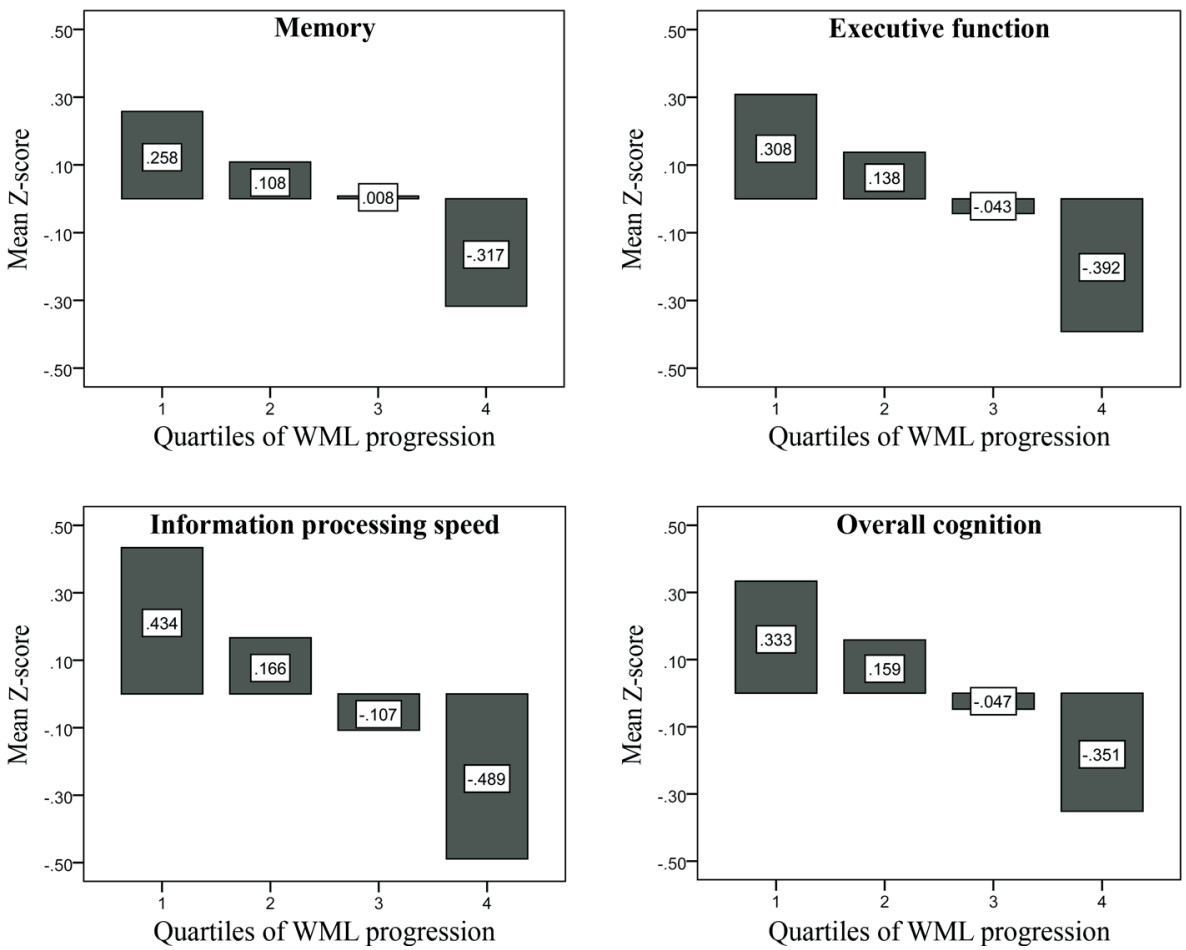

Table 2. Baseline characteristics of patients with and without progression of lacunar infarcts and brain microbleeds.

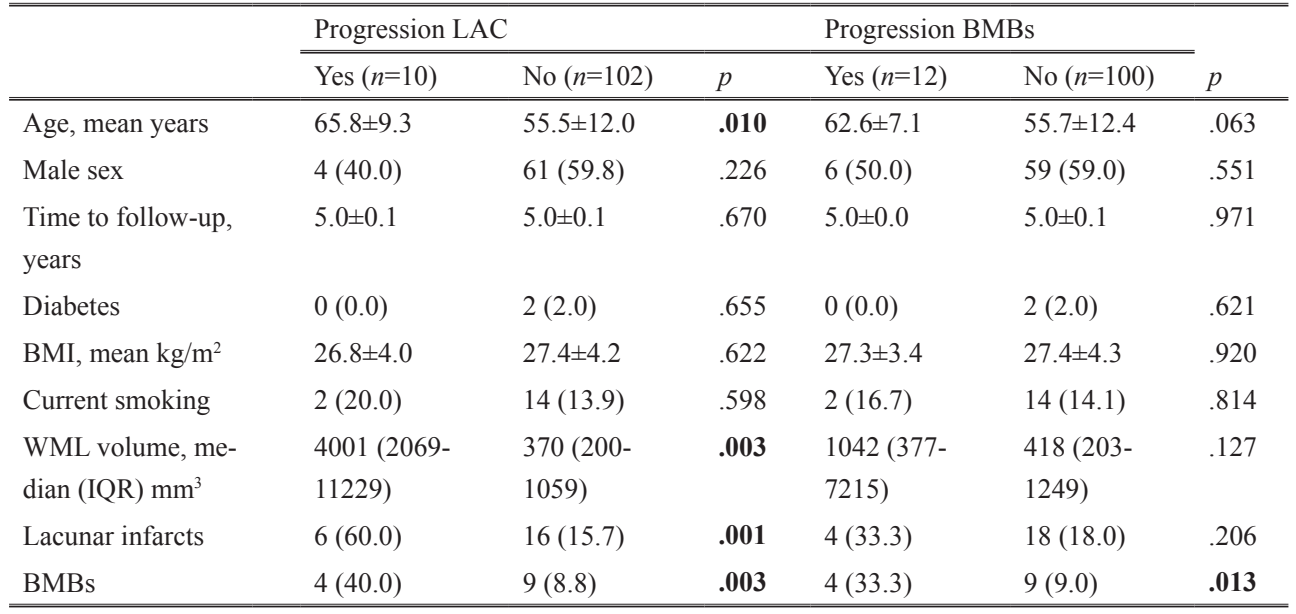

Numbers represent frequencies with their percentage, except where reported otherwise. BMI= body mass index; $\mathrm{WML}=$ white matter lesion; $\mathrm{IQR}=$ interquartile range; $\mathrm{BMBs}=$ brain microbleeds. $\mathrm{WML}$ volume is given in $\mathrm{mm}^{3}$ 
After additional adjustments for age and sex, only information processing speed remained significant $(p=.049)$. None of the cognitive domains were significantly different between patients with and without BMB progression.

Table 3. Relations of WML progression with cognitive function

\begin{tabular}{|c|c|c|c|c|c|c|c|}
\hline & & Model 1 & $p$ & Model 2 & $p$ & Model 3 & $p$ \\
\hline \multirow[t]{3}{*}{ Memory } & Q1-Q4 & $-.575 \pm .180$ & .002 & $-.519 \pm .185$ & .006 & $-.397 \pm .173$ & .023 \\
\hline & Q2-Q4 & $-.425 \pm .181$ & .021 & $-.283 \pm .216$ & .193 & $-.267 \pm .196$ & .176 \\
\hline & Q1-Q3 & $-.250 \pm .178$ & .164 & $-.265 \pm .178$ & .140 & $-.209 \pm .164$ & .204 \\
\hline \multirow[t]{3}{*}{ Executive function } & Q1-Q4 & $-.700 \pm .182$ & $<.001$ & $-.645 \pm .188$ & .001 & $-.490 \pm .187$ & .010 \\
\hline & Q2-Q4 & $-.530 \pm .182$ & .004 & $-.394 \pm .219$ & .074 & $-.329 \pm .212$ & .123 \\
\hline & Q1-Q3 & $-.352 \pm .180$ & .053 & $-.366 \pm .180$ & .045 & $-.263 \pm .177$ & .139 \\
\hline \multirow{3}{*}{$\begin{array}{l}\text { Information pro- } \\
\text { cessing speed }\end{array}$} & Q1-Q4 & $-.923 \pm .215$ & .000 & $-.733 \pm .217$ & .001 & $-.506 \pm .196$ & .011 \\
\hline & Q2-Q4 & $-.656 \pm .215$ & .003 & $-.289 \pm .252$ & .255 & $-.199 \pm .222$ & .373 \\
\hline & Q1-Q3 & $-.541 \pm .213$ & .012 & $-.580 \pm .208$ & .006 & $-.411 \pm .185$ & .028 \\
\hline \multirow[t]{3}{*}{ Overall cognition } & Q1-Q4 & $-.685 \pm .165$ & $<.001$ & $-.607 \pm .168$ & .000 & $-.436 \pm .155$ & .006 \\
\hline & Q2-Q4 & $-.510 \pm .166$ & .003 & $-.315 \pm .196$ & .110 & $-.264 \pm .176$ & .136 \\
\hline & Q1-Q3 & $-.381 \pm .162$ & .020 & $-.402 \pm .160$ & .014 & $-.296 \pm .146$ & .045 \\
\hline
\end{tabular}

Values refer to unstandardized Betas with standard errors and p-values. Model 1: univariate linear regression analysis with WML progression as independent and cognitive function as dependent variable. Model 2: linear regression analysis with correction for baseline WML volume. Model 3: linear regression analysis with correction for baseline WML volume, age and sex. Q1-Q4= quartile 1 compared to quartile 4 regarding progression of WML load between baseline and 5-years follow-up.

\section{Discussion}

We investigated whether cSVD-related brain damage at baseline, or its progression over years, can predict cognitive function at 5-year follow-up in a hypertensive population.

We found that progression of cSVD over 5 years predicted cognitive function at follow-up. Patients with the largest progression of WMLs over 5 years follow-up performed worse on all cognitive domains compared to patients with the least progression, even after adjustments for age, sex and baseline WML volume. Additionally, patients with progression of asymptomatic lacunar infarcts performed worse on information processing speed than those without progression after adjustments for age, sex and baseline presence of lacunar infarcts. Baseline cSVD however, did not predict cognitive function after 5 years. Progression of BMBs had no effect on cognition.

Additionally, at 5-year follow-up, cross-sectional analyses showed only minimal associations between cSVD and cognitive function. These results suggest that there exists a certain time-dependency for the relationship between cSVD and cognitive function in a hypertensive population, comparable to the relationship between blood pressure and cognitive function ${ }^{8}$ 9. An important difference however, is that in our study progression of cSVD over years was a better predictor for cognitive function than $\mathrm{CSVD}$ at baseline or follow-up. This might 
be explained by the fact that our hypertensive population is a relatively healthy population considering the minimal brain damage they have. Our results therefore imply that even only minimal progression of cSVD has consequences for cognitive functioning.

We found that patients with the largest progression of WML volume performed worse on all cognitive domains compared to patients with the least progression. This is in line with other studies ${ }^{13}$. Dufouil et $\mathrm{al}^{14}$ revealed an increased risk for cognitive decline and dementia in individuals with severe WMLs at baseline and progression of WMLs over 4 years. Though based on a visual rating scale, the LADIS study ${ }^{13}$ also found an inverse relationship between progression of WML severity and cognitive function. However, the significance of their results disappeared for patients with extensive WML lesions at baseline, while our results were all independent of baseline WML volume. The authors explained this finding by a pronounced cognitive decline already present at baseline in these individuals, irrespective of change in lesion extent. It might also be explained by a difference in inclusion criteria. Patients included in the LADIS study, by definition, had some degree of WMLs, while we also included patients without any WMLs. Patients with progression of silent lacunar infarcts performed worse on information processing speed than those without progression in our study. This is in line with recent findings by Jokinen et $\mathrm{al}^{12}$, who found that progression of lacunar infarcts was related to a steeper rate of decline in speed and motor control and executive function.

Our results support the view that prevention of cSVD progression could reduce the risk of decreased cognitive functioning. It has previously been shown that progression of WMLs was limited in adequately controlled hypertensive patients ${ }^{1,24}$. In another study ${ }^{25}$ it has been shown that progression of WML load was reduced by active blood pressure lowering in patients with cerebrovascular disease. The greatest beneficial effect on WML progression in that study was found in patients with severe WMLs at baseline. Another report ${ }^{26}$ showed a relative risk reduction of $34 \%$ for dementia and $45 \%$ for cognitive decline in patients on active blood pressure lowering treatment, but only in patients with recurrent stroke. In patients without recurrent stroke, no risk reductions were found. Our patients were treated for their hypertension according to standard guidelines and this could have influenced the progression of cSVD and accordingly their cognitive decline. Unfortunately we don't have detailed information about the treatment, blood pressure levels and meeting of blood pressure goals.

Strengths of our study include extensive neuropsychological testing, which enabled us to assess the effect on several cognitive domains. Another strength is the use of quantitative WML volume measurements. In longitudinal studies this is preferred since even a small change in WML volume can be detected. Specific visual ratings scales were developed for the grading of progression of white matter lesions, such as the Rotterdam Progression Scale ${ }^{27}$. Although the correlation with volumetric measurements was satisfactory, inter-rater agreement was only good after additional training. Moreover, it tended to overestimate lesion change in the subcortical areas, and underestimate change in the periventricular region. However, it should be noticed that due to the use of an upgraded version of GIANT, baseline WML volumes were different to what was published before ${ }^{17}$. This is a common and prevalent problem in 
quantitative volume measurements ${ }^{28}$. One of the limitations of this study is the absence of a neuropsychological assessment at baseline, which prevents statements about causality and the ability to assess a decline in cognitive function. Future studies are suggested to assess progression of all cSVD markers in relation to cognitive decline. Another limitation is the absence of blood pressure information, such as blood pressure measurements at follow-up as well as treatment information.

In conclusion, we found that progression of cSVD over 5 years predicted cognitive function at follow-up. Patients with the largest progression of WMLs and progression of lacunar infarcts over 5 years follow-up had worse cognitive function compared to patients with the least or no progression. These results suggest that specifically in this hypertensive population with minimal cSVD-related brain damage, progression of cSVD has a substantial impact on cognitive functioning and prevention measures are warranted. 


\section{References}

1. de Leeuw FE, de Groot JC, Oudkerk M, Witteman JC, Hofman A, van Gijn J, et al. Hypertension and cerebral white matter lesions in a prospective cohort study. Brain. 2002;125:765-772

2. Vermeer SE, Longstreth WT, Jr., Koudstaal PJ. Silent brain infarcts: a systematic review. Lancet Neurol. 2007;6:611-619

3. Wardlaw JM, Lewis SC, Keir SL, Dennis MS, Shenkin S. Cerebral microbleeds are associated with lacunar stroke defined clinically and radiologically, independently of white matter lesions. Stroke. 2006;37:26332636

4. Pantoni L. Cerebral small vessel disease: from pathogenesis and clinical characteristics to therapeutic challenges. Lancet Neurol. 2010;9:689-701

5. Henskens LH, van Oostenbrugge RJ, Kroon AA, Hofman PA, Lodder J, de Leeuw PW. Detection of silent cerebrovascular disease refines risk stratification of hypertensive patients. J Hypertens. 2009;27:846-853

6. van Boxtel MP, Henskens LH, Kroon AA, Hofman PA, Gronenschild EH, Jolles J, et al. Ambulatory blood pressure, asymptomatic cerebrovascular damage and cognitive function in essential hypertension. J Hum Hypertens. 2006;20:5-13

7. Sierra C, De La Sierra A, Salamero M, Sobrino J, Gomez-Angelats E, Coca A. Silent cerebral white matter lesions and cognitive function in middle-aged essential hypertensive patients. Am J Hypertens. 2004; $17: 529-534$

8. Farmer ME, White LR, Abbott RD, Kittner SJ, Kaplan E, Wolz MM, et al. Blood pressure and cognitive performance. The Framingham Study. Am J Epidemiol. 1987;126:1103-1114

9. Elias MF, Wolf PA, D’Agostino RB, Cobb J, White LR. Untreated blood pressure level is inversely related to cognitive functioning: the Framingham Study. Am J Epidemiol. 1993;138:353-364

10. van Dijk EJ, Prins ND, Vrooman HA, Hofman A, Koudstaal PJ, Breteler MM. Progression of cerebral small vessel disease in relation to risk factors and cognitive consequences: Rotterdam Scan study. Stroke. 2008;39:2712-2719

11. Gouw AA, van der Flier WM, Fazekas F, van Straaten EC, Pantoni L, Poggesi A, et al. Progression of white matter hyperintensities and incidence of new lacunes over a 3-year period: the Leukoaraiosis and Disability study. Stroke. 2008;39:1414-1420

12. Jokinen H, Gouw AA, Madureira S, Ylikoski R, van Straaten EC, van der Flier WM, et al. Incident lacunes influence cognitive decline: the LADIS study. Neurology. 2011;76:1872-1878

13. Schmidt R, Berghold A, Jokinen H, Gouw AA, van der Flier WM, Barkhof F, et al. White Matter Lesion Progression in LADIS: Frequency, Clinical Effects, and Sample Size Calculations. Stroke. 2012;43:26432647

14. Dufouil C, Godin O, Chalmers J, Coskun O, MacMahon S, Tzourio-Mazoyer N, et al. Severe cerebral white matter hyperintensities predict severe cognitive decline in patients with cerebrovascular disease history. Stroke. 2009;40:2219-2221

15. Gregoire SM, Smith K, Jager HR, Benjamin M, Kallis C, Brown MM, et al. Cerebral microbleeds and long-term cognitive outcome: longitudinal cohort study of stroke clinic patients. Cerebrovasc Dis. 2012;33:430435

16. van der Vlies AE, Goos JD, Barkhof F, Scheltens P, van der Flier WM. Microbleeds do not affect rate of cognitive decline in Alzheimer disease. Neurology. 2012

17. Henskens LH, Kroon AA, van Oostenbrugge RJ, Gronenschild EH, Fuss-Lejeune MM, Hofman PA, et al. Increased aortic pulse wave velocity is associated with silent cerebral small-vessel disease in hypertensive patients. Hypertension. 2008;52:1120-1126

18. Brand N, Jolles J. Learning and retrieval rate of words presented auditorily and visually. J Gen Psychol. $1985 ; 112: 201-210$ 
19. Golden CJ. Stroop Colour and Word Test. Chicago (Ill): Stoelling; 1978.

20. Reitan R. Trail Making Test: Manual for administration, scoring and interpretation. Bloomington: Indiana University; 1956.

21. Luteyn F. Een nieuwe verkorte GIT. Dutch J Psychol. 1966;2:675-682

22. Lezak M, Howieson, DB, \& Loring, DW. Neuropsychological assessment New York: Oxford University Press; 2004.

23. Wechsler D. WAIS III, nederlandstalige bewerking: technische handleiding. Lisse: Swets Test Publishers; 2001.

24. Dufouil C, de Kersaint-Gilly A, Besancon V, Levy C, Auffray E, Brunnereau L, et al. Longitudinal study of blood pressure and white matter hyperintensities: the EVA MRI Cohort. Neurology. 2001;56:921-926 25. Dufouil C, Chalmers J, Coskun O, Besancon V, Bousser MG, Guillon P, et al. Effects of blood pressure lowering on cerebral white matter hyperintensities in patients with stroke: the PROGRESS (Perindopril Protection Against Recurrent Stroke Study) Magnetic Resonance Imaging Substudy. Circulation. 2005;112:1644-1650 26. Tzourio C, Anderson C, Chapman N, Woodward M, Neal B, MacMahon S, et al. Effects of blood pressure lowering with perindopril and indapamide therapy on dementia and cognitive decline in patients with cerebrovascular disease. Arch Intern Med. 2003;163:1069-1075

27. Prins ND, van Straaten EC, van Dijk EJ, Simoni M, van Schijndel RA, Vrooman HA, et al. Measuring progression of cerebral white matter lesions on MRI: visual rating and volumetrics. Neurology. 2004;62:15331539

28. Gronenschild EH, Habets P, Jacobs HI, Mengelers R, Rozendaal N, van Os J, et al. The effects of FreeSurfer version, workstation type, and Macintosh operating system version on anatomical volume and cortical thickness measurements. PLoS One. 2012;7:e38234 
cSVD progression and cognitive function $\mid 63$ 
Chapter

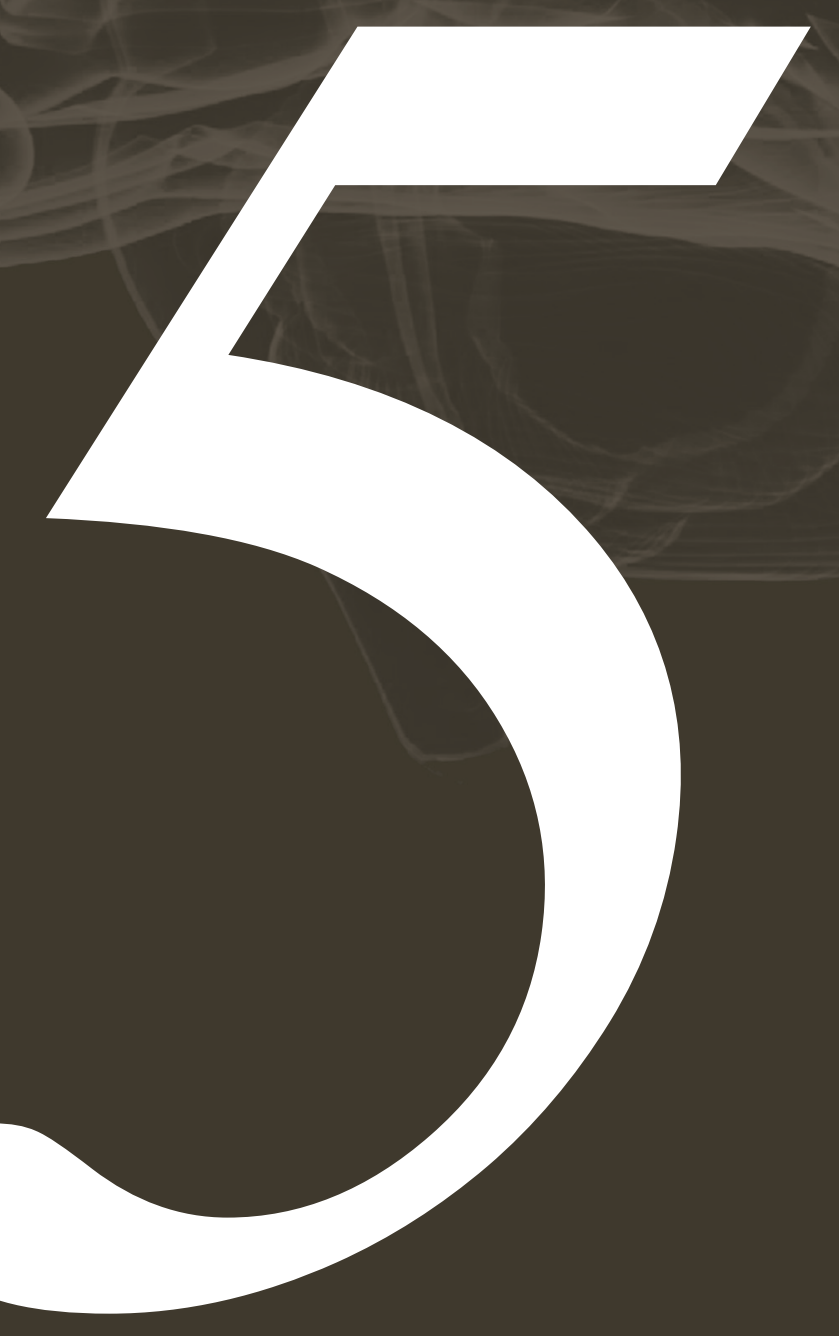




\begin{abstract}
Background - Up to $50 \%$ of patients with heart failure (HF) may suffer from severe cognitive impairment (SCI), but longitudinal studies are sparse and effects of changes in HF severity on cognitive function are unknown. Therefore, we assessed the prevalence of SCI in HF patients, its relationship with HF severity, its effects on morbidity and mortality and the relationship between changes in HF severity and cognitive function.

Methods - We included 611 patients from the Trial of Intensified versus standard Medical therapy in Elderly patients with Congestive Heart Failure (TIME-CHF) and assessed cognitive function (Hodkinson Abbreviated Mental Test [AMT]) in relation to severity of HF (New York Heart Association [NYHA] class, N-terminal brain natriuretic peptides [NT-proBNP]) at baseline and 18 months ( $\mathrm{N}=382)$ and effects on hospitalization-free survival and mortality. Results - SCI (i.e. AMT-score $\leq 7$ ) was present in $9.2 \%$ of patients at baseline, but only $20 \%$ of them had a diagnosis of dementia. Prevalence of SCI remained stable during follow-up. SCI was present at baseline more often in NYHA IV patients compared to NYHA II (OR=2.94; 95\%-CI=1.15-7.51, $p=.025)$, but it was not related to NT-proBNP levels. SCI was related to higher mortality ( $\mathrm{HR}=1.53,95 \%-\mathrm{CI}=1.02-2.30, p=.04)$, but not hospitalization-free survival. Changes in HF severity were not significantly related with changes in cognitive function.

Conclusion - SCI is a frequent, but often unrecognized finding in HF patients, but the influence of HF severity and its changes on cognitive function were less than hypothesized.

Clinical Trial Registration Information - http://www.controlled-trials.com/ISRCTN43596477
\end{abstract}

\title{
Chapter 5
}

\section{Cognitive impairment in heart failure: results from the Trial of Intensified vs standard Medical therapy in Elderly patients with Congestive Heart Failure (TIME-CHF) trial}

\author{
Marjolein Huijts, Robert van Oostenbrugge, Annelien Duits, Thilo Burkard, \\ Stefano Muzzarelli, Micha Maeder, Ruth Schindler, Matthias Pfisterer, Hans- \\ Peter Brunner- La Rocca
}

Published as: European Journal of Heart Failure 2013; 15 (6): 699-707 


\section{Introduction}

Cognitive impairment is a problem with thought processes including loss of higher reasoning, forgetfulness and concentration difficulties. In patients with heart failure (HF), cognitive impairment may have significant influence on outcome, since they have to adequately manage medication and diet, as well as to be alert on symptoms ${ }^{1}$. Evidence regarding high prevalence of cognitive impairment in $\mathrm{HF}$ is increasing ${ }^{2}$ as up to $50 \%$ may have some degree of cognitive impairment ${ }^{1}$. The exact mechanism of cognitive deficits associated with HF is, however, still unclear. Longitudinal studies on cognitive impairment in HF patients are sparse $^{1}$ and whether changes in cognitive impairment occur when HF severity changes is largely unknown ${ }^{3}$.

So far, only seven longitudinal studies were published regarding cognitive function in HF patients ${ }^{4-10}$. Screening tests as well as neuropsychological batteries were used and time intervals ranged from 18 weeks to 10 years. Some found improved or stable cognitive function ${ }^{5}$, others a decline of episodic memory9. Studies often did not investigate specific predictive factors for a change in cognition. Only receipt of an ACE inhibitor and exercise training were associated with improved cognition, and the effect of blood pressure was unclear. In order to investigate predictive factors for cognitive change, it seems plausible to study changes in $\mathrm{HF}$ severity in relation to changes in cognitive function.

Severity of HF can be measured in several objective and subjective ways. Some of these include New York Heart Association (NYHA) class, left ventricular ejection fraction (LVEF) and natriuretic peptide plasma concentrations. It was recently found that in an older HF population more than $70 \%$ presented with cognitive impairment ${ }^{11}$. However, $66 \%$ of the patients with cognitive impairment were classified in NYHA class III or IV, whereas most HF patients $(83 \%)$ with normal scores were classified in NYHA class I or II. The authors concluded that the presence of cognitive impairment was significantly more common in patients with advanced HF symptoms or a recent hospitalization ${ }^{11}$. In a non-demented population-based study B-type natriuretic peptide (BNP) levels were higher in patients with lower cognitive scores $^{12}$. Those authors concluded that worse cognitive function can already be observed in early stages of HF and that BNP may be a marker indicating a high risk for cognitive decline. Others observed an association of BNP levels with decline in cognition after 5 years in nondemented elderly patients and higher incidence of new onset dementia at follow-up ${ }^{13}$. However, BNP levels were only elevated in patients with vascular dementia, but not in patients with Alzheimer's disease ${ }^{14}$, suggesting that higher BNP levels may be explained by the larger cardiovascular burden in the former patients. Recently, a strong and independent relationship between higher N-terminal-proBNP (NT-proBNP) levels and worse cognitive function was found in an older community-dwelling population ${ }^{15}$. The association between NT-proBNP and cognitive function has, however, never beenstudied in HF patients.

Additionally, it is unclear whether treatments to improve cardiac function also translate into improved cognitive function. In end-stage HF such an association was suggested since cognitive function improved ${ }^{16}$ and cerebral blood flow increased ${ }^{17}$ after heart transplantation, 
supposedly due to improved cardiac function. An association was found between improved left ventricular ejection fraction (LVEF) and enhanced cognitive function after cardiac resynchronization therapy ${ }^{18}$, but no data are available on changes in HF severity and cognitive function. Moreover, effects of medication on cognition are unclear.

Therefore, we assessed the prevalence of severe cognitive impairment (SCI) in elderly patients with HF, its correlates with HF severity as measured by signs and symptoms of HF, LVEF, and NT-proBNP levels as well as its effect on morbidity and mortality. In addition we evaluated whether changes in HF severity would result in changes of cognitive function. We hypothesized that cognitive impairment would increase with increasing HF severity and that the risk for hospitalization and death would be higher in patients with cognitive impairment.

\section{Methods \\ Patients}

Patients included in the Trial of Intensified versus standard Medical therapy in Elderly patients with Congestive Heart Failure (TIME-CHF), a large prospective randomized controlled multicentre trial, formed the study population. Study design, methods ${ }^{19}$ and primary results $^{20}$ were reported previously. In brief, TIME-CHF included HF patients aged 60 years or more who suffered from dyspnoea (NYHA class II or higher). Patients had to be hospitalized for HF within the last year and to have an NT-proBNP level of $\geq 400 \mathrm{pg} / \mathrm{mL}$ (patients $<75$ years) or $\geq 800 \mathrm{pg} / \mathrm{mL}$ (patients $\geq 75$ years), respectively. Exclusion criteria were as follows: dyspnoea not mainly due to HF, valvular disease requiring surgery, acute coronary syndromes within the previous 10 days, angina pectoris (Canadian Cardiovascular Society Class $\geq \mathrm{II}$ ), revascularization within the previous month, body mass index $>35 \mathrm{~kg} / \mathrm{m}^{2}$, serum creatinine level $>220 \mu \mathrm{mol} / \mathrm{L}$, life expectancy of less than 3 years for non-cardiovascular diseases, unable to give informed consent, no follow-up possible, or participating in another study. Still, the patients did not differ on average from those included in large registries ${ }^{21,22}$. Patients were included between 2003 and 2006 and underwent three assessments of cognitive function at baseline and after 12 and 18 months, respectively. For comparison over time, only those patients who completed all three assessments of cognitive function were included in analyses. All patients gave written informed consent for study participation. The protocol was approved by the local Ethics Committees.

\section{Assessment of cognitive function}

Cognitive function was assessed with the Hodkinson Abbreviated Mental Test (AMT) ${ }^{23}$ by the co-investigators of each centre during regular visits. The AMT includes 10 items: What is your present age? What year is it? Please count backwards from 20 to 1 ? What is the time just now? What is your birthday? Could you repeat the address I gave you at the beginning? When did World War I begin? What is the name of this place? What is the name of the president? Can you recognize these... people (pictures of two famous people)? For each correct answer 1 point was scored. Total scores ranged from 0 (no correct answers) to 10 (all answers correct). Sensitivity and specificity analyses for the screening of dementia had previously 
revealed that a cut-off score of $\leq 7$ maximizes the efficacy of the test $(91.5 \%$ and $82.4 \%$ respectively $)^{24}$ and thus, this cut-off was used in this study to define SCI. Cognitive decline was defined as a deterioration of at least 1 point between the measurements at baseline and follow-up ${ }^{25}$.

\section{Assessment of heart failure}

Severity of HF was classified based on symptoms (dyspnoea, orthopnoea, and peripheral oedema as symptoms of congestion and fatigue and exercise intolerance as symptoms of low output) and signs of HF (peripheral oedema, central venous pressure, rales) as well as NT-proBNP level measurements (Roche Elecsys 2010). Transthoracic echocardiography was performed to classify patients into those with reduced (i.e. $\mathrm{LVEF}<45 \%$ ) and preserved (i.e. $\mathrm{LVEF} \geq 45 \%$ ) LVEF using standard equipment and techniques. Electrocardiography was performed to classify patients into those with or without atrial fibrillation. Influence of cognitive state on outcome was tested. Outcome was defined as all-cause mortality, HF hospitalization free survival and all-cause hospitalization free survival.

\section{Statistical analyses}

We used PASW Statistics 18 software. Differences between groups (table 1, 2 and 3) were analyzed with independent T-test, Mann-Whitney U-Test and Pearson Chi-square, as appropriate. We used logistic regression analyses to test associations between HF severity and the presence of SCI, adjusted for age. Correlations were analyzed using Spearman's correlation. Since NT-proBNP levels were not normally distributed, we used a log-transformation for its use in logistic regression analyses. To assess associations between physical condition and SCI, we used ordinal cross-tabulation (Goodman- Kruskal Gamma). Survival analyses were done using Kaplan-Meier and Cox proportional hazards regression analyses. We did not apply imputation for missing data. A p-value of $<0.05$ (two-sided) was considered to be statistically significant.

\section{Results}

We included 611 patients with baseline cognitive assessment (figure 1). In 56 (9.2\%) patients, SCI was present at baseline. Only half answered all questions correctly ( $\mathrm{N}=300,49.1 \%), 180$ (29.5\%) answered one question wrongly and 75 (12.3\%) two. Baseline characteristics of patients with and without SCI are compared in table 1. Patients with SCI at baseline were older, more often female, more often had anaemia, and had a higher heart rate (table 1). SCI was more common in patients with class IV compared to those in class II $(\mathrm{OR}=2.94 ; 95 \% \mathrm{CI}=$ 1.15 to $7.51, p=.025)$, independently of age. SCI in class III patients did not differ significantly from those in class II $(\mathrm{OR}=1.81 ; 95 \% \mathrm{CI}=.82$ to $4.00, p=.140)$. Neither fatigue nor exercise intolerance, as symptoms of low cardiac output, was associated with SCI at baseline $(\Gamma=.058$ and $\Gamma=.-.027$, both $p>.50$ ). SCI tended to be more prevalent in patients with preserved LVEF than with reduced LVEF. At baseline, $8.1 \%$ of patients with reduced LVEF suffered from SCI compared to $13.3 \%$ of those with preserved LVEF $(p=.078)$. Patients with AF showed a 
Table 1. Baseline characteristics for patients with baseline cognitive assessment.

\begin{tabular}{|c|c|c|c|c|}
\hline & All & $\begin{array}{l}\text { Severe cognitive } \\
\text { impairment } \\
(\mathrm{AMT} \leq 7)\end{array}$ & $\begin{array}{l}\text { No severe cogni- } \\
\text { tive impairment } \\
(\mathrm{AMT}>7)\end{array}$ & $p$ \\
\hline Patients, $\mathrm{n}$ & 611 & 56 & 555 & \\
\hline Age, years & $77 \pm 8$ & $79 \pm 7$ & $77 \pm 8$ & .029 \\
\hline Male gender & $365(59.7)$ & $21(37.5)$ & $344(62.0)$ & $<.001$ \\
\hline BMI, $\mathrm{kg} / \mathrm{m}^{2}$ & $25.6 \pm 4.4$ & $24.7 \pm 4.8$ & $25.7 \pm 4.4$ & .117 \\
\hline Main diagnosis CAD & $324(53.0)$ & $27(48.2)$ & $297(53.3)$ & .450 \\
\hline LVEF & $34.9 \pm 13.0$ & $37.6 \pm 15.3$ & $34.7 \pm 12.7$ & .163 \\
\hline Preserved LVEF & $120(19.6)$ & $16(28.6)$ & $104(18.7)$ & .078 \\
\hline Atrial fibrillation* & $204(33.6)$ & $20(35.7)$ & $184(33.4)$ & .726 \\
\hline Diabetes & $215(35.2)$ & $23(41.1)$ & $192(34.6)$ & .333 \\
\hline Dementia & $27(4.4)$ & $11(19.6)$ & $16(2.9)$ & $<.001$ \\
\hline Depression & 79 (12.9) & $8(14.3)$ & $71(12.8)$ & .751 \\
\hline Anaemia & $171(28.0)$ & $23(41.1)$ & $148(26.7)$ & .022 \\
\hline Renal failure & $349(57.1)$ & $32(57.1)$ & $317(57.1)$ & .997 \\
\hline COPD & $121(19.8)$ & $11(19.6)$ & $110(19.8)$ & .975 \\
\hline Charlsson score & $3(2-4)$ & $3(2-4)$ & $3(2-4)$ & .955 \\
\hline Edema & $253(41.6)$ & $26(46.4)$ & $227(41.1)$ & .443 \\
\hline Rales & $275(45.0)$ & $25(44.6)$ & $250(45.0)$ & .954 \\
\hline Exercise intolerance & $558(92.2)$ & $51(91.1)$ & $507(92.3)$ & .734 \\
\hline Fatigue & $526(86.1)$ & $49(87.5)$ & $477(85.9)$ & .749 \\
\hline History of stroke & $51(8.3)$ & $7(12.5)$ & $44(7.9)$ & .238 \\
\hline NYHA class II & $147(24.1)$ & $8(14.3)$ & $139(25.0)$ & .071 \\
\hline NYHA class III & $381(62.4)$ & $36(64.3)$ & $345(62.2)$ & \\
\hline NYHA class IV & 83 (13.6) & $12(21.4)$ & $71(12.8)$ & \\
\hline $\mathrm{SBP}, \mathrm{mmHg}$ & $122 \pm 20$ & $124 \pm 20$ & $122 \pm 20$ & .337 \\
\hline DBP, $\mathrm{mmHg}$ & $72 \pm 12$ & $72 \pm 12$ & $72 \pm 12$ & .686 \\
\hline Heart rate, bpm & $75 \pm 14$ & $79 \pm 14$ & $75 \pm 14$ & .032 \\
\hline NT-proBNP, ng/L & 3749 (1905-6871) & 3613 (1774-7926) & 3800 (1919-6805) & .789 \\
\hline NT-proBNP-guided & $303(49.6)$ & $34(60.7)$ & $269(48.5)$ & .081 \\
\hline
\end{tabular}

Data are given as number and percentages, mean \pm standard deviation, or median (interquartile range) as appropriate. $\mathrm{BMI}=$ Body Mass Index; $\mathrm{CAD}=$ Coronary Artery Disease; $\mathrm{LVEF}=$ Left Ventricular Ejection Fraction; $\mathrm{COPD}=$ Chronic Obstructive Pulmonary Disease; NYHA= New York Heart Association; SBP= Systolic Blood Pressure; $\mathrm{DBP}=$ Diastolic Blood Pressure; NT-proBNP= N-Terminal pro-B-type natriuretic peptide. $*$ Data are missing for 4 participants.

similar rate of SCI (9.8\%) to those without AF ( $8.9 \%, p=.726)$. Although NT-proBNP levels increased significantly with increasing NYHA class $(p<.001)$, NT-proBNP was not associated with $\mathrm{SCI}(p=.724)$.

The relationship between SCI and the outcome measures is depicted in figure 2. SCI at base- 
line had no influence on survival free of any hospitalizations or survival free of HF hospitalizations. However, overall survival was significantly worse in patients with SCI at baseline compared to those without.

Figure 1. Flow of participants at baseline and follow-up cognitive assessments. SCI = severe cognitive impairment

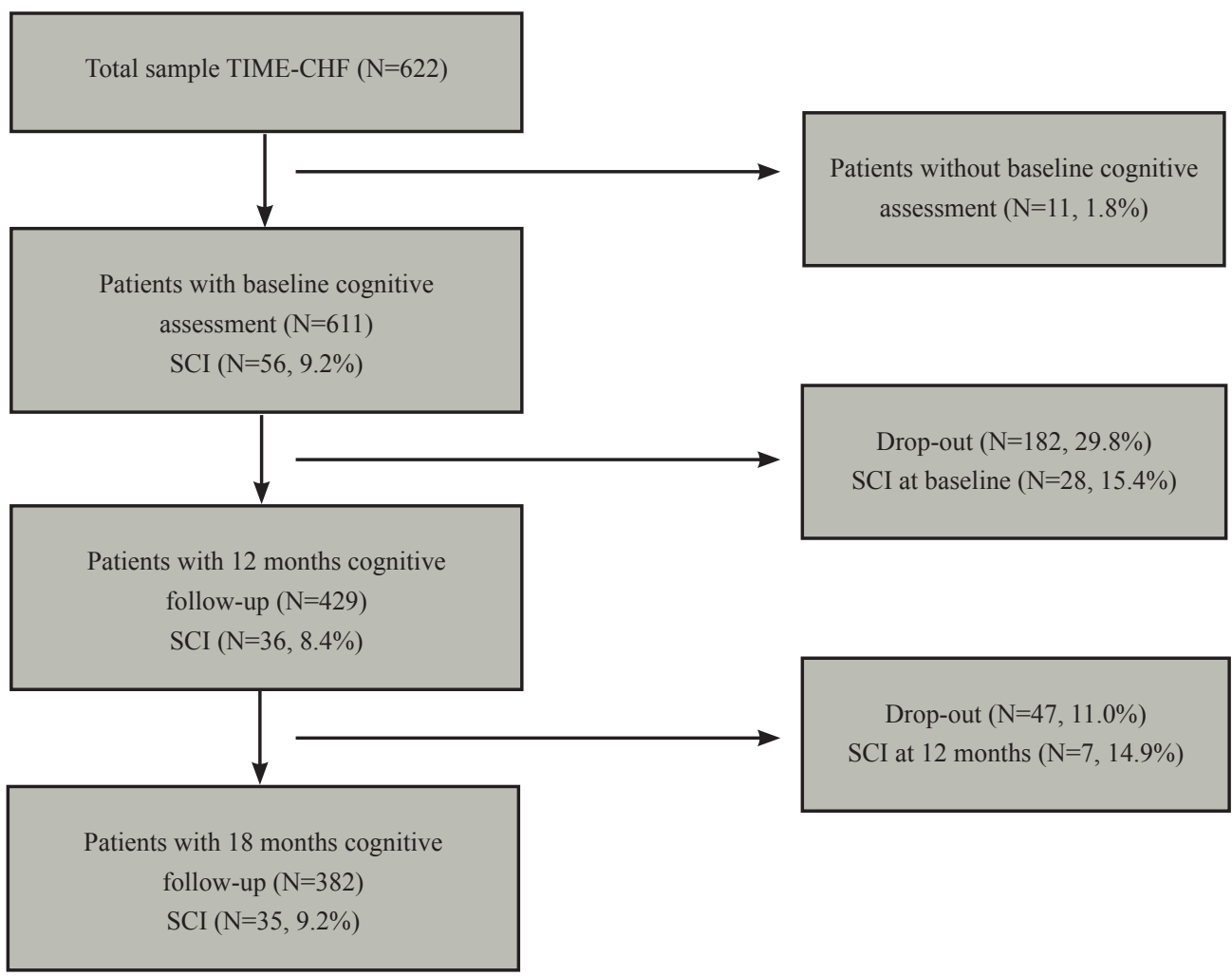

\section{Changes of cognition and CHF severity over time}

Cognitive assessment at 12 months was completed by 429 patients and at 18 months by 382 patients. The prevalence of SCI remained stable over time (figure 3). However, 36 patients of those who were severely cognitively impaired at baseline (64\%) were not available for the cognitive assessment at 18 months (14 died, 15 withdraw informed consent and 7 were not able to perform the test). The cumulative incidence of SCI was $13.5 \%$ at month 12 (i.e. 83 patients had SCI at least at one assessment) and 15.6\% (N=96) had SCI at least at one visit. Patients included in the 18 month assessment differed significantly from those who dropped out regarding age, NT-proBNP and haemoglobin levels, as well as HF aetiology and NYHA class and the presence of diabetes and anaemia (table 2). 
Table 2. Baseline characteristics of patients included in the 18 month follow-up and those who dropped out.

\begin{tabular}{|c|c|c|c|}
\hline & $\begin{array}{l}\text { Included in } 18 \text { months } \\
\text { follow-up }\end{array}$ & $\begin{array}{l}\text { Dropped-out at } 18 \\
\text { months }\end{array}$ & $p$ \\
\hline Patients, $\mathrm{n}$ & 382 & 229 & \\
\hline Age, years & $76 \pm 8$ & $78 \pm 7$ & .005 \\
\hline Male gender & $234(61.3)$ & $131(57.2)$ & .323 \\
\hline BMI, $\mathrm{kg} / \mathrm{m}^{2}$ & $25.7 \pm 4.2$ & $25.5 \pm 4.7$ & .551 \\
\hline Main diagnosis CAD & $176(46.1)$ & $148(64.6)$ & $<.001$ \\
\hline LVEF & $34.4 \pm 12.6$ & $35.9 \pm 13.5$ & .170 \\
\hline Preserved LVEF & $67(17.5)$ & $53(23.1)$ & .091 \\
\hline Atrial fibrillation* & $125(33.0)$ & $79(34.6)$ & .674 \\
\hline Diabetes & $123(32.2)$ & $92(40.2)$ & .046 \\
\hline Dementia & $13(3.4)$ & $14(6.1)$ & .115 \\
\hline Depression & $53(13.9)$ & $26(11.4)$ & .369 \\
\hline Anaemia & $94(24.6)$ & 77 (33.6) & .016 \\
\hline History of stroke & $30(7.9)$ & $21(9.2)$ & .569 \\
\hline NYHA class II & $107(28.0)$ & $40(17.5)$ & .003 \\
\hline NYHA class III & $233(61.0)$ & $148(64.6)$ & \\
\hline NYHA class IV & $42(11.0)$ & 41 (17.9) & \\
\hline $\mathrm{SBP}, \mathrm{mmHg}$ & $122 \pm 20$ & $122 \pm 21$ & .973 \\
\hline DBP, $\mathrm{mmHg}$ & $72 \pm 12$ & $71 \pm 12$ & .275 \\
\hline Heart rate, bpm & $75 \pm 14$ & $75 \pm 14$ & .956 \\
\hline NT-proBNP, ng/L & $3349(1773-6051)$ & $4844(2207-8928)$ & .003 \\
\hline NT-proBNP-guided & $195(51.0)$ & $108(47.2)$ & .352 \\
\hline
\end{tabular}

Data are given as number and percentages, mean \pm standard deviation, or median (interquartile range) as appropriate. $\mathrm{BMI}=$ Body Mass Index; $\mathrm{CAD}=$ Coronary Artery Disease LVEF $=$ Left Ventricular Ejection Fraction; NYHA = New York Heart Association; SBP= Systolic Blood Pressure; DBP = Diastolic Blood Pressure; NT-proBNP= $\mathrm{N}$-Terminal pro B-type natriuretic peptide. *Data are missing for 4 participants.

A decline of $\geq 1$ point on the AMT between baseline and 18 months occurred in 86 patients $(22.5 \%)$ whereas $23.8 \%$ showed improvement of $\geq 1$ point. Differences between patients with cognitive decline and those with cognitive improvement are shown in table 3. Patients with cognitive decline were older, more often had preserved LVEF and more often suffered from diabetes than those with cognitive improvement.

Patients in NYHA class IV at baseline showed a decline of $\geq 1$ point in $23.8 \%$, which was comparable to patients in class NYHA III $(23.2 \%)$ and II $(20.6 \% ; p=.592)$. NYHA class at baseline was not associated with a decline by $\geq 1$ point in logistic regression analyses either. Regarding changes in fatigue and exercise intolerance from baseline to 18 months, we found no significant correlations between directions of change in fatigue $(\Gamma=.039, p=.607)$ and exercise intolerance $(\Gamma=.069, p=.352)$ with changes in cognitive function. The same was true regarding the correlation between changes in NT-proBNP levels and changes in cognition $(p=.225)$. 
Table 3. Characteristics of patients with cognitive decline and cognitive improvement between baseline and 18-month follow-up.

\begin{tabular}{|c|c|c|c|}
\hline & $\begin{array}{l}\text { Decline of cognitive func- } \\
\text { tion }\end{array}$ & $\begin{array}{l}\text { Improvement of cognitive } \\
\text { function }\end{array}$ & $p$ \\
\hline Patients, $\mathrm{n}$ & $86(22.5)$ & $91(23.8)$ & \\
\hline Age, years & $79 \pm 8$ & $76 \pm 8$ & .005 \\
\hline Male gender & $50(58.1)$ & $61(67.0)$ & .221 \\
\hline LVEF & $36.2 \pm 13.4$ & $33.1 \pm 12.5$ & .114 \\
\hline Preserved LVEF & $21(24.4)$ & $10(11.0)$ & .019 \\
\hline Atrial fibrillation* & $38(44.2)$ & $29(32.6)$ & .114 \\
\hline Diabetes & $33(38.4)$ & $20(22.0)$ & .017 \\
\hline Depression & $13(15.1)$ & $15(16.5)$ & .803 \\
\hline History of stroke & $7(8.1)$ & $10(11.0)$ & .520 \\
\hline COPD & $19(22.1)$ & $25(27.5)$ & .408 \\
\hline Renal failure & $48(55.8)$ & $41(45.1)$ & .152 \\
\hline Charlsson score & $3(2-4)$ & $2(1-4)$ & .124 \\
\hline NYHA class II & $22(25.6)$ & $20(22.0)$ & .704 \\
\hline NYHA class III & $54(62.8)$ & $57(62.6)$ & \\
\hline NYHA class IV & $10(11.6)$ & $14(15.4)$ & \\
\hline $\mathrm{SBP}, \mathrm{mmHg}$ & $123 \pm 17$ & $120 \pm 17$ & .301 \\
\hline $\mathrm{DBP}, \mathrm{mmHg}$ & $72 \pm 10$ & $73 \pm 11$ & .856 \\
\hline NT-proBNP, ng/L & 3994 (1943-7085) & $3252(1608-6214)$ & .608 \\
\hline NT-proBNP-guided & $39(45.3)$ & $53(58.2)$ & .086 \\
\hline
\end{tabular}

Data are given as number and percentages, mean \pm standard deviation, or median (interquartile range) as appropriate. Values refer to those measured at baseline. $\mathrm{LVEF}=$ Left Ventricular Ejection Fraction; NYHA = New York Heart Association; $\mathrm{SBP}=$ systolic blood pressure; $\mathrm{DBP}=$ diastolic blood pressure; $\mathrm{NT}$-proBNP $=\mathrm{N}$-Terminal pro B-type natriuretic peptide. *Data are missing for 2 participants.

\section{Discussion}

We found a $10 \%$ prevalence of SCI amongst elderly HF patients despite the fact that a number of exclusion criteria were applied, some of which may have already reduced the proportion of patients with SCI. We found that HF symptoms were related to the presence of SCI, but this relationship was less than expected. Furthermore, changes in the severity of HF were not related to changes in cognitive function and effects of SCI at baseline on outcomes were less than anticipated.

Previous studies ${ }^{1}$ found a higher prevalence of cognitive impairment (25-50\%) in HF populations, but they also included milder forms of cognitive impairment than we did. In the present study, only half of patients answered all 10 questions of the AMT correctly. In addition to the fact that we considered only SCI, there are other potential reasons for the lower prevalence of cognitive impairment in the present study compared to previous ones. First, we excluded patients unable to give informed consent and those who were too sick to be treated. 
Figure 2. Kaplan-Meier plots showing hospitalization-free survival and overall survival in patients with and without severe cognitive impairment (SCI). HR indicates hazard ratio; CI, confidence interval.
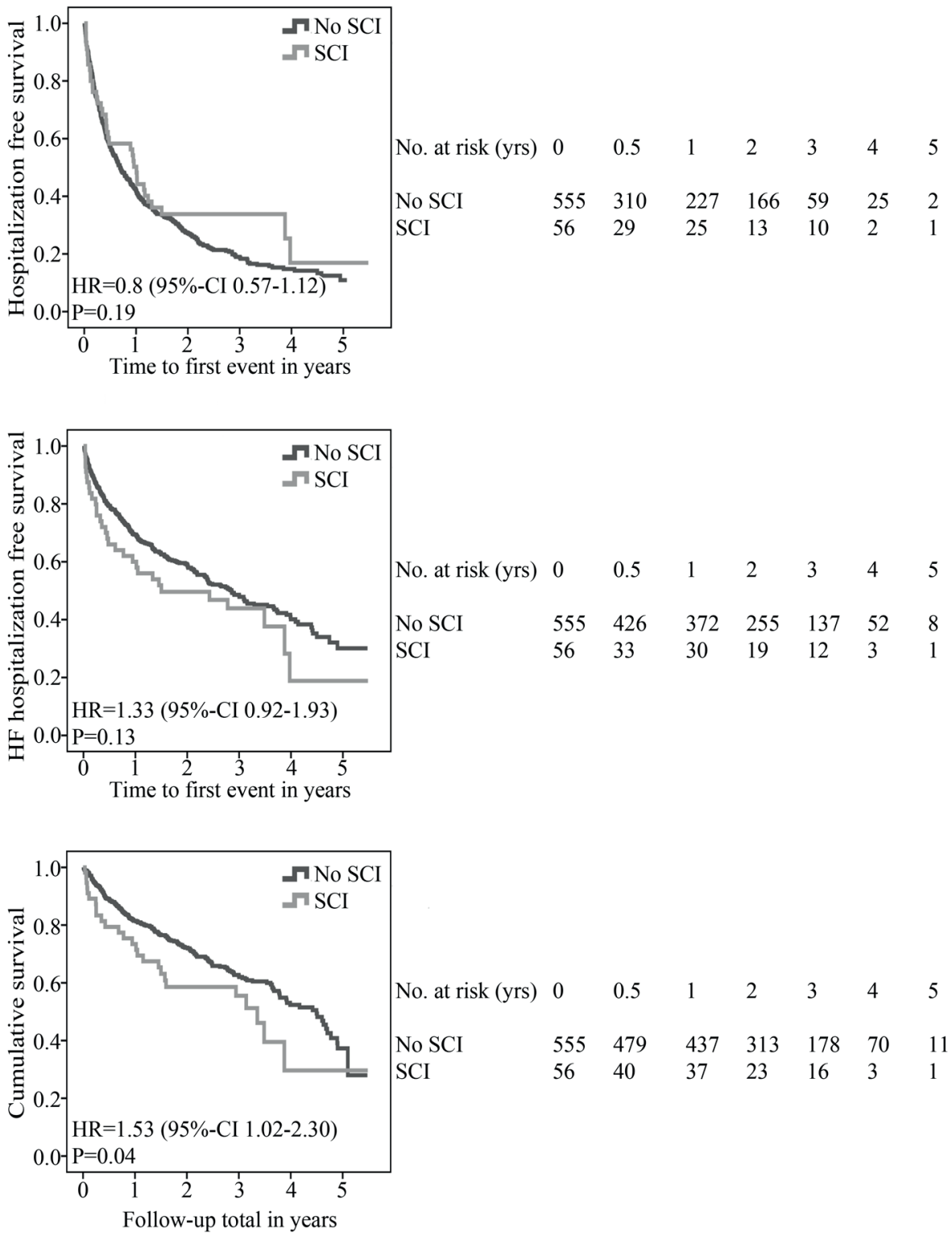
Figure 3. Frequencies of patients with or without severe cognitive impairment (SCI)

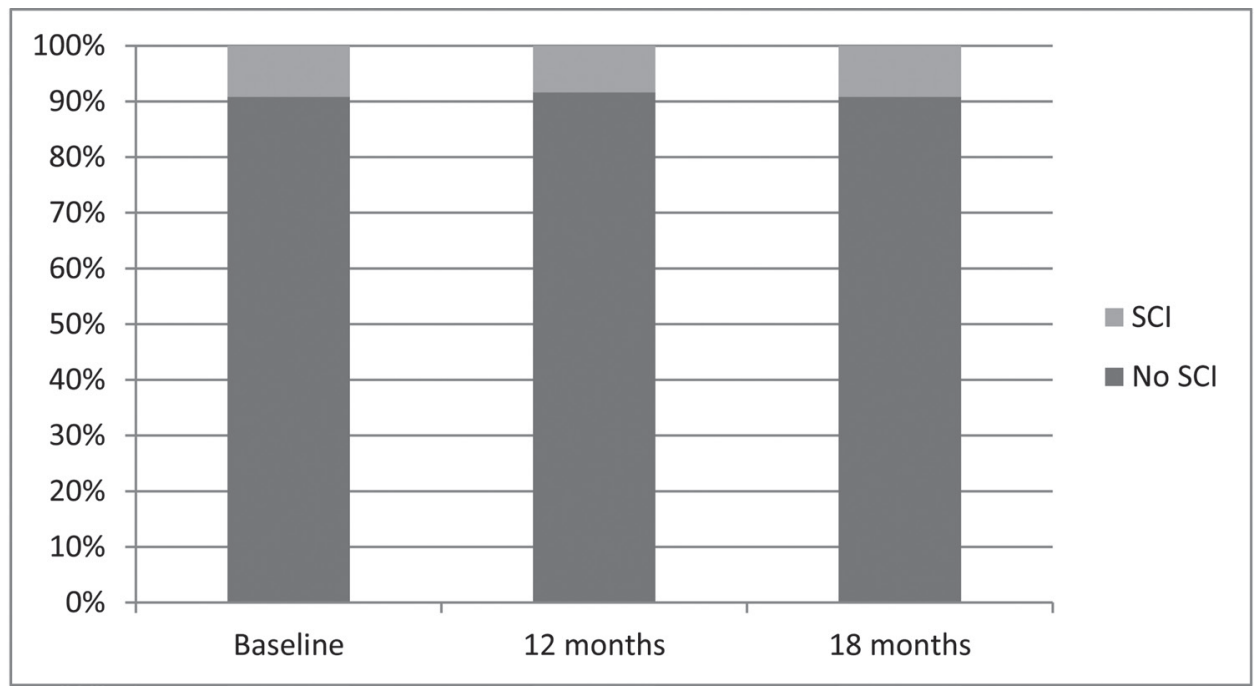

At baseline 56 of $611(9.2 \%)$ patients, at 12 months 36 of $429(8.4 \%)$ patients and at 18 months 35 of $382(9.2 \%)$ patients had SCI.

Second, the prevalence of cognitive impairment might have been underestimated, since those who performed worst were more likely to drop out. Almost two third of those with SCI at baseline were not available for further assessment. Thus, the cumulative incidence of SCI was higher (i.e. 16\%). Furthermore, the incidence is based on the chosen cut-off of the AMT leading to either under or overestimation. Based on earlier studies, the cut-off score of 7 on the AMT appeared to have the best trade-off between sensitivity and specificity for the detection of dementia ${ }^{24,26}$, which is comparable to a Mini Mental State Examination (MMSE) of $23 / 30$.

Symptoms of HF were only weakly related to SCI including the most objective measure of HF severity (i.e. NT-proBNP levels). Recently, individuals with higher BNP levels were shown to have lower scores on cognitive tests ${ }^{12}$. These results, however, were based on a general population. Since BNP levels are not only influenced by cardiac function ${ }^{27}$, noncardiac factors including higher age, worse renal function and lower haemoglobin may have influenced these findings ${ }^{28}$. In HF patients in whom NT-proBNP levels are mainly influenced by cardiac wall stress, these co-morbidities and age might be of less importance. Thus, our data suggest that cardiac function is of lesser importance with respect to SCI in the elderly population we studied.

This may explain the small changes in cognitive function related to changes in HF severity as found, while we expected parallel changes over time. Others also did not find a change in MMSE related to change in HF after 6 months with either nurse-based or primary health care follow-up ${ }^{6}$. There are different possible explanations for our negative finding. An effect of change in HF severity on cognitive function might be counteracted by the effect of increas- 
ing age as patients with declined cognitive function were older than those with improvement. Moreover, changes in symptoms do not necessarily indicate changes in cardiac function. Therefore, such an effect cannot be excluded and further studies are required to address the direct interaction between cardiac and cognitive (dys)function. Recent findings demonstrated that impairments in instrumental activities of daily living (consisting of physical as well cognitive requirements) were associated with an increased risk of incident $\mathrm{HF}^{29}$, which suggests a possible causal relationship in the other direction. Another explanation is a lack of sensitivity of these cognitive screening tests, including the one used in this study. Also, recovery of cognitive abilities might not be uniform over the whole range of cognitive impairment and, accordingly, effects of changed cardiac function may also not be uniform. In addition, comorbidities and type of HF may influence improvement or decline as we found significant differences in diabetic patients and those with preserved ejection fraction.

Others ${ }^{30}$ recently observed a U-shaped relationship between LVEF and accelerated cognitive aging. Patients in the lowest and highest quintile LVEF, as compared to the middle ones, performed worse on cognitive measures. Such a U-shaped relationship might mask the linear relationship we had been looking for.

The fact that about one fourth of the patients presented with SCI after 18 months is in line with the only other longitudinal study ${ }^{5}$, who also found that after 12 months cognitive performance either remained stable or improved. We were not able, however, to replicate the finding that a higher diastolic blood pressure at baseline was specifically associated with this improvement ${ }^{5}$. Possible explanations might be that patients in our study were older and suffered from more severe HF.

Another main finding is the poor correlation between SCI and outcomes. We hypothesized that patients with more SCI would be at higher risk for hospitalization, in particular HF hospitalization, since patients have to adequately manage their medication and diet, as well as to be alert on HF symptoms ${ }^{1}$. This hypothesis had to be rejected. However, we did find that patients with SCI had lower overall survival. Although earlier studies ${ }^{31}$ also found such an increase in mortality, we were not able to replicate the near 5-fold increase. This could be ascribed to a higher age $(M=82)$ of those with cognitive impairment in that study ${ }^{31}$, the study population being hospitalized, a more stringent cut-off for SCI (AMT $\leq 6)$, as well as the absence of exclusion criteria in their registry.

The strengths of our study are the number of patients included and the very good characterization of patients. One of the shortcomings of this study is a certain inclusion bias, excluding patients who did not understand the informed consent. This may lead to an underestimation of the prevalence of SCI in elderly HF patients. Still, we found a prevalence of SCI of around $10 \%$ in our sample, of whom only $20 \%$ were diagnosed with dementia. Obviously, there is little attention to dementia in clinical routine and our data highlight the fact that it may be unrecognized in many patients. Another shortcoming is the attrition by 18 months. Patients included in follow-up differed from those who were not available. Together with the fact that almost two third of those with SCI at baseline were not available for follow-up assessment, 
SCI might have been underestimated in our study. A final limitation concerns the selected methods of assessment. HF symptoms were measured with a pre-defined semi-quantitative scale instead of an established measure. Although cognitive screening tests such as the AMT are brief and easy to administer, they lack the power to identify subtle cognitive impairments and severity of impairment in the different domains ${ }^{1}$. Still, Cameron ${ }^{32}$ recently pleaded for the use of screening for global cognitive impairment in patients with chronic HF since it helps to identify those patients who would profit from intervention to minimize the effects of cognitive impairment. Instead of the AMT, a more sensitive screening test for cognitive impairment, such as the Montreal Cognitive Assessment (MOCA) ${ }^{11}$ is suggested fur future studies. As a next step, an elaborate neuropsychological assessment in those with cognitive impairment would give insight into specific cognitive (dys)functions in relation to HF. To screen for dementia, a higher cut-off value than 7 may be helpful. A cut-off of 8 would increase the proportion requiring further detailed testing to $>20 \%$.

In conclusion, SCI is a frequent, but often not recognized finding in elderly HF patients. Patients with more severe HF are at increased risk for SCI, which in turn is associated with higher mortality, but these effects were less than expected. Also, changes in cognitive function did not relate to changes in cardiac function. Improving the assessment of cognitive function might increase our understanding of the relationship with cardiac function. 


\section{References}

1. Pressler SJ. Cognitive functioning and chronic heart failure: a review of the literature (2002-July 2007). J Cardiovasc Nurs 2008;23(3):239-249.

2. Kindermann I, Fischer D, Karbach J, Link A, Walenta K, Barth C, Ukena C, Mahfoud F, Kollner V, Kindermann M, Bohm M. Cognitive function in patients with decompensated heart failure: the Cognitive Impairment in Heart Failure (CogImpair-HF) study. Eur J Heart Fail 2012;14(4):404-413.

3. Gaviria M, Pliskin N, Kney A. Cognitive impairment in patients with advanced heart failure and its implications on decision-making capacity. Congest Heart Fail 2011;17(4):175-179.

4. Riegel B, Lee CS, Glaser D, Moelter ST. Patterns of Change in Cognitive Function over Six Months in Adults with Chronic Heart Failure. Cardiol Res Pract 2012;2012:631075.

5. Stanek KM, Gunstad J, Paul RH, Poppas A, Jefferson AL, Sweet LH, Hoth KF, Haley AP, Forman DE, Cohen RA. Longitudinal cognitive performance in older adults with cardiovascular disease: evidence for improvement in heart failure. J Cardiovasc Nurs 2009;24(3):192-197.

6. Karlsson MR, Edner M, Henriksson P, Mejhert M, Persson H, Grut M, Billing E. A nurse-based management program in heart failure patients affects females and persons with cognitive dysfunction most. Patient Educ Couns 2005;58(2):146-153.

7. Zuccala G, Marzetti E, Cesari M, Lo Monaco MR, Antonica L, Cocchi A, Carbonin P, Bernabei R. Correlates of cognitive impairment among patients with heart failure: results of a multicenter survey. Am J Med 2005;118(5):496-502.

8. Tanne D, Freimark D, Poreh A, Merzeliak O, Bruck B, Schwammenthal Y, Schwammenthal E, Motro M, Adler Y. Cognitive functions in severe congestive heart failure before and after an exercise training program. Int J Cardiol 2005;103(2):145-149.

9. Hjelm C, Dahl A, Brostrom A, Martensson J, Johansson B, Stromberg A. The influence of heart failure on longitudinal changes in cognition among individuals 80 years of age and older. J Clin Nurs 2012;21(7-8):9941003.

10. Formiga F, Chivite D, Sole A, Manito N, Ramon JM, Pujol R. Functional outcomes of elderly patients after the first hospital admission for decompensated heart failure (HF). A prospective study. Arch Gerontol Geriatr 2006;43(2):175-185.

11. Harkness K, Demers C, Heckman GA, McKelvie RS. Screening for cognitive deficits using the Montreal cognitive assessment tool in outpatients $>/=65$ years of age with heart failure. Am J Cardiol 2011;107(8):1203-1207.

12. van den Hurk K, Reijmer YD, van den Berg E, Alssema M, Nijpels G, Kostense PJ, Stehouwer CD, Paulus WJ, Kamp O, Dekker JM, Biessels GJ. Heart failure and cognitive function in the general population: the Hoorn Study. Eur J Heart Fail 2011;13(12):1362-1369.

13. Kerola T, Nieminen T, Hartikainen S, Sulkava R, Vuolteenaho O, Kettunen R. B-type natriuretic peptide as a predictor of declining cognitive function and dementia--a cohort study of an elderly general population with a 5-year follow-up. Ann Med 2010;42(3):207-215.

14. Kondziella D, Gothlin M, Fu M, Zetterberg H, Wallin A. B-type natriuretic peptide plasma levels are elevated in subcortical vascular dementia. Neuroreport 2009;20(9):825-827.

15. Daniels LB, Laughlin GA, Kritz-Silverstein D, Clopton P, Chen WC, Maisel AS, Barrett-Connor E. Elevated natriuretic peptide levels and cognitive function in community-dwelling older adults. Am J Med 2011;124(7):670 e671-678.

16. Deshields TL, McDonough EM, Mannen RK, Miller LW. Psychological and cognitive status before and after heart transplantation. Gen Hosp Psychiatry 1996;18(6 Suppl):62S-69S.

17. Massaro AR, Dutra AP, Almeida DR, Diniz RV, Malheiros SM. Transcranial Doppler assessment of cerebral blood flow: effect of cardiac transplantation. Neurology 2006;66(1):124-126. 
18. Hoth KF, Poppas A, Ellison KE, Paul RH, Sokobin A, Cho Y, Cohen RA. Link between change in cognition and left ventricular function following cardiac resynchronization therapy. J Cardiopulm Rehabil Prev 2010;30(6):401-408.

19. Brunner-La Rocca HP, Buser PT, Schindler R, Bernheim A, Rickenbacher P, Pfisterer M. Management of elderly patients with congestive heart failure--design of the Trial of Intensified versus standard Medical therapy in Elderly patients with Congestive Heart Failure (TIME-CHF). Am Heart J 2006;151(5):949-955.

20. Pfisterer M, Buser P, Rickli H, Gutmann M, Erne P, Rickenbacher P, Vuillomenet A, Jeker U, Dubach P, Beer H, Yoon SI, Suter T, Osterhues HH, Schieber MM, Hilti P, Schindler R, Brunner-La Rocca HP. BNP-guided vs symptom-guided heart failure therapy: the Trial of Intensified vs Standard Medical Therapy in Elderly Patients With Congestive Heart Failure (TIME-CHF) randomized trial. JAMA 2009;301(4):383-392.

21. Curtis LH, Whellan DJ, Hammill BG, Hernandez AF, Anstrom KJ, Shea AM, Schulman KA. Incidence and prevalence of heart failure in elderly persons, 1994-2003. Arch Intern Med 2008;168(4):418-424.

22. Nieminen MS, Brutsaert D, Dickstein K, Drexler H, Follath F, Harjola VP, Hochadel M, Komajda M, Lassus J, Lopez-Sendon JL, Ponikowski P, Tavazzi L, EuroHeart Survey I, Heart Failure Association ESoC. EuroHeart Failure Survey II (EHFS II): a survey on hospitalized acute heart failure patients: description of population. Eur Heart J 2006;27(22):2725-2736.

23. Hodkinson HM. Evaluation of a mental test score for assessment of mental impairment in the elderly. Age Ageing 1972;1(4):233-238.

24. Sarasqueta C, Bergareche A, Arce A, Lopez de Munain A, Poza JJ, De La Puente E, Urtasun M, Emparanza JE, Marti Masso JF. The validity of Hodkinson's Abbreviated Mental Test for dementia screening in Guipuzcoa, Spain. Eur J Neurol 2001;8(5):435-440.

25. Pedone C, Ercolani S, Catani M, Maggio D, Ruggiero C, Quartesan R, Senin U, Mecocci P, Cherubini A. Elderly patients with cognitive impairment have a high risk for functional decline during hospitalization: The GIFA Study. J Gerontol A Biol Sci Med Sci 2005;60(12):1576-1580.

26. Bonaiuto S, Rocca WA, Lippi A, Luciani P, Giannandrea E, Cavarzeran F, Amaducci L. Study on the validity of the Hodkinson Abbreviated Mental Test Score (AMTS) in detecting dementia of elderly subjects in appignano (Macerata province), Italy. Arch Gerontol Geriatr 1992;15 Suppl 1:75-85.

27. Maeder MT, Mueller C, Pfisterer ME, Buser PT, Brunner-La Rocca HP. Use of B-type natriuretic peptide outside of the emergency department. Int J Cardiol 2008;127(1):5-16.

28. Cui H, Huo G, Liu L, Fan L, Ye P, Cao J, Bai Y, Wang F, Hu Y. Association of cardiac and renal function with extreme N-terminal fragment Pro-B-type natriuretic peptide levels in elderly patients. BMC Cardiovasc Disord 2012;12:57.

29. Bowling CB, Fonarow GC, Patel K, Zhang Y, Feller MA, Sui X, Blair SN, Alagiakrishnan K, Aban IB, Love TE, Allman RM, Ahmed A. Impairment of activities of daily living and incident heart failure in communitydwelling older adults. Eur J Heart Fail 2012;14(6):581-587.

30. Jefferson AL, Himali JJ, Au R, Seshadri S, Decarli C, O’Donnell CJ, Wolf PA, Manning WJ, Beiser AS, Benjamin EJ. Relation of left ventricular ejection fraction to cognitive aging (from the Framingham Heart Study). Am J Cardiol 2011;108(9):1346-1351.

31. Zuccala G, Pedone C, Cesari M, Onder G, Pahor M, Marzetti E, Lo Monaco MR, Cocchi A, Carbonin $\mathrm{P}$, Bernabei R. The effects of cognitive impairment on mortality among hospitalized patients with heart failure. Am J Med 2003;115(2):97-103.

32. Cameron J, Ski CF, Thompson DR. Cognitive impairment in chronic heart failure and the need for screening. Am J Cardiol 2011;107(10):1547-1548. 


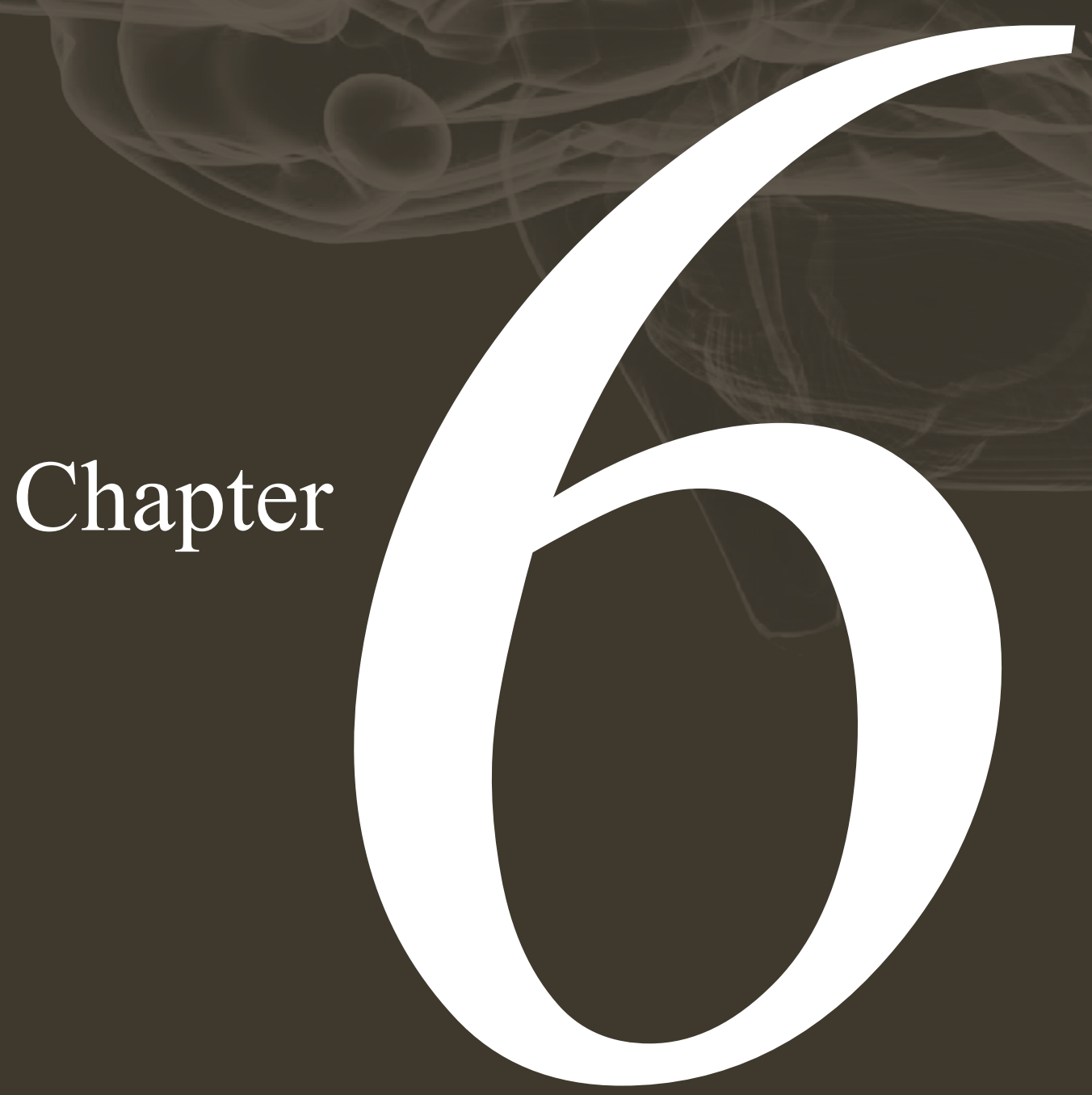




\begin{abstract}
Background - In lacunar stroke patients vitamin B12 deficiency is often found and a relationship with the degree of periventricular white matter lesions (pWMLs) is suggested. Given the known relationships between WMLs and depression and between depression and fatigue after stroke, we studied both depression and fatigue in lacunar stroke patients with and without vitamin B12 deficiency.

Methods - In 40 first-ever lacunar stroke patients vitamin B12 levels were determined and self-report questionnaires for fatigue and depression were completed three months after stroke.

Results - Lacunar stroke patients with vitamin B12 deficiency $(\mathrm{N}=13)$ reported significantly more fatigue $(90.7$ versus $59.4 ; p=.001)$ and depressive symptoms ( 6.62 versus $3.89 ; p<.05)$ than those without $(\mathrm{N}=27)$. In regression analyses, vitamin B12 deficiency was significantly and independently associated with the presence of severe fatigue and clinically significant depression.

Conclusions - Our preliminary results suggest a relationship between vitamin B12 deficiency and increased levels of fatigue and depression in lacunar stroke patients. If these findings could be replicated in a larger and general stroke sample, this would open treatment options and may improve quality of life after stroke.
\end{abstract}

\title{
Chapter 6
}

\section{Association of vitamin B12 deficiency with fatigue and depression after lacunar stroke}

\author{
Marjolein Huijts, Annelien Duits, Julie Staals, Robert van Oostenbrugge
}

Published as: PLoS ONE 2012; 7 (1): e30519 


\section{Introduction}

Recently, we found that around $30 \%$ of lacunar stroke patients were vitamin B12 deficient ${ }^{1}$ while in the normal elderly population this is only $10-15 \%$. This deficiency was related to the degree of periventricular white matter lesions (pWMLs) ${ }^{1}$. WMLs in turn are known to be related to depression ${ }^{3}$, while post-stroke depressive symptoms have been associated with an increased risk of post-stroke fatigue ${ }^{4}$. Recently, the prevalence of depression in lacunar stroke patients was found to be $35 \%$. The prevalence of fatigue in these patients is $38 \%{ }^{6}$. So far, there are no data available on the relationship between vitamin B12 deficiency and either depression or fatigue in lacunar stroke patients. In the present study we aimed to compare levels of fatigue and depression in first-ever lacunar stroke patients with and without vitamin B12 deficiency.

\section{Methods}

\section{Study population}

We consecutively included 40 first-ever lacunar stroke patients presenting at the Neurology Department of the Maastricht University Medical Centre between February 2009 and October 2010. Lacunar stroke was defined as an acute stroke syndrome with an ischemic lesion on brain MR compatible with the occlusion of a single perforating small artery (subcortical, demarcated, and a diameter $<20 \mathrm{~mm}$ ). Patients with severe co-morbidity, either neurological or psychiatric, were excluded. Patients were assessed at 3 months after stroke to exclude acute phase effects.

\section{Ethics statement}

The study was approved by the Medical Ethical Committee of the Maastricht University Medical Centre and all patients signed informed consent.

\section{Assessments}

Fatigue was measured by self-report with the Checklist Individual Strength (CIS) ${ }^{7}$. The questionnaire contains 20 statements with total scores ranging from 20 to 140 . The patient has to indicate on a 7-point scale to what extent the statement is applicable for him/her. A score $>76$ indicates severe fatigue ${ }^{7}$.

Symptoms of depression were measured by self-report with the Hospital Anxiety and Depression Scale-Depression subscale (HADS-D) ${ }^{8}$. This subscale consists of 7 items with 4 possible statements relating to the emotional aspects of depression. Total scores range from 0 to 21 . This subscale does not include physical and cognitive symptoms, including fatigue. As such, it is suitable to use in somatic populations. Since suicidal items are lacking, the instrument is less appropriate to assess the severity of depression. However, a score $>10$ is considered clinically significant.

Stroke severity was measured with the National Institutes of Health Stroke Scale (NIHSS) ${ }^{9}$ on admission. 


\section{Vitamin B12 level}

Vitamin B12 was measured in serum using a solid-phase time-resolved fluoroimmunoassay. Vitamin B12 level $<150$ pmol/L was considered deficient ${ }^{1}$, since this is clinically as well as scientifically used as a cut-off to decide for vitamin B12 deficiency ${ }^{10}$. Also, Pieters et al ${ }^{1}$ used a cut-off of $2.5 \%$ at both ends, which resulted in reference values between 150 and 630 $\mathrm{pmol} / \mathrm{L}$. To further substantiate this lower reference value, they applied the Bhattacharyatechnique and found the lower limit also to be at $150 \mathrm{pmol} / \mathrm{L}$.

\section{Brain MRI}

On brain MRI (standard T2-weighted and FLAIR sequences), two experienced neurologists (JS and RvO) individually graded pWMLs based on the Fazekas scale ${ }^{11}$. Extensive white matter lesions were defined according to Fazekas classification as T-2 weighted irregular periventricular hyperintensities extending into the deep white matter. In case of disagreement, lesions were ascertained by consensus.

\section{Statistical analysis}

We used PASW Statistics 18 software. Differences between groups were analyzed with Mann-Whitney U-tests and Pearson Chi-square. We used logistic regression analyses to test associations between the presence of severe fatigue and clinically significant depression, and vitamin B12 status, adjusted for the presence of extensive pWMLs. Since depression is found to be related to low vitamin B12 levels in the elderly population ${ }^{12}$, we also adjusted for age.

Table 1. Demographics and mean scores for lacunar stroke patients with and without vitamin B12 deficiency.

\begin{tabular}{llll}
\hline \hline & $\begin{array}{l}\text { With vitamin B12 deficiency } \\
(n=13)\end{array}$ & $\begin{array}{l}\text { Without vitamin B12 } \\
\text { deficiency }(n=27)\end{array}$ & $p$ \\
\hline Age, years (SD) & $66.6(14.0)$ & $68.6(12.1)$ & .795 \\
Female gender (\%) & $53.8 \%$ & $29.6 \%$ & .138 \\
NIHSS (SD)* & $3.00(2.00)$ & $3.67(2.50)$ & .506 \\
CIS score (SD) & $90.7(20.0)$ & $59.4(25.0)$ & .001 \\
Severe fatigue (\%) & $84.6 \%$ & $22.2 \%$ & .000 \\
HADS-D score (SD) & $6.6(4.0)$ & $3.7(3.5)$ & .019 \\
Clinically significant depres- & $30.8 \%$ & $7.4 \%$ & .053 \\
sive symptoms & & & \\
\hline
\end{tabular}

* NIHSS scores were only available for 9 (with vitamin B12 deficiency) and 15 (without deficiency) patients.

\section{Results}

We included 40 lacunar stroke patients with a mean age of 67.9 years $(\mathrm{SD}=12.6)$, of which 15 (38\%) females. Mean NIHSS score was 3.42 ( $\mathrm{SD}=2.30)$. All patients completed the questionnaires. Vitamin B12 deficiency was present in 13 (33\%) patients. The mean CIS score was 69.6 $(\mathrm{SD}=27.6)$ and the mean HADS-D score was $4.7(\mathrm{SD}=3.9)$. Severe fatigue was reported by $17(42.5 \%)$ patients and clinically significant depressive symptoms by 6 (15\%) patients. Table 1 presents the results of the fatigue and depression assessments in patients with and 
without vitamin B12 deficiency. Patients with vitamin B12 deficiency had significantly higher scores of overall fatigue and depressive symptoms.

Logistic regression analyses revealed that vitamin B12 deficiency was significantly associated with the presence of severe fatigue $(p=.002)$, independent of age and the presence of extensive pWMLs (table 2).

Table 2. Logistic regression analyses on the presence of severe fatigue

\begin{tabular}{lllllll}
\hline Model & Independent variables & $\beta$ & SE & OR & $95 \%$-CI for OR & $p$ \\
\hline \hline 1 & B12 deficiency & 2.958 & .897 & 19.250 & $3.316-111.747$ & .001 \\
2 & B12 deficiency & 3.043 & .971 & 20.976 & $3.130-140.549$ & $\mathbf{. 0 0 2}$ \\
& Age & -.039 & .037 & .961 & $.895-1.033$ & .280 \\
& Severe pWMLs & -.038 & 1.017 & .963 & $.131-7.068$ & .970 \\
\hline \hline
\end{tabular}

Model 1: univariate analysis. Model 2: multivariate analysis with adjustments for age and presence of severe pWMLs

\section{Discussion}

The results showed vitamin B12 deficiency in 33\% of our sample of lacunar stroke patients. Those with deficiency reported more fatigue and depressive symptoms than those without. In addition, vitamin B12 deficiency was found to be associated with fatigue and depressive symptoms independent of age and the presence of pWMLs.

Depression and fatigue are known to be strongly correlated ${ }^{13}$. Besides, fatigue is a common symptom of depression. To increase the construct validity, we used the HADS-D scale for measuring depressive symptoms. This scale does not contain somatic items including fatigue, and as such we reduced the overlap between the assessments of depression and fatigue. Limitation of this study however is the cross-sectional design, which makes it impossible to infer causality. To make causal inferences from the relationships found, we need longitudinal studies but preferably a randomized design.

Although we found a relationship between vitamin B12 deficiency and pWMLs in earlier work $^{1}$, WMLs did not affect the relationship between vitamin B12 deficiency and either fatigue or depressive symptoms. In this study we did not intend to examine the direct relationships between pWMLs and both fatigue and depression on the other hand. Larger samples are needed to study all interrelationships. So far, the present results, though preliminary, do not suggest a mediating role for WMLs in explaining the relationship between vitamin B12 deficiency and both fatigue and depression. Vitamin B12-induced anemia, on the other hand, could be a mediating factor, since this may induce fatigue. However, based on a retrospective search on hemoglobin-values, there was only one patient with values below threshold.

Although not significant in our sample, prevalence rates of vitamin B12 deficiency in general populations are higher for women than for men $^{2}$. It was suggested that this difference was related to hormone replacement therapy, but this appeared not to be a significant contributor to low vitamin B12 status $^{14}$.

Data about stroke severity (NIHSS) were not available for all patients. Although we cannot 
exclude that stroke severity influences the degree of fatigue and depression, we do not expect a major effect as, in general, lacunar stroke patients present with relatively mild neurological deficits.

Given the small sample size and cross-sectional design, our findings are statistically only preliminary. However, since vitamin B12 deficiency is easily treatable by supplementation, the results are clinically relevant making further research worthwhile. Both depression and fatigue may have a negative impact on rehabilitation and quality of life after stroke ${ }^{15}$. If these findings could be replicated in a larger and general stroke sample, this would open treatment options and may improve quality of life after stroke. Therefore, we suggest further research in these populations as well as in elderly people with vitamin B12 deficiency. We also suggest adding functional assessments of vitamin B12 deficiency such as homocysteine and methylmalonic acid measurements. To infer causality, intervention studies with vitamin B12 supplementation are warranted. 


\section{References}

1. Pieters B, Staals J, Knottnerus I, Rouhl R, Menheere P, Kessels A, et al. Periventricular white matter lucencies relate to low vitamin B12 levels in patients with small vessel stroke. Stroke. 2009;40:1623-1626

2. Baik HW, Russell RM. Vitamin B12 deficiency in the elderly. Annu Rev Nutr. 1999;19:357-377

3. O'Brien J, Desmond P, Ames D, Schweitzer I, Harrigan S, Tress B. A magnetic resonance imaging study of white matter lesions in depression and Alzheimer's disease. Br J Psychiatry. 1996;168:477-485

4. Snaphaan L, van der Werf S, de Leeuw FE. Time course and risk factors of post-stroke fatigue: a prospective cohort study. Eur J Neurol. 2011;18:611-617

5. Tang WK, Chen YK, Lu JY, Chu WC, Mok VC, Ungvari GS, et al. Cerebral Microbleeds and Depression in Lacunar Stroke. Stroke. 2011;42:2443-2446

6. Van Zandvoort MJ, Kappelle LJ, Algra A, De Haan EH. Decreased capacity for mental effort after single supratentorial lacunar infarct may affect performance in everyday life. J Neurol Neurosurg Psychiatry. 1998;65:697-702

7. Vercoulen JHMM, Alberts, M., \& Bleijenberg, G. De Checklist Individual strength (CIS). Gedragstherapie. 1999;32:131-136

8. Zigmond AS, Snaith RP. The hospital anxiety and depression scale. Acta Psychiatr Scand. 1983;67:361370

9. Brott T, Adams HP, Jr., Olinger CP, Marler JR, Barsan WG, Biller J, et al. Measurements of acute cerebral infarction: a clinical examination scale. Stroke. 1989;20:864-870

10. Carmel R, Green R, Rosenblatt DS, Watkins D. Update on cobalamin, folate, and homocysteine. Hematology Am Soc Hematol Educ Program. 2003:62-81

11. Fazekas F, Chawluk JB, Alavi A, Hurtig HI, Zimmerman RA. MR signal abnormalities at $1.5 \mathrm{~T}$ in Alzheimer's dementia and normal aging. AJR Am J Roentgenol. 1987;149:351-356

12. Tiemeier H, van Tuij1 HR, Hofman A, Meijer J, Kiliaan AJ, Breteler MM. Vitamin B12, folate, and homocysteine in depression: the Rotterdam Study. Am J Psychiatry. 2002;159:2099-2101

13. Bol Y, Duits AA, Hupperts RM, Vlaeyen JW, Verhey FR. The psychology of fatigue in patients with multiple sclerosis: a review. J Psychosom Res. 2009;66:3-11

14. Carmel R, Howard JM, Green R, Jacobsen DW, Azen C. Hormone replacement therapy and cobalamin status in elderly women. Am J Clin Nutr. 1996;64:856-859

15. Naess H, Waje-Andreassen U, Thomassen L, Nyland H, Myhr KM. Health-related quality of life among young adults with ischemic stroke on long-term follow-up. Stroke. 2006;37:1232-1236 


\section{Chapter}

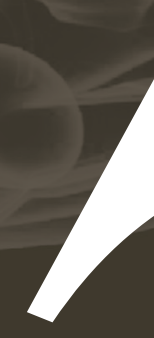




\begin{abstract}
Background - Around 30\% of lacunar stroke patients are vitamin B12 deficient. Vitamin B12 deficiency is related to decreased cognitive functioning and post-stroke fatigue and depression. Since vitamin B12 deficiency is easily treatable with supplementation, possible effects on cognitive function and post-stroke fatigue and depression may have significant effects on quality of life after lacunar stroke.

Methods - 14 first-ever lacunar stroke patients with vitamin B12 deficiency received vitamin B12 supplementation for at least 3 months. Before and after supplementation cognitive function was assessed and self-report questionnaires for fatigue and depression were completed. Besides paired T-tests, we also calculated reliable change indices in order to examine whether changes in cognitive tests were of any clinical significance for the patients.

Results - Significant differences between baseline assessment and follow-up were only found for RAVLT total immediate recall scores $(p=.008)$. Although fatigue and depressive symptoms decreased, this did not reach significance. In line with the group analyses we only found a consistent improvement in the total recall of the RAVLT. Six out of 14 patients ( $43 \%$ ) showed clinically significant improvement.

Discussion - We found a significant improvement in verbal learning, both on a group as well as on individual level. Despite the limitations of the present work, the results justify future multi-centre randomized controlled trials to study the effect of vitamin B12 supplementation on cognition, depression and fatigue.
\end{abstract}

\title{
Chapter 7
}

\section{Effects of vitamin B12 supplementation on cognition, depression and fatigue in patients with lacunar stroke}

\author{
Marjolein Huijts, Robert van Oostenbrugge, Rob Rouhl, Paul Menheere, An- \\ nelien Duits
}

Published as: International Psychogeriatrics 2013; 25 (3): 508-510 


\section{Introduction}

Around $30 \%$ of lacunar stroke patients are vitamin B12 deficient. This deficiency is related to the degree of periventricular white matter lesions (pWMLs) ${ }^{1}$. Vitamin B12 deficiency was also found to be related to decreased cognitive functioning ${ }^{2,3}$ and post-stroke fatigue and depression ${ }^{4}$. Since vitamin B12 deficiency is easily treatable with supplementation, possible effects on cognitive function and post-stroke fatigue and depression may have significant effects on quality of life after lacunar stroke.

A systematic review of randomized trials on the effect of vitamin B12 supplementation concluded that there is not enough evidence for an effect of vitamin B12 on cognitive function in people with either normal or impaired cognitive function ${ }^{5}$. A meta-analysis on randomized double-blind clinical trials in which vitamin B12 was compared with placebo, also revealed no effect of vitamin B12 supplementation on cognition in patients with a low vitamin B12 status $^{6}$. However, this was only based on three studies with low power and different measures for vitamin B12. A recent review by Moore et $\mathrm{al}^{7}$ concluded that vitamin B12 supplementation was effective in correcting biochemical deficiency, but improved cognitive function was only found in those with pre-existing vitamin B12 levels below $150 \mathrm{pmol} / \mathrm{L}$. The authors identified four intervention studies in neurological patients presenting with vitamin B12 deficiency. Although vitamin B12 is specifically associated with cerebrovascular pathology ${ }^{8}$, none of these studies included patients with cerebrovascular pathology in particular. Additionally, the studies did not select for patients who were vitamin B12 deficient and cognition was assessed with the Mini Mental State Examination (MMSE) only.

Although we recently demonstrated that post-stroke fatigue and depression are very common amongst lacunar stroke patients with a vitamin B12 deficiency ${ }^{4}$, effects of vitamin B12 supplementation on fatigue and depressive symptoms however, have not been studied before in this population. Therefore, the aim of this pilot study was to study the effect of vitamin B12 supplementation on cognition and both depression and fatigue in patients with lacunar stroke.

\section{Methods}

\section{Study population}

We consecutively included 18 first-ever lacunar stroke patients with a vitamin B12 deficiency and white matter lesions presenting at the Neurology Department between August 2008 and January 2011. Lacunar stroke was defined as an acute stroke syndrome with a small $(<20 \mathrm{~mm})$ ischemic lesion on acute brain MR in the brain stem, basal ganglia or internal capsule, compatible with the occlusion of a single perforating small artery. Exclusion criteria were previous brain infarction, severe comorbidity (either neurological or psychiatric), limited life expectancy and/or a history of inflammatory disease. The study was approved by the local Medical Ethical Committee and all patients signed informed consent. Patients were assessed at $>3$ months after stroke to exclude acute phase effects. 


\section{Neuropsychological assessment}

Cognitive function was assessed by 1 trained neuropsychologist $(\mathrm{MH})$ during a 2 hour session. The test battery included the Rey Auditory Verbal Learning Test (RAVLT) ${ }^{9}$, Stroop Colour Word Test $(\mathrm{SCWT})^{10}$, Trailmaking Test A and B (TMT) $)^{11}$, category and letter fluency ${ }^{12,13}$, and the following subtests of the Wechsler Adult Intelligence Scale III (WAIS III) ${ }^{14}$, Symbol Substitution, Digit span and Letter Number Sequencing. For the SCWT and TMT, interference scores were computed. Interference score SCWT $=$ time on card 3 - Mean (card $1+$ card 2). Interference score TMT = time card B - time card A. The Hospital Anxiety and Depression Scale (HADS) ${ }^{15}$ and the Checklist Individual Strength (CIS) ${ }^{16}$ were used to assess depression and fatigue. All assessments were repeated after vitamin B12 supplementation had been terminated (with a minimum of 3 months). At follow-up, we did not repeat the DART, and parallel versions of the RAVLT and letter fluency were used.

\section{Vitamin B12 and folate levels}

In order to find potential candidates for this study, vitamin B12 levels were first determined between admission and maximum 12 weeks post-stroke. A vitamin B12 level $<150$ pmol/L was considered deficient ${ }^{1}$, based on a clinically as well as scientifically used cut-off ${ }^{17}$. However, since vitamin B12 levels may vary minimally through time, patients with levels $<200$ $\mathrm{pmol} / \mathrm{L}$ were also potential candidates for this study. Vitamin B12 was measured in serum using a solid-phase time-resolved fluoroimmunoassay. Folate was measured in serum and levels $<10 \mathrm{nmol} / \mathrm{L}$ were considered a subclinical deficiency ${ }^{18}$. When included, levels of vitamin B12 and folate were determined again for study purposes at baseline and follow-up. Supplementation (1 $\mathrm{mg}$ hydroxocobalamine) was administered for at least 3 months by their general practitioner.

\section{Statistical analysis}

We used PASW Statistics 18 software. We used paired T-tests to determine within-subject differences pre-and post supplementation. We also used linear regression analyses to test associations between differences in vitamin B12 level and differences in cognitive performance and subjective depression and fatigue, adjusted for age.

In addition, we calculated reliable change indices (RCI) in order to examine whether changes in cognitive tests were of any clinical significance for the patients. By taking into account the reliability of the test, the reliable change indices statistical analysis determines whether the test score of an individual has changed significantly between the two time points (e.g. pre-to post supplementation). Reliable change indices therefore measure whether the change in a test score falls beyond the range that could be attributed to measurement variability of the test itself $\mathrm{f}^{19}$. Standard deviations of pre-supplementation assessments and test-retest reliability coefficients from the test manuals were used to calculate the respective reliable change indices. 


\section{Results}

Eighteen patients were included at baseline (table 1). Four patients were not available for follow-up assessment. Patients without follow-up assessment did not differ from those with follow-up concerning age, sex or vitamin B12 level at admission (all $p>.05$ ). Means, standard deviations and significance levels are shown in table 2.

Table 1. Baseline characteristics

\begin{tabular}{ll}
\hline \hline & All patients $(n=18)$ \\
\hline \hline Age, years (SD) & $63.50 \pm 12.54$ \\
Male gender (\%) & $11(61.1 \%)$ \\
Time since stroke, weeks (SD) & $14.39 \pm 6.52$ \\
BMI, kg/m²(SD) & $26.15 \pm 4.96$ \\
Smoking (\%) & $33.3 \%$ \\
Hypertensive (\%) & $10(55.6 \%)$ \\
Diabetes (\%) & $2(11.1 \%)$ \\
Hypercholesterolemia (\%) & $15(83.3 \%)$ \\
Affected side left (\%) & $10(55.6 \%)$ \\
Positive family history cardiovascular disease $(\%)$ & $6(33.3 \%)$ \\
\hline \hline
\end{tabular}

Numbers represent frequencies, except where reported otherwise.

Table 2. Mean scores on neuropsychological tests at baseline and follow-up

\begin{tabular}{|c|c|c|c|c|}
\hline & & Baseline & Follow-up & $p$ \\
\hline \multirow[t]{3}{*}{ RAVLT } & Total recall & 36.14 & 42.71 & .008 \\
\hline & Delayed recall & 7.50 & 7.93 & .648 \\
\hline & Recognition (RP) & 12.92 & 13.21 & .618 \\
\hline \multirow[t]{4}{*}{ Stroop test, sec } & Card 1 & 56.36 & 58.14 & .152 \\
\hline & Card 2 & 67.93 & 69.07 & .605 \\
\hline & Card 3 & 134.50 & 131.57 & .704 \\
\hline & Interference & 72.36 & 67.96 & .545 \\
\hline \multirow[t]{3}{*}{ Trail making test, sec } & Card A & 42.00 & 37.07 & .111 \\
\hline & Card B & 107.14 & 108.29 & .852 \\
\hline & Interference & 65.14 & 71.21 & .391 \\
\hline WCST & Perseverative errors & 14.00 & 15.50 & .461 \\
\hline \multirow[t]{2}{*}{ Category fluency, number } & Animals & 18.86 & 17.79 & .324 \\
\hline & Professions & 12.14 & 12.57 & .568 \\
\hline Letter fluency, number & Total & 26.93 & 27.50 & .715 \\
\hline Symbol substitution & Total & 51.86 & 52.43 & .651 \\
\hline \multirow[t]{2}{*}{ Digit span } & Forward & 8.07 & 8.00 & .836 \\
\hline & Backward & 5.64 & 6.14 & .110 \\
\hline Letter number sequencing & Total & 9.57 & 9.00 & .302 \\
\hline
\end{tabular}

Numbers represent the total amount of right answers, unless where reported otherwise. RAVLT= Rey Auditory Verbal Learning Test; WCST= Wisconsin Card Sorting Task; RP= right positive 
Significant differences between baseline assessment and follow-up were only found for RAVLT total immediate recall scores $(p=.008)$.

Although fatigue and depressive symptoms decreased, this did not reach significance (table $3)$.

Table 3. Mean scores on psychological questionnaires

\begin{tabular}{lllll}
\hline \hline \multirow{2}{*}{ HADS } & & Baseline & Follow-up & $p$ \\
& Anxiety & 8.14 & 7.36 & .295 \\
CIS & Depression & 6.64 & 5.21 & .119 \\
& Total & 85.43 & 79.79 & .175 \\
& Fatigue & 37.86 & 34.50 & .190 \\
& Concentration & 18.71 & 19.14 & .837 \\
& Motivation & 15.64 & 14.71 & .436 \\
& Activity & 13.21 & 11.43 & .182 \\
\hline \hline
\end{tabular}

HADS = Hospital Anxiety and Depression Scale; CIS = Checklist Individual Strength

\section{Reliable Change Index}

In line with the group analyses we only found a consistent improvement in the total recall of the RAVLT. Six out of 14 patients (43\%) showed clinically significant improvement. Overall, these individuals were younger ( $\mathrm{M}=56.0$ vs $\mathrm{M}=65.5$ years) and higher educated than those who remained stable $(\mathrm{n}=6)$ or declined $(\mathrm{n}=2)$, though not significant $(p=.189$ and $p=.068$ respectively).

\section{Discussion}

We studied the effect of vitamin B12 supplementation on cognition, fatigue and depressive symptoms in a group of patients with lacunar stroke and vitamin B12 deficiency. As far as we know this is the first study to describe the effects of vitamin B12 supplementation in patients with lacunar stroke and vitamin B12 deficiency. Although the power of our study is low and the results are only preliminary, we found a significant improvement in verbal learning, both on a group as well as on individual level. Overall, individuals showing improvement were younger and higher educated than those who remained stable or declined. Although in a different population, the observed memory improvement is in line with a previous study on vitamin B12 supplementation by Walker ${ }^{20}$. They found an improvement of cognitive function after 24 months folic acid and vitamin B12 supplementation, in particular in immediate and delayed memory performance.

No effect was found for vitamin B12 supplementation on fatigue and depressive symptoms. Although mean scores on depression and fatigue questionnaires were lower at follow-up, this did not reach significance. This is most probably due to the small sample size.

Besides the small power there might be other factors which could have influenced the absence of a clear improvement. First, the question is whether the duration and doses of supplementation were sufficient or whether other administration routes should have been used. 
However, all but one patient were not deficient after supplementation, with 6 out of 14 patients with levels over $1000 \mathrm{pmol} / \mathrm{L}$. The one patient that was still deficient was diabetic and under treatment of metformin, which is known to impair absorption of vitamin B12 ${ }^{18}$. Some suggest that other indicators of vitamin B12, such as homocysteine or methylmalonic acid should also have been used. The sensitivity of vitamin B12 is good, but specificity is lacking. Additional measures of methylmalonic acid might have increased the predictive value, but have not been evaluated afterwards or retrospectively. The disadvantage of homocysteine is that levels can be increased independently of vitamin B12 status ${ }^{21}$. Another methodological issue is the absence of a placebo and/or control group. In order to draw conclusions on causative relationships longitudinal follow-up studies with placebo-control groups are necessary. A complicating factor could be that vitamin B12 intervention only commenced after the onset of irreversible cognitive changes ${ }^{22}$. In a meta-analysis by Clarfield ${ }^{23}$, only $0.6 \%$ of all dementias partially or fully resolved. A final limitation is the impossibility to measure the period of exposure to vitamin B12 deficiency. Long exposure may cause neurological complications which may not simply be reversed by starting vitamin B12 replacement therapy ${ }^{22}$. A study by Martin et $\mathrm{al}^{24}$ showed that vitamin B12 supplementation was significantly more beneficial for patients with cognitive impairments present for less than one year.

To provide future studies with a guideline for a minimal number of patients for a randomized controlled trial (RCT), we performed sample size estimations ${ }^{25}$ based on our database. Expected differences between treatment and control group were set at $25 \%$. Taking into account a drop-out rate of $20 \%$, we estimated the minimal sample size to test a difference in memory function after supplementation to be 1008 (504 per treatment arm). In order to detect a difference in fatigue and depression, 4388 and 2178 patients are needed respectively. Assuming that $33 \%$ of lacunar stroke patients are vitamin B12 deficient ${ }^{4}, 3024,13164$ and 6534 lacunar stroke patients respectively, will have to be screened in order to include these numbers. Considering these large sample sizes, future studies need a multi-centre setting.

In conclusion, despite the limitations of the present work, the results justify future multicentre randomized controlled trials to study the effect of vitamin B12 supplementation on cognition, depression and fatigue. 


\section{References}

1. Pieters B, Staals J, Knottnerus I, Rouhl R, Menheere P, Kessels A, et al. Periventricular white matter lucencies relate to low vitamin B12 levels in patients with small vessel stroke. Stroke. 2009;40:1623-1626

2. Riggs KM, Spiro A, 3rd, Tucker K, Rush D. Relations of vitamin B-12, vitamin B-6, folate, and homocysteine to cognitive performance in the Normative Aging Study. Am J Clin Nutr. 1996;63:306-314

3. Wang HX, Wahlin A, Basun H, Fastbom J, Winblad B, Fratiglioni L. Vitamin B(12) and folate in relation to the development of Alzheimer's disease. Neurology. 2001;56:1188-1194

4. Huijts M, Duits A, Staals J, van Oostenbrugge RJ. Association of vitamin B12 deficiency with fatigue and depression after lacunar stroke. PLoS One. 2012;7:e30519

5. Balk EM, Raman G, Tatsioni A, Chung M, Lau J, Rosenberg IH. Vitamin B6, B12, and folic acid supplementation and cognitive function: a systematic review of randomized trials. Arch Intern Med. 2007;167:21-30 6. Malouf R, Areosa Sastre A. Vitamin B12 for cognition. Cochrane Database Syst Rev. 2003:CD004326

7. Moore E, Mander A, Ames D, Carne R, Sanders K, Watters D. Cognitive impairment and vitamin B12: a review. Int Psychogeriatr. 2012;24:541-556

8. Fassbender K, Mielke O, Bertsch T, Nafe B, Froschen S, Hennerici M. Homocysteine in cerebral macroangiography and microangiopathy. Lancet. 1999;353:1586-1587

9. Brand N, Jolles J. Learning and retrieval rate of words presented auditorily and visually. J Gen Psychol. 1985;112:201-210

10. Golden CJ. Stroop Colour and Word Test. Chicago (Ill): Stoelling; 1978.

11. Reitan R. Trail Making Test: Manual for administration, scoring and interpretation. Bloomington: Indiana University; 1956.

12. Luteyn F. Een nieuwe verkorte GIT. Dutch J Psychol. 1966;2:675-682

13. Lezak M, Howieson, DB, \& Loring, DW. Neuropsychological assessment New York: Oxford University Press; 2004.

14. Wechsler D. WAIS III, nederlandstalige bewerking: technische handleiding. Lisse: Swets Test Publishers; 2001.

15. Zigmond AS, Snaith RP. The hospital anxiety and depression scale. Acta Psychiatr Scand. 1983;67:361370

16. Vercoulen JHMM, Alberts, M., \& Bleijenberg, G. De Checklist Individual strength (CIS). Gedragstherapie. 1999;32:131-136

17. Carmel R, Green R, Rosenblatt DS, Watkins D. Update on cobalamin, folate, and homocysteine. Hematology Am Soc Hematol Educ Program. 2003:62-81

18. Green R. Indicators for assessing folate and vitamin B-12 status and for monitoring the efficacy of intervention strategies. Am J Clin Nutr. 2011;94:666S-672S

19. Jacobson NS, Truax P. Clinical significance: a statistical approach to defining meaningful change in psychotherapy research. J Consult Clin Psychol. 1991;59:12-19

20. Walker JG, Batterham PJ, Mackinnon AJ, Jorm AF, Hickie I, Fenech M, et al. Oral folic acid and vitamin B-12 supplementation to prevent cognitive decline in community-dwelling older adults with depressive symptoms--the Beyond Ageing Project: a randomized controlled trial. Am J Clin Nutr. 2012;95:194-203

21. Serot JM, Barbe F, Arning E, Bottiglieri T, Franck P, Montagne P, et al. Homocysteine and methylmalonic acid concentrations in cerebrospinal fluid: relation with age and Alzheimer's disease. J Neurol Neurosurg Psychiatry. 2005;76:1585-1587

22. Moore E, Mander A, Ames D, Carne R, Sanders K, Watters D. Cognitive impairment and vitamin B12: a review. Int Psychogeriatr. 2012:1-16

23. Clarfield AM. The decreasing prevalence of reversible dementias: an updated meta-analysis. Arch Intern Med. 2003;163:2219-2229 
24. Martin DC, Francis J, Protetch J, Huff FJ. Time dependency of cognitive recovery with cobalamin replacement: report of a pilot study. J Am Geriatr Soc. 1992;40:168-172

25. Erdfelder E, Faul, F., \& Buchner, A. GPOWER: a general power analysis program. Behavior Research Methods, Instruments, \& Computers. 1996;28:1-11 
98 
Chapter

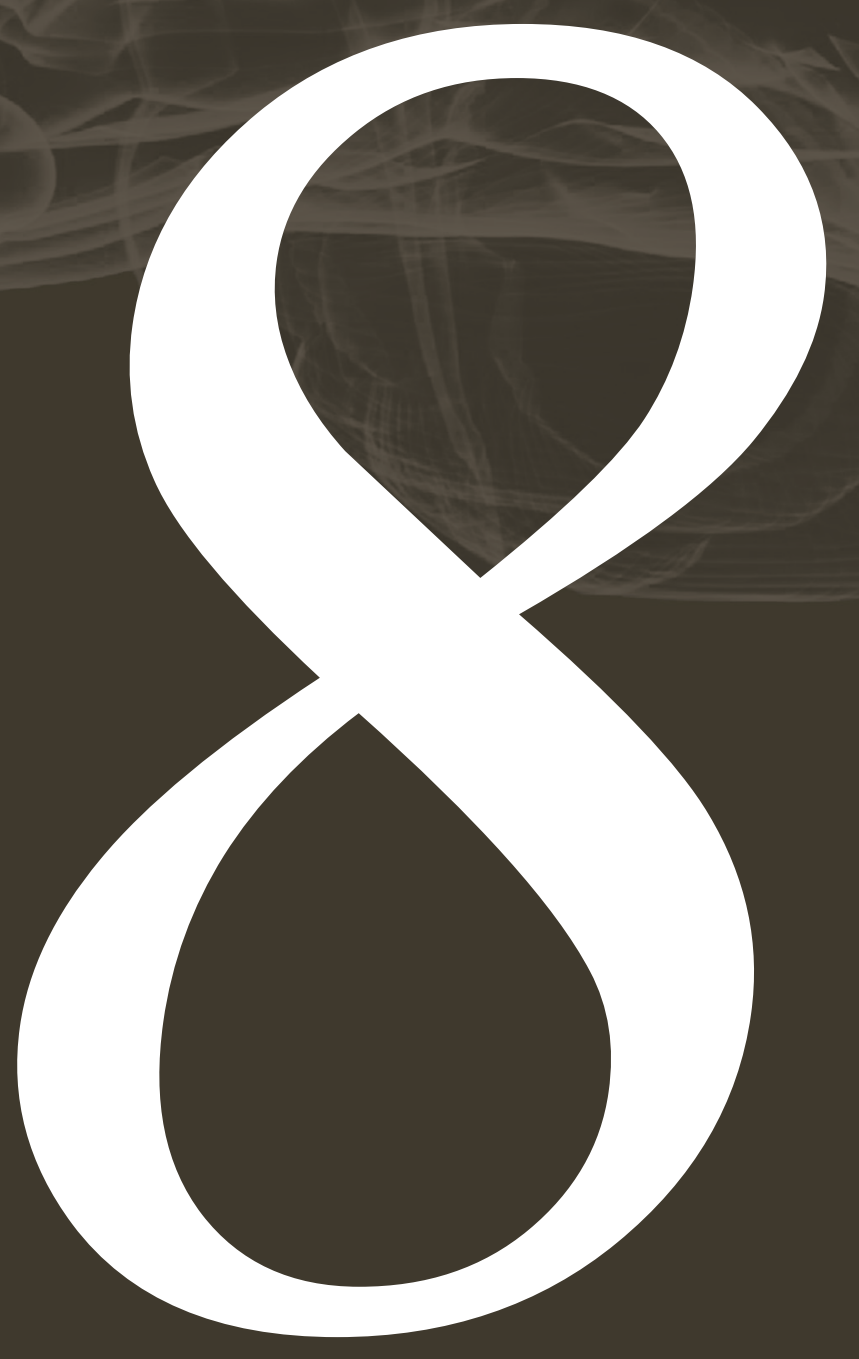




\begin{abstract}
Background - Brain microbleeds (BMBs) are considered to be a marker for cerebral small vessel disease (cSVD). Evidence for an independent association with decreased cognitive performance is found by some, but not by others, and studies in patients at risk for or with manifest CSVD are sparse. The aim of this study was to assess the relationship between cognition and BMBs in terms of presence, number and location, while adjusting for WMLs and lacunar infarcts.

Methods - number and location, while adjusting for WMLs and lacunar infarcts.

Methods - We included 188 patients with a high prevalence of cSVD (112 hypertensive patients and 76 first-ever lacunar stroke patients). Patients underwent brain MRI and neuropsychological assessment. We rated the presence and number of BMB and distinguished deep, lobar and infratentorial BMBs. The presence of other markers of cSVD such as (silent) lacunar infarcts and white matter lesions was also rated. Associations with cognitive domains were analyzed using regression analyses, adjusting for these other imaging markers of cSVD and age.

Results - BMBs were present in $21 \%$ of our sample. Patients with BMBs significantly more often presented with the other markers of cSVD. The presence of BMBs was not associated with any of the cognitive domains after correction for the other markers of cSVD and age.

Discussion - BMBs are highly prevalent in a population with CSVD and co-occur with other markers of cSVD. Instead of an independent relationship, BMBs most likely are a marker of cSVD severity, without having a direct effect on cognitive function in this population.
\end{abstract}

\title{
Chapter 8
}

\section{Brain microbleeds do not independently relate to cognition in patients with cerebral small vessel disease}

\author{
Marjolein Huijts, Robert van Oostenbrugge, Julie Staals, Bram Kroon, Peter \\ de Leeuw, Annelien Duits
}

\section{Submitted}




\section{Introduction}

Cognitive impairment caused by vascular disease is frequently found and vascular dementia is the second most common form of dementia ${ }^{1}$. White matter lesions (WMLs) and lacunar infarcts, both markers of cerebral small vessel disease (cSVD), appear to be the most common forms of cerebrovascular damage, and a frequent cause of cognitive impairment. More recently, brain microbleeds (BMBs) have also been recognized as a marker of $\mathrm{cSVD}^{2}$, but their relationship with cognition is less evident.

Whereas the lobar located BMBs have been suggested to be attributable to cerebral amyloid angiopathy ${ }^{3}$, BMBs in the basal ganglia and thalamus have been specifically linked to hypertensive small vessel vasculopathy ${ }^{2,4,5}$.

Associations between BMBs and cognitive function have been found in healthy elderly populations $s^{6-9}$, stroke or TIA patients ${ }^{10,11}$ and patients from memory clinics ${ }^{12,13}$. In the healthy (elderly) population, BMBs were associated with decreased cognitive performance ${ }^{7,9}$ and in case of multiple BMBs with a decreased performance on tests of executive function and information processing speed ${ }^{7}, 8$. In a study on patients with WMLs or lacunar infarcts on MRI, the presence and number of BMBs were independently related to overall cognitive function, psychomotor speed and attention ${ }^{14}$. In another study on elderly patients with an increased vascular risk it was found that specifically infratentorial BMBs were associated with cognitive impairment ${ }^{15}$. Recently, Patel et $\mathrm{al}^{16}$ found that in patients with symptomatic cSVD the association between BMB count and executive function was no longer significant after controlling for other MRI parameters such as lesion load and lacune count. Only the top decile of BMB count remained significantly associated with executive function ${ }^{17}$. Others found that strictly lobar BMBs were associated with executive dysfunction in patients with ischemic stroke or TIA ${ }^{18}$. Whereas evidence for an independent association between BMBs and cognitive performance has been found by some $\mathrm{e}^{6,11-13,19,20}$, others did not find an association $^{16,21,22}$. These differences might be due to the use of different populations such as healthy populations and patients from memory clinics. The underlying pathology for BMBs in these populations is not homogeneous, and may include BMBs due to the abovementioned two types of vascular pathological changes: cerebral amyloid angiopathy and hypertensive vasculopathy. BMBs due to hypertensive vasculopathy have been specifically related to cSVD². So far, studies on the relationship of BMBs and cognition in patients at risk for or with manifest cSVD are sparse.

The aim of this study was to assess the presence of BMBs in patients with a high risk of cSVD (essential hypertensive patients) and patients with manifest cSVD (first-ever lacunar stroke patients). The focus was on the relationship between cognition and BMBs in terms of presence, number and location, while adjusting for WMLs and lacunar infarcts. We hypothesized that with increasing BMBs cognitive function decreases. Additionally, we hypothesize that specifically deep BMBs are related to executive function and information processing speed. Associations were analyzed for the total sample, as well as for the two subgroups separately. 


\section{Methods \\ Participants}

Patients included in this study participated in two larger studies; the hypertensive patients in a longitudinal study on brain damage in hypertension (HYBRiD) ${ }^{23}$, whereas the lacunar stroke patients participated in a study on cognitive function after lacunar stroke. Both populations show a high prevalence of cSVD and we assume that the underlying pathology as well as the consequences of BMBs for cognitive function are similar, regardless of the underlying stage of cSVD.

Hypertensive patients were referred to the hypertension outpatient clinic of the Department of Internal Medicine of the Maastricht University Medical Centre. Of 218 patients included at baseline (July 2004 to September 2006), 198 patients were available for possible followup studies, of whom 112 patients completed a brain MRI and extensive neuropsychological assessment at 5-year follow-up. Exclusion criteria were a history of symptomatic cardio- or cerebrovascular disease or contraindications for MRI. Data collected at 5-year follow-up were used for the present study.

Of 208 first-ever lacunar stroke patients presenting at the Neurology Department of the Maastricht University Medical Centre between February 2009 and July 2012, we consecutively included 76 patients. Lacunar stroke was defined as an acute stroke syndrome with a small $(<20 \mathrm{~mm})$ ischemic lacunar lesion in the pons, basal ganglia, thalamus or capsula interna on acute brain MR compatible with the occlusion of a single perforating small artery. If no such lesion was visible, we used established clinical criteria for lacunar stroke ${ }^{24}$. Patients with severe co-morbidity, either neurological or psychiatric, were excluded. Furthermore, patients without MRI or with possible other causes than cSVD (cardiac embolic source, cerebral large vessel disease, or carotid stenosis), were excluded. Patients underwent neuropsychological assessment at 3 months after stroke to exclude acute phase effects.

The presence of vascular risk factors was recorded for all patients including hypertension, diabetes mellitus, hypercholesterolemia and smoking. Data of vascular risk factors were missing for 4 hypertensive patients.

Both studies were approved by the Medical Ethics Committee of the Maastricht University Medical Centre and all participants gave written informed consent.

\section{Brain magnetic resonance imaging}

On brain MRI (standard T2-weighted, FLAIR and T2*-weighted sequences; $1.5 \mathrm{~T}$ or 3T), two experienced neurologists ( $\mathrm{JS}$ and $\mathrm{RvO}$ ) individually graded BMBs and other markers of cSVD. BMBs were defined as punctate $(<10 \mathrm{~mm})$ homogeneous foci of low signal intensity on $\mathrm{T} 2 *$-weighted images. Symmetrical hypointensities in the globi pallidi were disregarded, since these most likely represent calcification. We distinguished lobar (cortical gray and subcortical white matter), deep (basal ganglia, thalamus, and internal, external and extreme capsule) and infratentorial (cerebellum and brain stem) microbleeds. The inter-observer agreement for the presence of BMBs was substantial $(\kappa=.63)$. Regarding number of BMBs, we distinguished between $1 \mathrm{BMB}, 2-4 \mathrm{BMBs}$ or more than $5 \mathrm{BMB}^{6}$. In case of disagreement, 
lesions were ascertained by consensus. Two patients were excluded due to missing T2*weighted images.

\section{Other markers of cSVD}

Asymptomatic lacunar infarcts - We identified asymptomatic lacunar infarcts as sharply demarcated hyperintense lesions $<20 \mathrm{~mm}$ on T2-weighted images with corresponding hypointense lesions with a hyperintense rim on FLAIR. In case of the lacunar stroke patients, the lesion could not be compatible with the clinical stroke and Diffusion Weighted Imaging was used to distinguish between the symptomatic and asymptomatic lacunar infarcts. Presence of lacunar infarcts was based on $\geq 1$ lacunar infarct.

White matter lesions - White matter lesions were identified as hyperintense areas on T2weighted and FLAIR images. WMLs connected to the lateral ventricles were rated as periventricular, otherwise we considered them as deep. WMLs were graded according to the Fazekas scale ${ }^{25}$. We defined extensive WMLs as: periventricular WMLs score 3 (irregular lesions extending into the deep white matter) and/or deep WMLs with a score of 2 (beginning confluence of lesions) or 3 (large confluent areas).

\section{Assessment of cognitive function}

Cognitive function was assessed by 1 trained neuropsychologist (MH) during a 2 hour session. The test battery included the Rey Auditory Verbal Learning Test (RAVLT) ${ }^{26}$, Stroop Colour Word Test (SCWT) $)^{27}$, Trailmaking Test A and B (TMT) ${ }^{28}$, category and letter fluency 29,30, and the following subtests of the Wechsler Adult Intelligence Scale III (WAIS III) ${ }^{31}$, Symbol Substitution, Digit span and Letter Number Sequencing. For the SCWT and TMT, interference scores were computed. Interference score SCWT= time on card 3 - Mean (card $1+$ card 2). Interference score TMT= time card B - time card A.

We compared performances on different cognitive domains by using $\mathrm{Z}$ standard scores. For each domain we computed compound scores. Memory domain $=(Z /$ RAVLT immediate recall $+\mathrm{Z} /$ RAVLT delayed recall + Z/RAVLT word recognition + Z/digit span forward)/4; Executive functions domain $=(\mathrm{Z} / \mathrm{SCWT}$ interference $+\mathrm{Z} / \mathrm{TMT}$ interference $+\mathrm{Z} /$ category fluency + Z/letter fluency + Z/digit span backward + Z/letter number sequencing)/6; Information processing speed $=(Z /$ symbol substitution $+Z / T M T A+Z /$ mean of Stroop card 1 and 2$) / 3$. A compound score for overall cognitive function was calculated as the mean score of the three compound scores. Z-scores of tests with higher scores representing worse performance were inverted before computing the compound scores. Compound scores for memory, executive function, information processing speed and overall cognition were missing for 5, 5, 1 and 9 patients respectively. Therefore, analyses on these variables were performed with a different number of subjects.

\section{Statistical analysis}

We presented baseline characteristics as frequencies, except for age (mean and SD) and compared patients with and without BMBs with $\mathrm{X}^{2}$ tests and an independent T-test. The associa- 
tion between presence, number and location of BMBs with cognitive domains was investigated using univariate regression analyses, additionally adjusted for silent lacunar infarcts and severe WMLs, as well as age and sex. Results are presented for the total sample as well as for hypertensive and lacunar stroke patients separately. Due to small numbers, we did not repeat the analyses for location of BMBs in these two subgroups.

\section{Results}

In total, 188 patients were included (112 hypertensive patients and 76 lacunar stroke patients) and 218 excluded (86 hypertensive patients and 132 lacunar stroke patients). Included patients were younger $(60.0 \pm 12.7$ vs $66.3 \pm 15.1$ years, $p<.001)$ and more often male $(58 \%$ vs $48 \%, p=.048$ ) than patients who were excluded from the study. Reasons for exclusion were: not interested $(\mathrm{N}=102)$, atrial fibrillation $(\mathrm{N}=35)$, other cerebrovascular accident or transient ischemic attack before inclusion $(\mathrm{N}=9)$, pre-existent cognitive problems $(\mathrm{N}=7)$, carotid stenosis $(\mathrm{N}=7)$, exclusion criteria for MRI $(\mathrm{N}=6)$, death $(\mathrm{N}=4)$, or other reasons $(\mathrm{N}=48)$.

BMBs were present in 39 patients $(21 \%), 62 \%$ presenting with $1 \mathrm{BMB}, 28 \%$ with 2 to 4 BMBs and $10 \%$ with 5 or more BMBs. Patients with BMBs were older $(p=.001)$ and more often male ( $p=.020$ ) than those without (table 1). Regarding cSVD markers, patients with BMBs more often suffered from a symptomatic lacunar infarct $(p=.022)$ and more often had WMLs $(p=.005)$. Borderline significance was found for the presence of asymptomatic lacunar infarcts $(p=.060)$.

Table 1. Patients characteristics

\begin{tabular}{lllll}
\hline \hline & & \multicolumn{2}{l}{ Microbleeds } & \\
\cline { 3 - 5 } & All $(n=188)$ & Yes $(n=39)$ & No $(n=149)$ & $p$ \\
\hline \hline Age, mean years (SD) & $60.0 \pm 12.7$ & $66.0 \pm 10.4$ & $58.5 \pm 12.8$ & $\mathbf{. 0 0 1}$ \\
Male sex & $109(58.0)$ & $29(74.4)$ & $80(53.7)$ &. $\mathbf{0 2 0}$ \\
Hypertension & $160(85.1)$ & $33(84.6)$ & $127(85.2)$ & .923 \\
Diabetes & $11(5.9)$ & $1(2.6)$ & $10(6.7)$ & .326 \\
Hypercholesterolemia & $95(51.9)$ & $15(39.5)$ & $80(55.2)$ & .085 \\
Current smoking & $40(21.4)$ & $10(25.6)$ & $30(20.3)$ & .645 \\
cSVD markers & & & & \\
- Symptomatic lacunar infarct & $76(40.4)$ & $22(56.4)$ & $54(36.2)$ & $\mathbf{. 0 2 2}$ \\
- Asymptomatic lacunar infarcts & $63(33.5)$ & $18(46.2)$ & $45(30.2)$ & .060 \\
- WMLs & $34(18.1)$ & $13(33.3)$ & $21(14.1)$ & $\mathbf{. 0 0 5}$ \\
\hline \hline
\end{tabular}

Data are shown in frequencies (\%), except where reported otherwise. WMLs = white matter lesions. P-values refer to the difference between patients with and without brain microbleeds.

\section{Presence of BMBs and cognition}

Significant associations between presence of BMBs and memory, information processing speed and overall cognition were found in univariate regression analyses (table 2). However, when adjusted for the presence of asymptomatic lacunar infarcts, severe WMLs or age and 
sex, none of the results remained significant.

Table 2. Regression coefficients of the association between presence of BMBs and cognitive function

\begin{tabular}{|c|c|}
\hline Cognitive domain & Presence of BMBs \\
\hline \multicolumn{2}{|l|}{ Memory } \\
\hline - Unadjusted & $-0.259(-0.518 \text { to } 0.001)^{*}$ \\
\hline - Model 1 & $-0.020(-0.260$ to 0.221$)$ \\
\hline - Model 2 & $-0.225(-0.485$ to 0.035$)$ \\
\hline - Model 3 & $-0.202(-0.461$ to. 0.058$)$ \\
\hline \multicolumn{2}{|l|}{ Executive function } \\
\hline - Unadjusted & $-0.197(-0.451$ to 0.058$)$ \\
\hline - Model 1 & $-0.063(-0.305$ to 0.180$)$ \\
\hline - Model 2 & $-0.163(-0.419$ to 0.092$)$ \\
\hline - Model 3 & $-0.101(-0.352$ to 0.149$)$ \\
\hline \multicolumn{2}{|c|}{ Information processing speed } \\
\hline - Unadjusted & $-0.371(-0.678 \text { to }-0.064)^{*}$ \\
\hline - Model 1 & $-0.110(-0.372$ to 0.151$)$ \\
\hline - Model 2 & $-0.278(-0.575$ to 0.020$)$ \\
\hline - Model 3 & $-0.233(-0.533$ to 0.068$)$ \\
\hline \multicolumn{2}{|c|}{ Overall cognitive function } \\
\hline - Unadjusted & $-0.246(-0.488 \text { to }-0.004)^{*}$ \\
\hline - Model 1 & $-0.050(-0.264$ to 0.164$)$ \\
\hline - Model 2 & $-0.196(-0.435$ to 0.042$)$ \\
\hline - Model 3 & $-0.171(-0.406$ to 0.064$)$ \\
\hline
\end{tabular}

Model 1: Linear regression analyses adjusted for age and sex. Model 2: Linear regression analyses adjusted for the presence of silent lacunar infarcts. Model 3: Linear regression analyses adjusted for severe WMLs. * $\mathrm{p} \leq .05$

\section{Location of BMBs and cognition}

Regarding location, one or more deep BMBs were present in 27 patients, lobar BMBs in 17 and infratentorial BMBs in 6 patients. The presence of one or more deep BMBs was associated with memory ( $p=.031)$, executive function $(p=.046)$, information processing speed $(p=.015)$ and overall cognition $(p=.026)$, but this disappeared after correction for the presence of other cSVD markers or age and sex. The presence of one or more lobar BMBs was associated with memory $(p=.020)$, information processing speed $(p=.032)$ and overall cognition $(p=.036)$, but only memory remained significant after correction for silent lacunar infarcts $(p=.037)$ or WMLs $(p=.051)$, but significance disappeared after correction for age and sex. The presence of one or more infratentorial BMBs was not associated with any of the cognitive domains.

\section{Hypertensive and lacunar stroke patients}

Brain microbleeds were present in 17 hypertensive patients (15\%), 77\% presented with 1 BMB, $18 \%$ with 2 to 4 BMBs and $6 \%$ with 5 or more BMBs. Patients with BMBs were older (55.4 years vs 62.5 years, $p=.025$ ), but did not differ regarding vascular risk factors or the presence of other cSVD markers. The presence of BMBs was significantly associated with 
memory $(p=.046)$ in univariate regression analyses. In multivariate regression analyses adjusted for asymptomatic lacunar infarcts and severe WMLs this remained significant ( $p=.036$ and $p=.046$ respectively), but disappeared after correction for age and sex.

Brain microbleeds were present in 22 lacunar stroke patients $(29 \%), 50 \%$ presented with 1 $\mathrm{BMB}, 36 \%$ with 2 to $4 \mathrm{BMBs}$ and $14 \%$ with 5 or more BMBs. Patients with BMBs were more often male $(86 \%, p=.001)$ and less often had hypercholesterolemia $(52 \%, p=.030)$. Regarding cSVD markers, patients with BMBs more often had asymptomatic lacunar infarcts $(p=.011)$ and WMLs $(p=.016)$. The presence of BMBs was not associated with any of the cognitive domains.

\section{Discussion}

The aim of this study was to assess the presence of BMBs in patients with a high risk of cSVD (essential hypertensive) and first-ever lacunar stroke patients and the relationship between cognition and BMBs in terms of presence, number and location, while adjusting for WMLs and lacunar infarcts. We were interested in the associations for the total sample, but also for the two subgroups (hypertensive and lacunar stroke patients) separately. We found a high prevalence of BMBs of $21 \%$ in our cSVD population. BMBs were present in $15 \%$ of the hypertensive population and in $29 \%$ of the lacunar stroke patients. The presence of BMBs was not independently associated with any of the cognitive domains, when adjusted for other markers of cSVD and age and sex.

The prevalence of BMBs in hypertensive patients (15\%) was lower than in the lacunar stroke patients (29\%). This was expected since hypertensive patients are at risk for cSVD, but by definition had no cSVD symptoms. The prevalence of BMBs in the lacunar stroke patients is somewhat lower than what was found by Patel et al ${ }^{16}$ (40\%). Our patients were younger and not selected based on the presence of WMLs. We were unable to compare the prevalence of the hypertensive patients to other studies, since no specific data on hypertensive patients are available.

When we analyzed the data for hypertensive and lacunar stroke patients separately, we found that in hypertensive patients, the presence of BMBs was related to memory function, also after adjusting for other markers of cSVD, but not when adjusting for age and sex. In lacunar stroke patients on the other hand, the presence of BMBs was not related to any of the cognitive domains. Possibly, the presence of a symptomatic lacunar stroke overpowered the effect of microbleeds on cognitive functioning. Another explanation might be the lack of power, since the number of patients in each subcategory was quite small in order to draw conclusions on cognitive functioning.

Recently, Charidimou and Werring ${ }^{32}$ proposed several different mechanisms by which BMBs might influence cognitive function, since the underlying mechanism is still speculative. They proposed that 1) BMBs cause direct structural damage to the surrounding tissue, resulting in disconnecting cortical from subcortical structures; 2) BMBs cause functional disturbances in surrounding tissue, affecting cognition; 3) BMBs have an indirect influence on cognition or 
4) BMBs are just a marker of cSVD severity or type, without having a direct and independent effect on cognitive function. The present results support the fourth proposal as our results often lost significance after correcting for other markers of cSVD. Patients with microbleeds significantly more often presented with other markers of cSVD, which shows that BMBs often co-occur with these other markers of cSVD. In case of isolated BMBs, associations with cognitive function may resemble those found in univariate analyses.

Other studies with cerebrovascular populations found significant associations between BMBs and cognitive function, even after correction for the presence of WMLs and/or lacunes. However, exact populations differed and consequently the distribution of BMBs due to hypertensive vasculopathy and cerebral amyloid angiopathy might have been different. Additionally, our patients with BMBs were younger (66 years) than those in these other studies ${ }^{11,14,15}$. So far, studies that reported negative findings regarding the relationship between BMBs and cognitive function concerned mainly populations with $\mathrm{AD}$ or other dementias. Van der Flier ${ }^{33}$ recently concluded that negative findings might be due to small sample sizes, the frequent occurrence of only $1 \mathrm{BMB}$, but more importantly, that the disease process has advanced too far, masking the subtle effect of BMBs on cognitive function. Since our patients with BMBs significantly more often presented with other markers of cSVD, its process may also be too advanced to reveal any associations between BMBs and cognitive function.

One of the limitations of our study is the cross-sectional nature of our study, which prevents statements about causality. Longitudinal studies following increase of BMBs and cognitive decline over time are needed in order to confirm a causal relationship between the two. Another limitation is the variable MRI field strength that was used in our population. As it was found that more BMBs can be detected at $3 \mathrm{~T}$ than at $1.5 \mathrm{~T}^{34}$, this might have led to underrating in about three fourth of our patients that was scanned at $1.5 \mathrm{~T}$, compared to the other patients at 3T. However, it was found that enhanced sensitivity in detecting BMBs had no improved clinical relevance regarding relations with vascular risk factors, cognition or markers of $\mathrm{cSVD}^{35}$. Additionally, results remained unchanged after correction for field strength (results not shown). Additionally, we included relatively young patients, in which the level of cognitive impairments is expected to be relatively low.

The strength of this study is the substantial amount of cSVD patients in which relatively extensive neuropsychological assessment was performed. In addition, we are the first to present results on the relationship of BMBs with cognition in lacunar stroke patients. This relation has not been studied in patients with cerebrovascular disease that intensively yet, which is surprising, since BMBs are particularly expected in these populations.

In conclusion, BMBs are highly prevalent in a cSVD population. The presence of BMBs is associated with decreased memory, information processing speed and overall cognition, but not independent of other markers of cSVD. This suggests that BMBs are, most likely, a marker of cSVD severity, without having a direct and independent effect on cognitive function in this population. 


\section{References}

1. Korczyn AD, Vakhapova V, Grinberg LT. Vascular dementia. J Neurol Sci. 2012;322:2-10

2. Vernooij MW, van der Lugt A, Ikram MA, Wielopolski PA, Niessen WJ, Hofman A, et al. Prevalence and risk factors of cerebral microbleeds: the Rotterdam Scan Study. Neurology. 2008;70:1208-1214

3. Mesker DJ, Poels MM, Ikram MA, Vernooij MW, Hofman A, Vrooman HA, et al. Lobar distribution of cerebral microbleeds: the Rotterdam Scan Study. Arch Neurol. 2011;68:656-659

4. Poels MM, Ikram MA, van der Lugt A, Hofman A, Krestin GP, Breteler MM, et al. Incidence of cerebral microbleeds in the general population: the Rotterdam Scan Study. Stroke. 2011;42:656-661

5. Staals J, van Oostenbrugge RJ, Knottnerus IL, Rouhl RP, Henskens LH, Lodder J. Brain microbleeds relate to higher ambulatory blood pressure levels in first-ever lacunar stroke patients. Stroke. 2009;40:3264-3268

6. Poels MM, Ikram MA, van der Lugt A, Hofman A, Niessen WJ, Krestin GP, et al. Cerebral microbleeds are associated with worse cognitive function: the Rotterdam Scan Study. Neurology. 2012;78:326-333

7. Yakushiji Y, Nishiyama M, Yakushiji S, Hirotsu T, Uchino A, Nakajima J, et al. Brain microbleeds and global cognitive function in adults without neurological disorder. Stroke. 2008;39:3323-3328

8. Qiu C, Cotch MF, Sigurdsson S, Jonsson PV, Jonsdottir MK, Sveinbjrnsdottir S, et al. Cerebral microbleeds, retinopathy, and dementia: the AGES-Reykjavik Study. Neurology. 2010;75:2221-2228

9. Takashima Y, Mori T, Hashimoto M, Kinukawa N, Uchino A, Yuzuriha T, et al. Clinical correlating factors and cognitive function in community-dwelling healthy subjects with cerebral microbleeds. J Stroke Cerebrovasc Dis. 2011;20:105-110

10. Gregoire SM, Smith K, Jager HR, Benjamin M, Kallis C, Brown MM, et al. Cerebral microbleeds and long-term cognitive outcome: longitudinal cohort study of stroke clinic patients. Cerebrovasc Dis. 2012;33:430435

11. Werring DJ, Frazer DW, Coward LJ, Losseff NA, Watt H, Cipolotti L, et al. Cognitive dysfunction in patients with cerebral microbleeds on T2*-weighted gradient-echo MRI. Brain. 2004;127:2265-2275

12. Goos JD, Henneman WJ, Sluimer JD, Vrenken H, Sluimer IC, Barkhof F, et al. Incidence of cerebral microbleeds: a longitudinal study in a memory clinic population. Neurology. 2010;74:1954-1960

13. Cordonnier C, van der Flier WM, Sluimer JD, Leys D, Barkhof F, Scheltens P. Prevalence and severity of microbleeds in a memory clinic setting. Neurology. 2006;66:1356-1360

14. van Norden AG, van den Berg HA, de Laat KF, Gons RA, van Dijk EJ, de Leeuw FE. Frontal and temporal microbleeds are related to cognitive function: the Radboud University Nijmegen Diffusion Tensor and Magnetic Resonance Cohort (RUN DMC) Study. Stroke. 2011;42:3382-3386

15. van Es AC, van der Grond J, de Craen AJ, Westendorp RG, Bollen EL, Blauw GJ, et al. Cerebral microbleeds and cognitive functioning in the PROSPER study. Neurology. 2011;77:1446-1452

16. Patel B, Lawrence AJ, Chung AW, Rich P, Mackinnon AD, Morris RG, et al. Cerebral microbleeds and cognition in patients with symptomatic small vessel disease. Stroke. 2013;44:356-361

17. Huijts M, Staals J, Duits A. Letter by Huijts et al regarding article "Cerebral microbleeds and cognition in patients with symptomatic small vessel disease". Stroke. 2013

18. Gregoire SM, Scheffler G, Jager HR, Yousry TA, Brown MM, Kallis C, et al. Strictly Lobar Microbleeds Are Associated With Executive Impairment in Patients With Ischemic Stroke or Transient Ischemic Attack. Stroke. 2013

19. van Es AC, van der Grond J, de Craen AJ, Westendorp RG, Bollen EL, Blauw GJ, et al. Cerebral microbleeds and cognitive functioning in the PROSPER study. Neurology. 2011;77:1446-1452

20. Yakushiji Y, Noguchi T, Hara M, Nishihara M, Eriguchi M, Nanri Y, et al. Distributional impact of brain microbleeds on global cognitive function in adults without neurological disorder. Stroke. 2012;43:1800-1805 21. van der Vlies AE, Goos JD, Barkhof F, Scheltens P, van der Flier WM. Microbleeds do not affect rate of cognitive decline in Alzheimer disease. Neurology. 2012 
22. Pettersen JA, Sathiyamoorthy G, Gao FQ, Szilagyi G, Nadkarni NK, St George-Hyslop P, et al. Microbleed topography, leukoaraiosis, and cognition in probable Alzheimer disease from the Sunnybrook dementia study. Arch Neurol. 2008;65:790-795

23. Henskens LH, Kroon AA, van Oostenbrugge RJ, Gronenschild EH, Hofman PA, Lodder J, et al. Associations of ambulatory blood pressure levels with white matter hyperintensity volumes in hypertensive patients. J Hypertens. 2009;27:1446-1452

24. de Jong G, Kessels F, Lodder J. Two types of lacunar infarcts: further arguments from a study on prognosis. Stroke. 2002;33:2072-2076

25. Fazekas F, Chawluk JB, Alavi A, Hurtig HI, Zimmerman RA. MR signal abnormalities at $1.5 \mathrm{~T}$ in Alzheimer's dementia and normal aging. AJR Am J Roentgenol. 1987;149:351-356

26. Brand N, Jolles J. Learning and retrieval rate of words presented auditorily and visually. J Gen Psychol. 1985;112:201-210

27. Golden CJ. Stroop Colour and Word Test. Chicago (Ill): Stoelling; 1978.

28. Reitan R. Trail Making Test: Manual for administration, scoring and interpretation. Bloomington: Indiana University; 1956.

29. Luteyn F. Een nieuwe verkorte GIT. Dutch J Psychol. 1966;2:675-682

30. Lezak M, Howieson, DB, \& Loring, DW. Neuropsychological assessment New York: Oxford University Press; 2004.

31. Wechsler D. WAIS III, nederlandstalige bewerking: technische handleiding. Lisse: Swets Test Publishers; 2001 .

32. Charidimou A, Werring DJ. Cerebral microbleeds and cognition in cerebrovascular disease: An update. J Neurol Sci. 2012;322:50-55

33. van der Flier WM. Clinical aspects of microbleeds in Alzheimer's disease. J Neurol Sci. 2012;322:5658

34. Stehling C, Wersching H, Kloska SP, Kirchhof P, Ring J, Nassenstein I, et al. Detection of asymptomatic cerebral microbleeds: a comparative study at 1.5 and 3.0 T. Acad Radiol. 2008;15:895-900

35. Goos JD, van der Flier WM, Knol DL, Pouwels PJ, Scheltens P, Barkhof F, et al. Clinical relevance of improved microbleed detection by susceptibility-weighted magnetic resonance imaging. Stroke. 2011;42:1894-

1900 
110 
Chapter

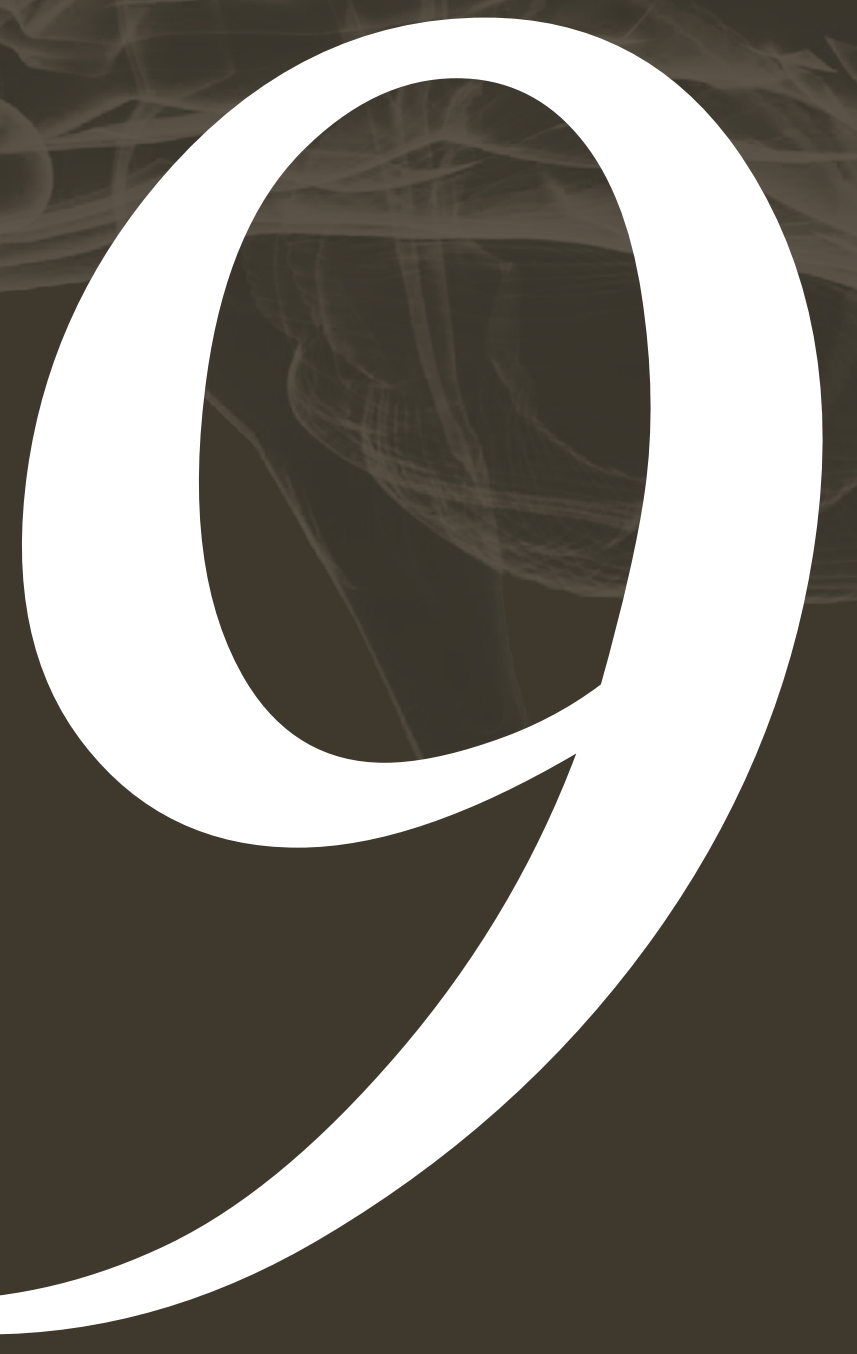




\begin{abstract}
Background - Enlarged perivascular spaces (EPVS) are a feature of cerebral small vessel disease (CSVD) and have been related to cSVD severity. A higher number of EPVS were related to decreased cognition in healthy elderly, but this has never been investigated in patients at high risk of CSVD.

Methods - We included 189 patients with a high risk of cSVD (hypertensive patients and lacunar stroke patients). Patients underwent brain MRI and extensive neuropsychological assessment. EPVS were rated in the basal ganglia (BG) and centrum semiovale (CSO). Correlation analyses between EPVS and cognitive domains were adjusted for white matter lesions (WMLs), age, sex and symptomatic stroke.

Results - Negative correlations were found between EPVS in the BG and all cognitive domains, independent of WMLs. After correction for age, results remained significant for information processing speed (IPS) only. No independent correlation was found between EPVS in the CSO and cognition.

Conclusions - We demonstrated that more BG EPVS were associated with a decrease in IPS, independent of age and WMLs. This emphasizes that specifically EPVS in the BG are associated with CSVD, and with CSVD-related decreases in cognition.
\end{abstract}

\title{
Chapter 9
}

\section{Cognitive function and enlarged perivascular spaces in patients with cerebral small vessel disease}

\author{
Marjolein Huijts, Annelien Duits, Julie Staals, Bram Kroon, Peter de Leeuw, \\ Robert van Oostenbrugge
}

Submitted 


\section{Introduction}

Enlarged perivascular spaces (EPVS), or Virchow-Robin spaces, are widened cerebrospinal fluid-filled cavities surrounding the perforating arteries of the brain ${ }^{1}$. On T2-weighted images they appear as punctuate or linear hyperintensities in the basal ganglia and centrum semiovale. EPVS are a feature of cerebral small vessel disease (cSVD) ${ }^{2}$ and have been related to cSVD severity ${ }^{3,4}$.

EPVS are not commonly present in the younger healthy population, but become increasingly common with older age ${ }^{5}$. In general, patients with EPVS remain asymptomatic ${ }^{6}$ and therefore EPVS are considered benign. However, MacLullich et $\mathrm{al}^{7}$ found that increased EPVS were related to decreased cognitive function in healthy elderly men. This relationship however, was not independent from white matter lesions (WMLs). Chen et $\mathrm{al}^{8}$ found that patients with Alzheimer's Disease (AD) and mild cognitive impairment (MCI) showed more EPVS than control subjects. Zhu et $\mathrm{al}^{9}$ even found a higher rate of cognitive decline in elderly patients with a high degree of EPVS in the basal ganglia.

Although EPVS have been related to cSVD, its clinical consequences in patients with cSVD are unknown. Therefore, the objective of the present study was to assess the relationship between EPVS and cognitive function, adjusted for confounding factors such as WMLs, age and sex, in a population with a high prevalence of cSVD: first-ever lacunar stroke patients as well as essential hypertensive patients.

\section{Methods}

\section{Study population}

Patients included in our study participated in two larger studies, the hypertensive patients in a longitudinal study on brain damage in hypertension (HYBRiD) $)^{10}$, whereas the lacunar stroke patients participated in an ongoing study on cognitive function after lacunar stroke. Both populations are at risk for cSVD and we assume that the consequences of EPVS for cognition are similar, regardless of the underlying stage of cSVD.

Hypertensive patients were referred to the hypertension outpatient clinic of the Department of Internal Medicine of the Maastricht University Medical Centre. Of 218 patients included at baseline (July 2004 to September 2006), 198 patients were available for possible followup studies, of whom 112 patients completed a brain MRI and extensive neuropsychological assessment at 5-year follow-up. Exclusion criteria were a history of symptomatic cardio- or cerebrovascular disease or contraindications for MRI. Data collected at 5-year follow-up were used for the present study.

Of 208 first-ever lacunar stroke patients presenting at the Neurology Department of the Maastricht University Medical Centre between February 2009 and July 2012, we consecutively included 77 patients. Lacunar stroke was defined as an acute stroke syndrome with a small $(<20 \mathrm{~mm})$ ischemic lacunar lesion in the brain stem, basal ganglia or capsula interna on acute brain MR compatible with the occlusion of a single perforating small artery. If no such lesion was visible, we used established clinical criteria for lacunar stroke ${ }^{11}$. Patients with severe co-morbidity, either neurological or psychiatric, were excluded. Furthermore, patients 
without brain MR or with symptoms suggesting other causes than cSVD (cardiac embolic source, cerebral large vessel disease, or carotid stenosis), were excluded. Patients underwent neuropsychological assessment at 3 months after stroke to exclude acute phase effects.

The presence of vascular risk factors was recorded for all patients: hypertension, diabetes mellitus, hypercholesterolemia and smoking. Data of vascular risk factors were missing for 4 hypertensive patients.

Both studies were approved by the Medical Ethics Committee of the Maastricht University Medical Centre and all participants gave written informed consent.

\section{Image analysis}

On brain MRI (standard T2-weighted and FLAIR sequences, 1.5 or 3T), two experienced neurologists (JS and RvO) individually graded EPVS and WMLs. We distinguished EPVS at two different levels: the basal ganglia and the white matter of the centrum semiovale. EPVS were defined as round, oval or linear shaped lesions with a smooth margin, absence of mass effect and with signal intensity equal to cerebrospinal fluid on T2-weighted images and (if visible) hypointense on FLAIR images without hyperintense rim to distinguish them from old lacunar infarcts ${ }^{12}$. The quantity of EPVS were rated as follows: category $1=<10$ EPVS, category $2=10-25$ EPVS and category $3=>25$ EPVS $^{4}$. Only the most affected hemisphere was rated on one slice only ${ }^{2,7}$. In case of disagreement, lesions were ascertained by consensus. WMLs were graded according to the Fazekas scale ${ }^{13}$. We defined extensive WMLs as: periventricular WMLs score 3 (irregular lesions extending into the deep white matter) or deep WMLs with a score of 2 (beginning confluence of lesions) or 3 (large confluent areas). Ratings of EPVS and WMLs showed a weighted $\kappa$ of 0.6 or above.

\section{Neuropsychological assessment}

Cognitive function was assessed by 1 trained neuropsychologist $(\mathrm{MH})$ during a 2 hour session. The test battery included the Rey Auditory Verbal Learning Test (RAVLT) ${ }^{14}$, Stroop Colour Word Test (SCWT) $)^{15}$, Trailmaking Test A and B (TMT) ${ }^{16}$, category and letter fluency ${ }^{17,18}$, and the following subtests of the Wechsler Adult Intelligence Scale III (WAIS III) ${ }^{19}$, Symbol Substitution, Digit span and Letter Number Sequencing. For the SCWT and TMT, interference scores were computed. Interference score SCWT= time on card 3 - Mean (card $1+$ card 2). Interference score TMT= time card B - time card A.

We compared performances on different cognitive domains by using $\mathrm{Z}$ standard scores (based on the cohort scores). For each domain we computed compound scores. Memory domain= (Z/RAVLT immediate recall + Z/RAVLT delayed recall + Z/RAVLT word recognition + Z/ digit span forward $) / 4$; Executive functions domain $=(\mathrm{Z} / \mathrm{SCWT}$ interference $+\mathrm{Z} / \mathrm{TMT}$ interference $+\mathrm{Z} /$ category fluency $+\mathrm{Z} /$ letter fluency $+\mathrm{Z} /$ digit span backward $+\mathrm{Z} /$ letter number sequencing $) / 6$; Information processing speed $=(Z /$ symbol substitution $+\mathrm{Z} / \mathrm{TMT} \mathrm{A}+\mathrm{Z} /$ mean of Stroop card 1 and 2)/3. A compound score for overall cognitive function was calculated as the mean score of the three compound scores. Z-scores of tests with higher scores representing worse performance were inverted before computing the compound scores. Compound 
scores for memory, executive function, information processing speed and overall cognition were missing for 5, 5, 1 and 9 patients respectively. Therefore, analyses on these variables were performed with a different number of subjects.

\section{Statistical analysis}

In the unadjusted analysis, we compared cognitive compound scores (memory, information processing speed, executive function and overall cognition) between the different levels of EPVS quantifications, using bivariate correlation analyses. All analyses were done using the non-parametric Spearman's Rho due to the ordinal nature of the EPVS quantification. In order to adjust for known and possible confounders, such as severe periventricular or deep WMLs, age, sex and the presence of a symptomatic lacunar stroke, we performed separate linear regression analyses with the confounding factor as independent and cognitive domain as dependent variable. Residuals were saved and then used in the non-parametric correlation analyses. Besides putting all variables in one model, we also performed separate analyses for each confounding factor to assess the effect of each confounding factor on the relationship under study.

All analyses were performed using PASW 18.0 (Statistical Package for the Social Sciences; Chicago, IL, USA).

\section{Results}

In total, 189 patients (112 hypertensive patients and 77 lacunar stroke patients) were included and 217 (86 hypertensive patients and 131 lacunar stroke patients) excluded. Excluded patients were older than those who were included ( $66.4 \pm 15.0$ vs $59.9 \pm 12.7$ years, $p<.001)$, but did not differ regarding sex $(p=.095)$.

Table 1. Characteristics of lacunar stroke and hypertensive patients

\begin{tabular}{llll}
\hline \hline & All $(n=189)$ & $\begin{array}{l}\text { Lacunar stroke } \\
\text { patients }(n=77)\end{array}$ & $\begin{array}{l}\text { Hypertensive } \\
\text { patients }(n=112)\end{array}$ \\
\hline \hline Age, mean years (SD) & $63.1(14.3)$ & $65.0(12.0)$ & $56.5(12.1)$ \\
Male sex & $108(57.1)$ & $43(55.8)$ & $65(58.0)$ \\
Hypertension & $159(84.1)$ & $47(61.0)$ & $112(100.0)$ \\
Diabetes & $9(4.7)$ & $7(9.1)$ & $2(1.8)$ \\
Hypercholesterolemia & $95(51.6)$ & $53(69.7)$ & $42(38.9)$ \\
Current smoking & $40(21.3)$ & $24(31.2)$ & $16(14.4)$ \\
Extensive WMLs* & & $18(23.4)$ & $13(11.6)$ \\
- Periventricular & $31(16.4)$ & $19(24.7)$ & $8(7.1)$ \\
- Deep & $27(14.3)$ & & \\
EPVS in BG & & $37(48.1)$ & $93(83.0)$ \\
- Category 1 & $130(68.8)$ & $23(29.9)$ & $15(13.4)$ \\
- Category 2 & $38(20.1)$ & $17(22.1)$ & $4(3.6)$ \\
- Category 3 & $21(11.1)$ & &
\end{tabular}


EPVS in CSO

$\begin{array}{llll}\text { - Category } 1 & 88(46.6) & 39(50.6) & 49(43.8) \\ \text { - Category } 2 & 72(38.1) & 23(29.9) & 49(43.8) \\ \text { - category 3 } & 29(15.3) & 15(19.5) & 14(12.5)\end{array}$

Data are shown in frequencies (\%), except where reported otherwise. * According to Fazekas scale. WMLs= white matter lesions; $\mathrm{EPVS}=$ enlarged perivascular spaces; $\mathrm{BG}=$ basal ganglia; $\mathrm{CSO}=$ centrum semiovale

Reasons for exclusion were: not interested $(\mathrm{N}=102)$, atrial fibrillation $(\mathrm{N}=35)$, recurrent cerebrovascular accident or transient ischemic attack before inclusion $(\mathrm{N}=2$; for lacunar stroke patients only), cerebrovascular accident or transient ischemic attack between baseline and follow-up ( $\mathrm{N}=7$; for hypertensive patients only), pre-existent cognitive problems $(\mathrm{N}=7)$, carotid stenosis $(\mathrm{N}=7)$, exclusion criteria for MRI $(\mathrm{N}=6)$, death $(\mathrm{N}=4)$, or other reasons $(\mathrm{N}=47)$. Patient characteristics of both the included lacunar stroke and hypertensive patients are shown in table 1. Patient characteristics per EPVS category are shown in table 2.

\section{EPVS scores and white matter lesions}

EPVS in the basal ganglia were correlated with the presence of extensive WMLs, both periventricular $(\mathrm{Rho}=.404, p<.001)$ and deep WMLs $(\mathrm{Rho}=.411, p<.001)$. EPVS in the centrum semiovale were not correlated with extensive deep or periventricular WMLs.

Table 2. Characteristics by EPVS categories

\begin{tabular}{lllllll}
\hline & \multicolumn{5}{l}{ EPVS in BG } & \multicolumn{3}{l}{ EPVS in CSO } \\
\cline { 2 - 6 } & $<10$ & $10-25$ & $>25$ & $<10$ & $10-25$ & $>25$ \\
\hline Age, mean years (SD) & $56.0(11.8)$ & $66.4(9.8)$ & $72.1(10.4)$ & $57.8(13.9)$ & $60.5(11.8)$ & $65.1(9.4)$ \\
Male sex & $74(56.9)$ & $20(52.6)$ & $14(66.7)$ & $51(58.0)$ & $42(58.3)$ & $15(51.7)$ \\
Hypertension & $117(90.0)$ & $28(73.7)$ & $15(71.4)$ & $72(81.8)$ & $64(88.9)$ & $24(82.8)$ \\
Diabetes & $7(5.4)$ & $4(10.5)$ & $0(0.0)$ & $4(4.5)$ & $5(6.9)$ & $2(6.9)$ \\
Hypercholesterolemia & $57(45.2)$ & $25(67.6)$ & $13(61.9)$ & $42(49.4)$ & $37(52.1)$ & $16(57.1)$ \\
Current smoking & $26(20.2)$ & $10(26.3)$ & $4(19.0)$ & $15(17.0)$ & $16(22.5)$ & $9(31.0)$ \\
Extensive WMLs & & & & & & $6(20.7)$ \\
- Periventricular & $9(6.9)$ & $11(28.9)$ & $11(52.4)$ & $16(18.2)$ & $9(12.5)$ & $6(11.1)$ \\
- Deep & $7(5.4)$ & $9(23.7)$ & $11(52.4)$ & $14(15.9)$ & $5(17.2)$ \\
\hline \hline
\end{tabular}

Data are shown in frequencies (\%), except where reported otherwise. EPVS= enlarged perivascular spaces; $\mathrm{BG}=$ basal ganglia; $\mathrm{CSO}=$ centrum semiovale; $\mathrm{SD}=$ standard deviation; $\mathrm{WMLs}=$ white matter lesions

\section{EPVS scores and cognitive function}

Overall, mean Z-scores of all cognitive domains decreased with higher numbers of EPVS in the basal ganglia (figure 1). Bivariate correlation analyses revealed significant negative correlations between EPVS in the basal ganglia and all cognitive domains (all $p<.001$ ) (table 3 ). Regarding EPVS in the centrum semiovale, a significant negative correlation with memory was found ( $p=.016)$, but not with the other cognitive domains (table 4). 
Table 3. Correlation coefficients of EPVS in the basal ganglia and cognitive function

\begin{tabular}{|c|c|c|c|c|}
\hline & Memory & Executive function & $\begin{array}{l}\text { Information pro- } \\
\text { cessing speed }\end{array}$ & Overall cognition \\
\hline Model 1 & $-.280 \%$ & $-.277 \ddagger$ & $-.402 \ddagger$ & $-.363 t$ \\
\hline Model 2 & $-.206 \dagger$ & $-.185^{*}$ & $-.278 \ddagger$ & $-.264 \%$ \\
\hline Model 3 & $-.172 *$ & -.143 & $-.246 \$$ & $-.209 \dagger$ \\
\hline Model 4 & -.063 & -.086 & $-.146^{*}$ & -.136 \\
\hline Model 5 & $-.285+$ & $-.280 \ddagger$ & $-.402 \ddagger$ & $-.361 \%$ \\
\hline Model 6 & $-.159 *$ & $-.151 *$ & $-.232 t$ & $-.214 \dagger$ \\
\hline Model 7 & .009 & .020 & -.027 & -.006 \\
\hline \multicolumn{5}{|c|}{$\begin{array}{l}\text { Numbers are presented as correlation coefficients. Model 1: bivariate correlation analyses. Model 2: Correlation } \\
\text { analyses with adjustment for periventricular white matter lesions. Model 3: Correlation analyses with adjustment } \\
\text { for deep white matter lesions. Mode1 4: Correlation analyses with adjustment for age. Model 5: Correlation analy- } \\
\text { ses with adjustment for sex. Model 6: Correlation analyses with adjustment for group (hypertension or lacunar } \\
\text { stroke patients). Model 7: Correlation analyses with adjustment for all of the above. EPVS= enlarged perivascular } \\
\text { spaces. } \\
* \mathrm{p} \leq .05 \\
\dagger \mathrm{p} \leq .01 \\
+\mathrm{p} \leq .001\end{array}$} \\
\hline
\end{tabular}

Table 4. Correlation of EPVS in the centrum semiovale and cognitive function

\begin{tabular}{lllll}
\hline \hline & Memory & Executive function & $\begin{array}{l}\text { Information pro- } \\
\text { cessing speed }\end{array}$ & Overall cognition \\
\hline Model 1 & $-.177^{*}$ & -.039 & -.125 & -.086 \\
Model 2 & $-.183^{*}$ & -.055 & $-.147^{*}$ & -.106 \\
Model 3 & $-.198 \dagger$ & -.073 & $-.169^{*}$ & -.141 \\
Model 4 & -.107 & .035 & -.032 & .003 \\
Model 5 & $-.189 \dagger$ & -.031 & -.122 & -.084 \\
Model 6 & $-.207 \dagger$ & -.077 & $-.157^{*}$ & -.140 \\
Model 7 & $-.159^{*}$ & -.015 & -.096 & -.087 \\
\hline
\end{tabular}

Numbers are presented as correlation coefficients. Model 1: bivariate correlation analyses. Model 2: Correlation analyses with adjustment for periventricular white matter lesions. Model 3: Correlation analyses with adjustment for deep white matter lesions. Model 4: Correlation analyses with adjustment for age. Model 5: Correlation analyses with adjustment for sex. Model 6: Correlation analyses with adjustment for group (hypertension or lacunar stroke patients). Model 7: Correlation analyses with adjustment for all of the above. EPVS= enlarged perivascular spaces.

$* \mathrm{p} \leq .05$

$\dagger \mathrm{p} \leq .01$

$\ddagger \mathrm{p} \leq .001$

Correction for WMLs - In the basal ganglia, correlation analyses adjusted for periventricular WMLs revealed a significant negative correlation with all cognitive domains. When we corrected for deep WMLs, results also remained significant for all cognitive domains, except executive function. In the centrum semiovale, significant correlations were found for EPVS 
and memory and information processing speed, when corrected for periventricular or deep WMLs.

Figure 1. Enlarged perivascular spaces at the basal ganglia and centrum semiovale level and its relation to cognitive domains
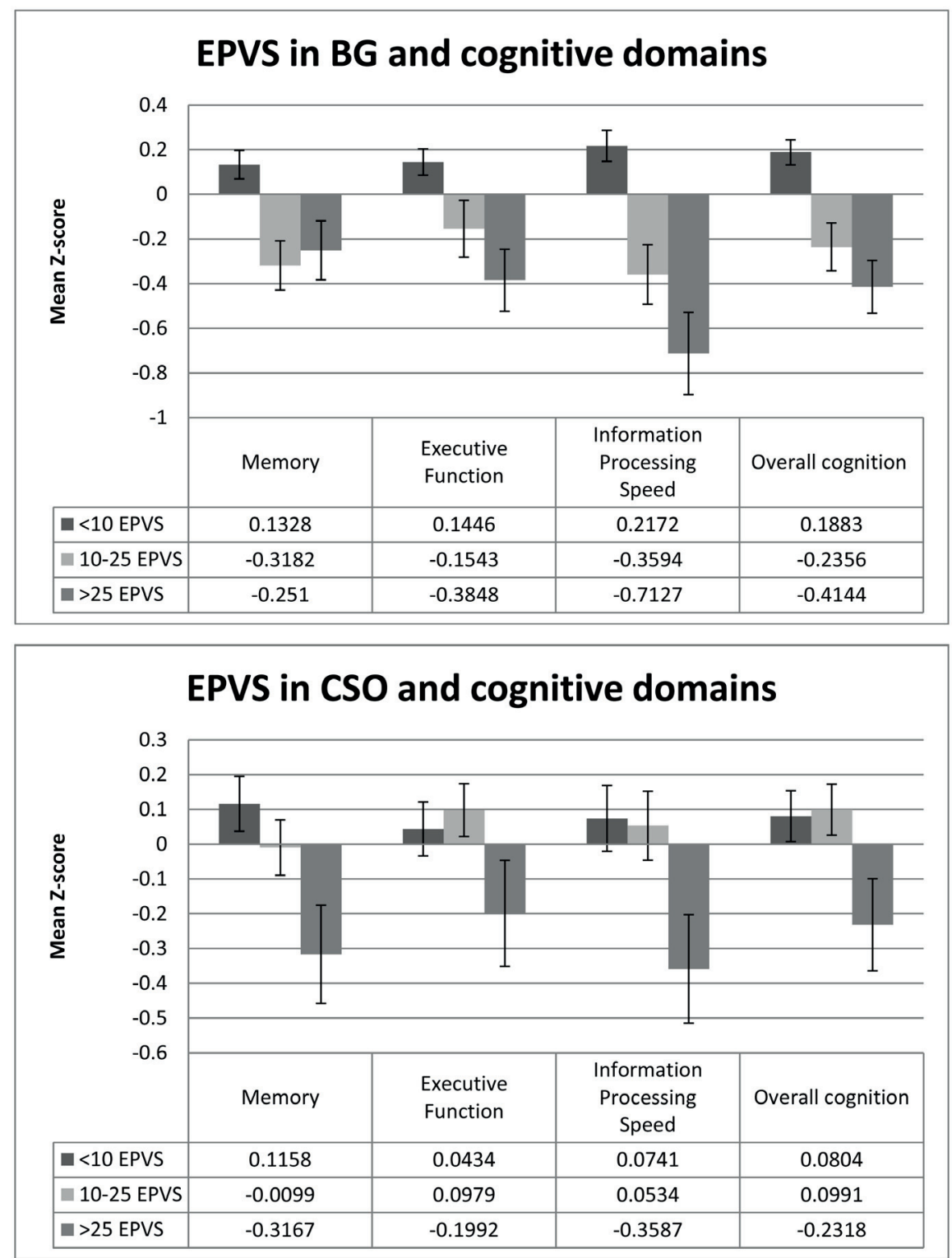

Bars represent the mean Z-score on each of the cognitive domains. Error bars represent the standard error of the mean. $\mathrm{EPVS}=$ enlarged perivascular spaces; $\mathrm{BG}=$ basal ganglia; $\mathrm{CSO}=$ centrum semiovale 
Correction for age - In correlation analyses with adjustment for age, information processing was the only variable to remain significantly associated with EPVS in the basal ganglia, although overall cognition was also borderline significant $(p=.069)$. No significant correlations were found for EPVS in the centrum semiovale. Correction for sex - After adjustment for sex, significant correlations were found with EPVS in the basal ganglia and all cognitive domains (all $p<.001)$. Significant correlations were found for EPVS in the centrum semiovale with memory.

Correction for lacunar stroke - Finally, we adjusted for the presence of a symptomatic lacunar stroke. Correlations between EPVS in the basal ganglia remained significant for all cognitive domains. A significant correlation was found for EPVS in the centrum semiovale and memory and information processing speed.

\section{Discussion}

We demonstrated that higher numbers of basal ganglia EPVS were associated with a decrease in all domains of cognitive function. Results remained significant after correction for WMLs (except for executive function after correction for deep WMLs). However, after correction for age, only information processing speed remained significantly correlated with basal ganglia EPVS. EPVS in the centrum semiovale were associated with memory, independent of WMLs, but results lost significance after correction for age.

We weren't able to fully replicate the findings by MacLullich et $\mathrm{al}^{7}$, who found that higher numbers of EPVS were related to overall decreased cognitive function, while we only found a relation with information processing speed after correction for age. Their relationship was however not independent of WMLs, contrary to our findings in which we found an independent effect. Although the results by MacLullich et al are the only ones to compare our study to, patient populations are rather different and therefore hard to compare. The study sample by MacLullich consisted of healthy elderly men with a small age range (65-70 years) and limited white matter disease. The authors suggested that an independent association may be found for larger populations with more severe EPVS, WMLs and more cognitive dysfunction. By including hypertensive as well lacunar stroke patients, both patient groups with a high prevalence of cSVD, we thought to fulfill this criterion suggested by MacLullich et al.

The independent association of EPVS in the basal ganglia with information processing speed is in line with the current literature on cSVD and cognitive function, in which specifically subcortical functions such as information processing speed and executive function appear to be affected ${ }^{20}$. We also found an association between memory function and EPVS in both the basal ganglia and the centrum semiovale with memory function, although not independent of age. Although memory function is not specifically affected by cSVD, this is in line with results by Chen et $\mathrm{al}^{8}$ who found an increased frequency of EPVS in patients with Alzheimer's Disease. Although they did not separately present their results for different brain regions, EPVS in the centrum semiovale were most prevalent.

We mainly found associations of cognitive function with EPVS in the basal ganglia. In the 
current literature, it appears that EPVS in the basal ganglia, and not in the white matter of the centrum semiovale, are specifically related to WMLs and $\mathrm{CSVD}^{2,3}$. In our study the relation between EPVS and WMLs was also strongest for EPVS in the basal ganglia. All together this might suggest that not EPVS in general, but specifically the EPVS in the basal ganglia are associated with cSVD-related reductions of cognitive function.

The strength of this study is the substantial amount of cSVD patients with good neuropsychological assessment. One of the limitations of our study is that we included hypertensive as well as lacunar stroke patients, which makes our population heterogeneous. However, both populations are at risk for cSVD and we assume that the consequences of EPVS for cognition are similar, regardless of the underlying stage of cSVD. Furthermore, the correlation between EPVS and cognitive function remained significant after correction for a symptomatic lacunar stroke, justifying the use of these two populations as one sample. Another limitation is the absence of atrophy measures. Total EPVS score was found to increase with increasing atrophy severity in cognitively normal patients, but not in patients with mild cognitive impairment or Alzheimer's Disease ${ }^{8}$.

In conclusion, we demonstrated that an increase in basal ganglia EPVS was associated with a decrease in information processing speed, independent of age and WMLs. This not only emphasizes that specifically EPVS in the basal ganglia are associated with cSVD, but also with cSVD-related decreases in cognitive performance. 


\section{References}

1. Braffman BH, Zimmerman RA, Trojanowski JQ, Gonatas NK, Hickey WF, Schlaepfer WW. Brain MR: pathologic correlation with gross and histopathology. 1. Lacunar infarction and Virchow-Robin spaces. AJR Am J Roentgenol. 1988;151:551-558

2. Doubal FN, MacLullich AM, Ferguson KJ, Dennis MS, Wardlaw JM. Enlarged perivascular spaces on MRI are a feature of cerebral small vessel disease. Stroke. 2010;41:450-454

3. Rouhl RP, van Oostenbrugge RJ, Knottnerus IL, Staals JE, Lodder J. Virchow-Robin spaces relate to cerebral small vessel disease severity. J Neurol. 2008;255:692-696

4. Klarenbeek P, van Oostenbrugge RJ, Lodder J, Rouhl RP, Knottnerus IL, Staals J. Higher ambulatory blood pressure relates to enlarged Virchow-Robin spaces in first-ever lacunar stroke patients. J Neurol. 2013;260:115-121

5. Heier LA, Bauer CJ, Schwartz L, Zimmerman RD, Morgello S, Deck MD. Large Virchow-Robin spaces: MR-clinical correlation. AJNR Am J Neuroradiol. 1989;10:929-936

6. Mathias J, Koessler L, Brissart H, Foscolo S, Schmitt E, Bracard S, et al. Giant cystic widening of Virchow-Robin spaces: an anatomofunctional study. AJNR Am J Neuroradiol. 2007;28:1523-1525

7. Maclullich AM, Wardlaw JM, Ferguson KJ, Starr JM, Seck1 JR, Deary IJ. Enlarged perivascular spaces are associated with cognitive function in healthy elderly men. J Neurol Neurosurg Psychiatry. 2004;75:1519-1523

8. Chen W, Song X, Zhang Y. Assessment of the Virchow-Robin Spaces in Alzheimer disease, mild cognitive impairment, and normal aging, using high-field MR imaging. AJNR Am J Neuroradiol. 2011;32:1490-1495

9. Zhu YC, Dufouil C, Soumare A, Mazoyer B, Chabriat H, Tzourio C. High degree of dilated VirchowRobin spaces on MRI is associated with increased risk of dementia. J Alzheimers Dis. 2010;22:663-672

10. Henskens LH, Kroon AA, van Oostenbrugge RJ, Gronenschild EH, Hofman PA, Lodder J, et al. Associations of ambulatory blood pressure levels with white matter hyperintensity volumes in hypertensive patients. J Hypertens. 2009;27:1446-1452

11. de Jong G, Kessels F, Lodder J. Two types of lacunar infarcts: further arguments from a study on prognosis. Stroke. 2002;33:2072-2076

12. Bokura H, Kobayashi S, Yamaguchi S. Distinguishing silent lacunar infarction from enlarged VirchowRobin spaces: a magnetic resonance imaging and pathological study. J Neurol. 1998;245:116-122

13. Fazekas F, Chawluk JB, Alavi A, Hurtig HI, Zimmerman RA. MR signal abnormalities at $1.5 \mathrm{~T}$ in Alzheimer's dementia and normal aging. AJR Am J Roentgenol. 1987;149:351-356

14. Brand N, Jolles J. Learning and retrieval rate of words presented auditorily and visually. J Gen Psychol. 1985;112:201-210

15. Golden CJ. Stroop Colour and Word Test. Chicago (Ill): Stoelling; 1978.

16. Reitan R. Trail Making Test: Manual for administration, scoring and interpretation. Bloomington: Indiana University; 1956.

17. Luteyn F. Een nieuwe verkorte GIT. Dutch J Psychol. 1966;2:675-682

18. Lezak M, Howieson, DB, \& Loring, DW. Neuropsychological assessment New York: Oxford University Press; 2004.

19. Wechsler D. WAIS III, nederlandstalige bewerking: technische handleiding. Lisse: Swets Test Publishers; 2001.

20. Prins ND, van Dijk EJ, den Heijer T, Vermeer SE, Jolles J, Koudstaal PJ, et al. Cerebral small-vessel disease and decline in information processing speed, executive function and memory. Brain. 2005;128:2034-2041 
122 
Chapter 


\begin{abstract}
Background - White matter lesions (WMLs), asymptomatic lacunar infarcts, brain microbleeds (BMBs) and enlarged perivascular spaces (EPVS) have been identified as silent lesions due to cerebral small vessel disease (cSVD). All these markers have been individually linked to cognitive functioning, but are also strongly correlated with each other. The combined effect of these markers on cognitive function has never been studied and would possibly provide more useful information on the effect on cognitive function.

Methods - Brain MRI and extensive neuropsychological assessment were performed in 189 patients at risk for cSVD (112 hypertensive patients and 77 first-ever lacunar stroke patients). We rated the presence of any asymptomatic lacunar infarct, extensive WMLs, any deep BMB, and moderate to extensive EPVS in the basal ganglia. The presence of each marker was summed to an ordinal score between 0 and 4 . Associations with domains of cognitive function (memory, executive function, information processing speed and overall cognition) were analyzed with correlation analyses.

Results - Correlation analyses revealed significant associations between accumulating cSVD burden and decreased performance on all cognitive domains (all $p \leq .001$ ). Results remained significant for information processing speed $(\mathrm{r}=-181, p=.013)$ and overall cognition $(\mathrm{r}=-.178, p=.017)$, after correction for age and sex. Testing of trend using linear regression analyses revealed the same results.

Discussion - We tested a new approach to capture total brain damage resulting from cSVD and found that accumulation of MRI burden of CSVD is associated with decreased performance on tests of information processing speed and overall cognition, implying that accumulating brain damage is accompanied by worse cognitive functioning.
\end{abstract}

\title{
Chapter 10
}

\section{Accumulation of MRI markers of cerebral small vessel disease is associated with decreased cogni- tive function. A study first-ever lacunar stroke and hypertensive patients}

\author{
Marjolein Huijts, Annelien Duits, Robert van Oostenbrugge, Bram Kroon, \\ Peter de Leeuw, Julie Staals
}

Published as: Frontiers in Aging Neuroscience 2013; 5: 72 


\section{Introduction}

Cerebral small vessel disease (cSVD) is a disorder affecting the small perforating vessels in the brain ${ }^{1}$. This may result in clinically overt lacunar stroke syndromes, but also in clinically "silent" manifestations as white matter lesions (WMLs), asymptomatic lacunar infarcts, brain microbleeds (BMBs) and enlarged perivascular spaces (EPVS) ${ }^{1-4}$.

Lesions due to CSVD are thought to disrupt frontal-subcortical circuits ${ }^{5}$ and consequently impair cognitive functioning. The abovementioned four markers of cSVD have all been individually linked to cognitive dysfunctioning ${ }^{6-9}$. However, these MRI markers of brain damage do not occur separately, and studies investigating the effect of the combined and accumulating presence of these individual markers on cognition are lacking. Recently, Wardlaw et al ${ }^{10}$ suggested to search for methods to assess the total CSVD load on imaging in order to avoid over-reliance on one feature only.

Some studies focused on the combination of lacunar infarcts and WMLs ${ }^{11,12}$. Baune et $\mathrm{al}^{11}$ found a combined occurrence of lacunar infarcts and WMLs in $10 \%$ of the population and a significant difference between those patients with only one lesion type and patients affected by both on information processing speed and memory. The authors suggested that the combined occurrence was associated with stronger reductions in cognitive function than each of the two lesion types alone. Additionally, Jokinen et al ${ }^{12}$ recently found that the relationship between progression of WMLs and new lacunes with cognitive decline was additive, but not synergistic.

No data are available on the clinical consequences of the total burden of 'silent' cSVD on brain MRI, expressed by the co-occurrence of all four different markers of cSVD. The aim of this study therefore was to try a new method to capture the total brain damage caused by cSVD and investigate whether an accumulation of MRI markers of cSVD was associated with a decreased performance on cognitive function. We investigated this in patients at risk for silent cSVD, most probably due to hypertension-related occlusive arteriolosclerosis: patients with lacunar (small vessel) stroke and essential hypertensive patients.

\section{Methods \\ Participants}

Patients included in this study participated in two larger studies; the hypertensive patients in a longitudinal study on brain damage in hypertension (HYBRiD) ${ }^{13}$, whereas the lacunar stroke patients participated in a study on cognitive function after lacunar stroke.

Hypertensive patients were referred to our hypertension outpatient clinic of the Department of Internal Medicine of the Maastricht University Medical Centre. Of 218 patients included, 112 patients completed a brain MRI and extensive neuropsychological assessment for this cross-sectional study. Exclusion criteria at baseline were a history of symptomatic cardio- or cerebrovascular disease or contraindications for MRI.

Of 208 first-ever lacunar stroke patients presenting at the Neurology Department of the Maastricht University Medical Centre between February 2009 and July 2012, we consecutively included 77 patients. Lacunar stroke was defined as an acute stroke syndrome with a 
small $(<20 \mathrm{~mm})$ ischemic lesion on acute brain MR in the brain stem, basal ganglia or internal capsule, compatible with the occlusion of a single perforating small artery. If no such lesion was visible, we used established clinical criteria for lacunar stroke ${ }^{14}$. Patients with severe comorbidity, either neurological or psychiatric, were excluded. Furthermore, patients without MRI or with possible other causes than cSVD (cardiac embolic source, cerebral large vessel disease, or carotid stenosis), were also excluded. Patients underwent neuropsychological assessment at 3 months after stroke to exclude acute phase effects.

The presence of vascular risk factors was recorded for all patients: hypertension, diabetes mellitus, hypercholesterolemia and smoking. Data of vascular risk factors was missing for 4 hypertensive patients.

Both studies were approved by the Medical Ethics Committee of the Maastricht University Medical Centre and all participants gave written informed consent.

\section{Brain magnetic resonance imaging}

MRI of the brain (1.5 or 3T) was performed to obtain axial T2-weighted, fluid-attenuated inversion recovery (FLAIR) and T2*-weighted gradient echo images. Images were independently rated by two vascular neurologists ( JS and $\mathrm{RvO}$ ) for the presence of asymptomatic lacunar infarcts, WMLs, BMBs and EPVS for the first 137 patients. Kappas appeared to be satisfactory and the remaining images were rated by one vascular neurologist only. In case of disagreement or doubt, lesions were ascertained by consensus. Kappa's for the presence of asymptomatic lacunar infarcts and deep BMBs were 0.62 and 0.63 respectively. Weighted kappa's for dWMLs and EPVS in the basal ganglia were 0.77 and 0.69 respectively.

\section{Total burden of cSVD}

We created an ordinal scale representing the total burden of cSVD, expressed by the co-occurrence of the different MRI markers. The presence of each of the four MRI markers for cSVD mentioned above (asymptomatic lacunar infarcts, WMLs, BMBs and EPVS), was awarded with one point, resulting in a minimum of 0 and a maximum of 4 .

Asymptomatic lacunar infarcts - We identified asymptomatic lacunar infarcts as sharply demarcated hyperintense lesions $<20 \mathrm{~mm}$ on T2-weighted images with corresponding hypointense lesions with a hyperintense rim on FLAIR. In lacunar stroke patients, the lesion could not be compatible with the clinical stroke. One point was awarded when one or more asymptomatic lacunar infarcts were present.

White matter lesions - WMLs were graded according to Fazekas' scale ${ }^{15}$. One point was awarded in case of periventricular white matter lesions Fazekas score 3 (irregular hyperintensities extending into the deep white matter), and/or in case of deep white matter lesions Fazekas score 2 or 3 (confluent white matter hyperintensities). We used the Fazekas scores because they are histopathologically related to $\mathrm{CSVD}^{16}$.

Brain microbleeds - BMBs were defined as punctate $(<10 \mathrm{~mm})$ homogeneous foci of low signal intensity on $\mathrm{T} 2 *$-weighted images. Symmetrical hypointensities in the globi pallidi were disregarded, since these most likely represent calcification. Since it was suggested that 
specifically deep BMBs (defined as basal ganglia, thalamus, and internal, external and extreme capsule) are related to $\mathrm{CSVD}^{17}$, one point was awarded only in case of the presence of one or more deep BMBs.

Enlarged perivascular spaces - EPVS were defined as round, oval or linear shaped lesions with a smooth margin, absence of mass effect and with signal intensity equal to cerebrospinal fluid on T2-weighted images and (if visible) hypointense on FLAIR images without hyperintense rim to distinguish them from old lacunar infarcts ${ }^{18}$. Since EPVS at the level of the basal ganglia are specifically related to $\mathrm{cSVD}^{3}, \mathrm{EPVS}$ at this level were scored, on one slice and at one side in the most affected hemisphere only. The quantity of EPVS were rated as follows: category $1=<10$ EPVS, category $2=10-25$ EPVS and category $3=>25$ EPVS. One point was awarded in case of moderate (category 2 ) to extensive (category 3 ) EPVS.

\section{Assessment of cognitive function}

Cognitive function was assessed by 1 trained neuropsychologist (MH) during a 2 hour session. The test battery included the Rey Auditory Verbal Learning Test (RAVLT) ${ }^{19}$, Stroop Colour Word Test (SCWT) $)^{20}$, Trailmaking Test A and B (TMT) ${ }^{21}$, category and letter fluency $^{22,23}$, and the following subtests of the Wechsler Adult Intelligence Scale III (WAIS III) ${ }^{24}$, Symbol Substitution, Digit span and Letter Number Sequencing. For the SCWT and TMT, interference scores were computed. Interference score SCWT= time on card 3 - Mean (card $1+$ card 2). Interference score TMT= time card B - time card A.

We compared performances on different cognitive domains by using $\mathrm{Z}$ standard scores. A Z-score was calculated for each test score separately. For each domain we computed compound scores. Memory domain $=(Z /$ RAVLT immediate recall $+Z /$ RAVLT delayed recall + Z/RAVLT word recognition + Z/digit span forward $) / 4$; Executive functions domain $=(Z /$ $\mathrm{SCWT}$ interference $+\mathrm{Z} / \mathrm{TMT}$ interference $+\mathrm{Z} /$ category fluency $+\mathrm{Z} /$ letter fluency $+\mathrm{Z} /$ digit span backward $+Z /$ letter number sequencing $) / 6$; Information processing speed $=(Z /$ symbol substitution + Z/TMT A + Z/mean of Stroop card 1 and 2)/3. A compound score for overall cognitive function was calculated as the mean score of the three compound scores. Z-scores of tests with higher scores representing worse performance were inverted before computing the compound scores. Compound scores for memory, executive function, information processing speed and overall cognition were missing for 5, 5, 1 and 9 patients respectively. Therefore, analyses on these variables were performed with a different number of subjects.

\section{Statistical analysis}

In the unadjusted analysis, we associated cognitive compound scores (memory, information processing speed, executive function and overall cognition) with the levels of the total burden of cSVD, using bivariate correlation analyses. All analyses were done using the non-parametric spearman's Rho due to the ordinal nature of the total cSVD burden quantification. In order to adjust for possible confounders, such as age and sex, we performed linear regression analyses with the confounding factors as independent and the cognitive domain as dependent variable. Residuals were saved and used in the non-parametric correlation analyses. 
For testing of trend, the ordinal scale expressing the total burden of cSVD was considered as a continuous variable in a linear regression model with cognition as dependent variable, with adjustments for age and sex.

All analyses were performed using IBM SPSS statistics 18.0.

\section{Results}

In total, 189 patients (112 hypertensive patients and 77 lacunar stroke patients) were included and 217 (86 hypertensive patients and 131 lacunar stroke patients) excluded. Excluded patients were older than those who were included ( $66.4 \pm 15.0$ vs $59.9 \pm 12.7$ years, $p<.001)$, but did not differ regarding sex $(p=.095)$. Reasons for exclusion were: not interested $(47.0 \%)$, atrial fibrillation (16.1\%), cerebrovascular accident or transient ischemic attack before inclusion (4.1\%; for hypertensive patients only), pre-existent cognitive problems (3.2\%), carotid stenosis (3.2\%), contra-indications for MRI $(2.8 \%)$, death $(1.8 \%)$, or other reasons $(21.7 \%)$. Patient characteristics as well as the distribution of cSVD categories of the included lacunar stroke and hypertensive patients are shown in table 1.

Table 1. Patient characteristics and frequencies of cSVD extent

\begin{tabular}{llll}
\hline \hline & All $(n=189)$ & $\begin{array}{l}\text { Lacunar stroke } \\
\text { patients }(n=77)\end{array}$ & $\begin{array}{l}\text { Hypertensive pa- } \\
\text { tients }(n=112)\end{array}$ \\
\hline Age, mean years (SD) & $63.1(14.3)$ & $65.0(12.0)$ & $56.5(12.1)$ \\
Male sex & $108(57.1)$ & $43(55.8)$ & $65(58.0)$ \\
Hypertension & $159(84.1)$ & $47(61.0)$ & $112(100.0)$ \\
Diabetes & $9(4.7)$ & $7(9.1)$ & $2(1.8)$ \\
Hypercholesterolemia & $95(51.6)$ & $53(69.7)$ & $42(38.9)$ \\
Current smoking & $40(21.3)$ & $24(31.2)$ & $16(14.4)$ \\
cSVD category & & & $68(60.7)$ \\
0 & $91(48.1)$ & $23(29.9)$ & $26(23.2)$ \\
1 & $41(21.7)$ & $15(19.5)$ & $12(10.7)$ \\
2 & $33(17.5)$ & $21(27.3)$ & $6(5.4)$ \\
3 & $19(10.1)$ & $13(16.9)$ & $0(0.0)$ \\
4
\end{tabular}

Data are shown in frequencies (\%), except where reported otherwise.

\section{Total burden of cSVD}

Ninety-one patients $(48.1 \%)$ had none of the silent MRI markers for cSVD, and 5 patients (2.6\%) presented with all 4 markers. For patients with 1,2 or 3 markers, the presence of the cSVD markers within each category is shown in table 2 and the distribution of combinations is shown in figure 1. Age increased significantly with increasing categories (0-4) of total burden of cSVD $(54.4 \pm 12.4 ; 60.6 \pm 9.3 ; 65.5 \pm 11.2 ; 70.6 \pm 9.1 ; 77.8 \pm 6.0$ years respectively, $p<.001)$. Sex was not significantly different across the categories. 
Figure 1. Distribution of (combinations of) cSVD manifestations according to total burden of cSVD
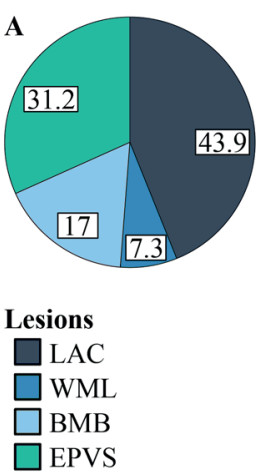

B

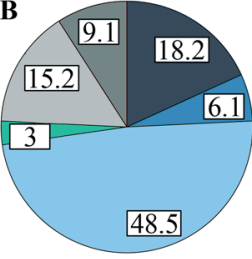

Combinations

$\square \mathrm{LAC}+\mathrm{WML}$

$\square \mathrm{LAC}+\mathrm{BMB}$

$\square \mathrm{LAC}+\mathrm{EPVS}$

$\square \mathrm{WML}+\mathrm{BMB}$

$\square \mathrm{WML}+\mathrm{EPVS}$

$\square \mathrm{BMB}+\mathrm{EPVS}$

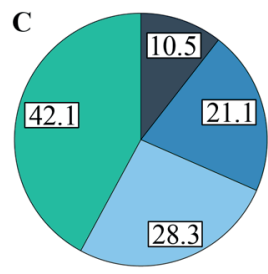

Combinations

$\square \mathrm{LAC}+\mathrm{WML}+$ BMB

$\square \mathrm{WML}+\mathrm{BMB}+$ EPVS

$\square \mathrm{LAC}+\mathrm{BMB}+$ EPVS

$\mathrm{LAC}+\mathrm{WML}+$ EPVS

a) Percentages of each lesion when one lesion is present b) Percentages of the combinations when two lesions are present c) Percentages of the combinations when three lesions are present. LAC $=$ asymptomatic lacunar infarcts; $\mathrm{WML}=$ white matter lesions; $\mathrm{BMB}=$ brain microbleeds; $\mathrm{EPVS}=$ enlarged perivascular spaces

Table 2. Distribution of cSVD manifestations according to total burden of cSVD

\begin{tabular}{llll}
\hline \hline & Category 1 & Category 2 & Category 3 \\
\hline \hline Asymptomatic infarct & $18(43.9)$ & $24(72.7)$ & $15(78.9)$ \\
White matter lesions & $3(7.3)$ & $12(36.4)$ & $14(73.3)$ \\
Brain microbleeds & $7(17.1)$ & $6(18.2)$ & $11(57.9)$ \\
Enlarged perivascular spaces & $13(31.7)$ & $24(72.7)$ & $17(89.5)$ \\
\hline
\end{tabular}

Data are shown in frequencies (\%).

\section{Association with cognitive function}

Figure 2 shows the mean Z-scores on each of the cognitive domains, stratified by cSVD category. Correlation analyses revealed significant negative correlations between cSVD category and all cognitive domains (all $p<.001$ ). When we adjusted for age and sex in the analyses, results remained significant for information processing speed and overall cognition (table 3 ).

Table 3. Correlation analyses between total burden of cSVD and cognitive function

\begin{tabular}{lll}
\hline & Model 1 correlation coefficient & Model 2 correlation coefficient \\
\hline Memory & $-.333 \ddagger$ & -.108 \\
Executive function & $-.312 \ddagger$ & -.129 \\
Information processing speed & $-.438 \ddagger$ & $-.181^{*}$ \\
Overall cognitive function & $-.407 \ddagger$ & $-.178^{*}$ \\
\hline \hline
\end{tabular}

Model 1: bivariate correlation analyses. Model 2: Correlation analyses with adjustment for age and sex.

$* \mathrm{p}<.05$

$\ddagger \mathrm{p}<.001$ 
For the test of trend using linear regression analyses we found significant negative associations between cSVD category and all cognitive domains. When we adjusted for age and sex, results remained significant for information processing speed $(\beta=-.154 ; 95 \% \mathrm{CI}=-.254$ to $-.054, p=.003)$ and overall cognition $(\beta=-.099 ; 95 \% \mathrm{CI}=-.183$ to $-.016, p=.019)$. Results for executive function were borderline significant $(\beta=-.087 ; 95 \% \mathrm{CI}=-.181$ to $.007, p=.070)$. Frequencies for the different combinations within each category were too small in order to compare cognitive function.

Figure 2. Mean Z-scores on each of the cognitive domains, stratified by cSVD category. cSVD = cerebral small vessel disease
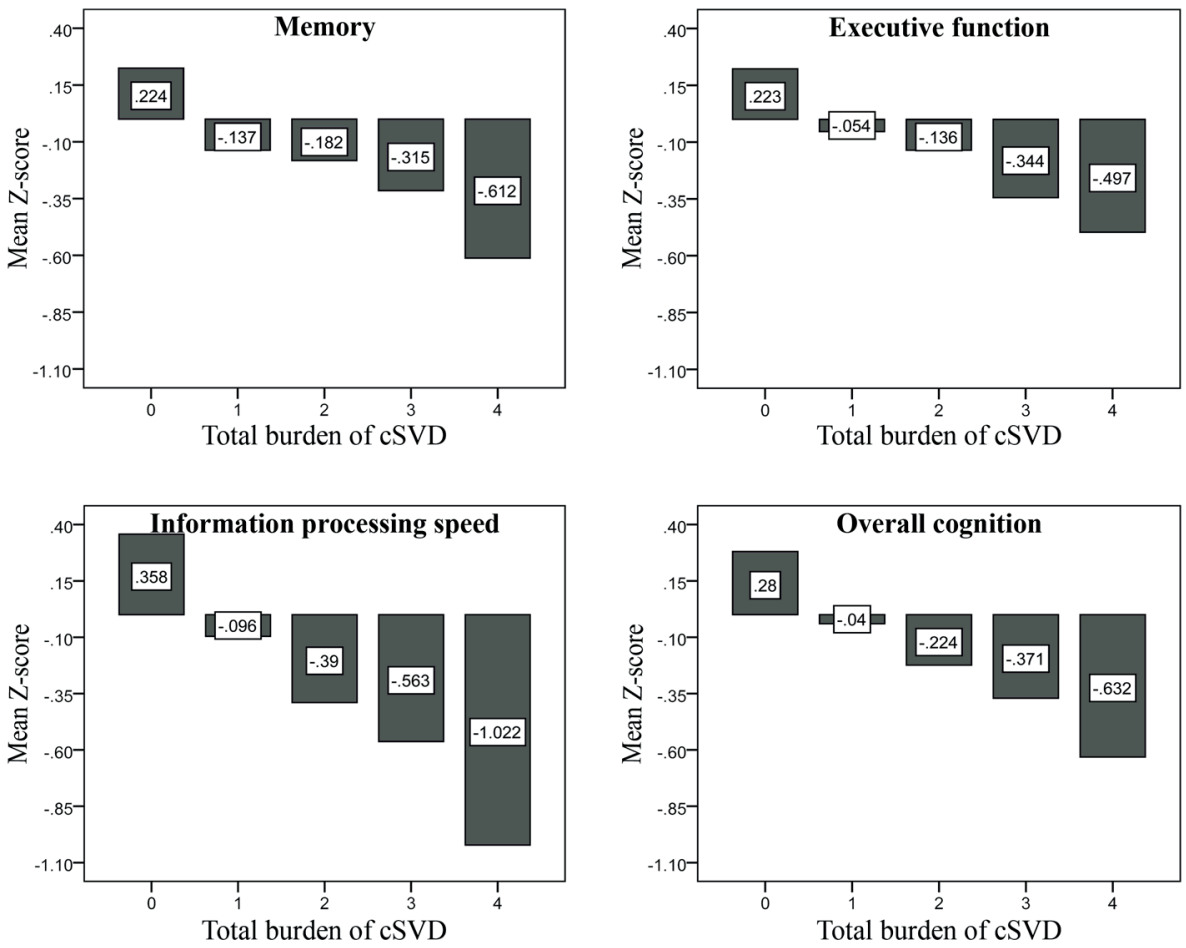

\section{Discussion}

We demonstrated that accumulation of MRI markers of cSVD, expressed by the co-occurrence of these markers, is associated with decreased performance on all cognitive domains. After adjustments for age and sex, results remained significant for information processing speed and overall cognition.

The present literature mainly focused on the effect of single markers of cSVD on cognitive function, but no study has ever investigated the effect of the total burden of cSVD, expressed by all four MRI features that are now recognized as markers of cSVD, on cognitive function 
before. Our results extend the results of Baune et $\mathrm{al}^{11}$ who found that the occurrence of two different MRI features (WMLs and lacunar infarcts) was associated with stronger reductions of cognitive function than the occurrence of one lesion only.

A recent study ${ }^{25}$ proposed a pathology score for extent of cSVD and showed a relation between severity of cSVD pathology and cognitive impairment. From our results, it can be speculated that the co-occurrence of several different lesions represents more severe and extensive cSVD with more subcortical microstructural brain damage, resulting in cognitive dysfunction. However, the cross-sectional nature of our study prevents statements about causality. Longitudinal studies following increase of MRI markers and cognitive decline over time are needed in order to confirm a causal relationship between total burden of cSVD and cognitive function.

We do not know whether one silent MRI marker has more effect on cognition than the other marker. Regarding different combinations of cSVD markers, we were not able to compare cognitive function within each category of cSVD due to low frequencies. When higher numbers of patients can be included in future studies, it would be interesting to study whether one marker has a different effect weight than the other, or whether specific combinations of cSVD markers are associated with decreased cognitive performance more than others.

The major strength of this study is the extensive neuropsychological assessment which made it possible to evaluate cognitive function in several domains. The fact that the domain of information processing speed was most strongly and significantly related to cSVD, is in line with other studies that report information processing speed as one of the most affected cognitive domains in patients with $\mathrm{cSVD}^{26}$.

Limitations of our study are mainly situated in the construction of the cSVD scale. We did not take into account all aspects, like the extent, location or progression of each cSVD marker. Based on previous literature of $\mathrm{cSVD}^{3,17}$, we rated only deep BMBs and basal ganglia EPVS. However, we did not integrate for example the number of asymptomatic lacunar infarcts or number of BMBs, although it was recently found that a higher number of infarcts ${ }^{27}$ or $\mathrm{BMBs}^{28}$ is associated with decreased cognitive performance. We dichotomized each marker which might lead to loss of power and information, and cut-off points may be arbitrary, although chosen with arguments. Nevertheless, according to a recent review by Wardlaw et $\mathrm{al}^{10}$ on neuroimaging aspects of cSVD, approaches that try to capture the total cSVD burden on MRI are needed and we made a first attempt that is now open for further discussion, testing and refinement. Another limitation is the variable MRI field strength that was used in our population. It was found that more BMBs can be detected at $3 \mathrm{~T}$ than at $1.5 \mathrm{~T}^{29}$ and this might have led to overrating in some of our patients. However, analyses with a correction for field strength did not change our results (results not shown). A final but important limitation is the mixed population of lacunar stroke and hypertensive patients, although both groups are at considerable risk of silent cSVD. The symptomatic stroke could have had a negative impact on cognitive function although we feel that the background silent cSVD is a more important determinant of cognitive function ${ }^{30}$. 
In conclusion, we tested a new approach to capture total brain damage resulting from cSVD. We found that accumulation of MRI markers of cSVD is associated with decreased performance on tests of information processing speed and overall cognition, implying that accumulating brain damage is accompanied by worse cognitive functioning. We suggest further longitudinal studies in more homogeneous patient samples, and studies including more patients with higher prevalence of cSVD features in order to refine our cSVD scale and to be able to investigate whether specific combinations of cSVD markers are associated with decreased cognitive performance. 


\section{References}

1. Pantoni L. Cerebral small vessel disease: from pathogenesis and clinical characteristics to therapeutic challenges. Lancet Neurol. 2010;9:689-701

2. Vermeer SE, Longstreth WT, Jr., Koudstaal PJ. Silent brain infarcts: a systematic review. Lancet Neurol. 2007;6:611-619

3. Doubal FN, MacLullich AM, Ferguson KJ, Dennis MS, Wardlaw JM. Enlarged perivascular spaces on MRI are a feature of cerebral small vessel disease. Stroke. 2010;41:450-454

4. Wardlaw JM, Lewis SC, Keir SL, Dennis MS, Shenkin S. Cerebral microbleeds are associated with lacunar stroke defined clinically and radiologically, independently of white matter lesions. Stroke. 2006;37:26332636

5. Schmidtke K, Hull M. Cerebral small vessel disease: how does it progress? J Neurol Sci. 2005;229230:13-20

6. Werring DJ, Frazer DW, Coward LJ, Losseff NA, Watt H, Cipolotti L, et al. Cognitive dysfunction in patients with cerebral microbleeds on T2*-weighted gradient-echo MRI. Brain. 2004;127:2265-2275

7. van den Heuvel DM, ten Dam VH, de Craen AJ, Admiraal-Behloul F, Olofsen H, Bollen EL, et al. Increase in periventricular white matter hyperintensities parallels decline in mental processing speed in a nondemented elderly population. J Neurol Neurosurg Psychiatry. 2006;77:149-153

8. Zhu YC, Dufouil C, Soumare A, Mazoyer B, Chabriat H, Tzourio C. High degree of dilated VirchowRobin spaces on MRI is associated with increased risk of dementia. J Alzheimers Dis. 2010;22:663-672

9. Carey CL, Kramer JH, Josephson SA, Mungas D, Reed BR, Schuff N, et al. Subcortical lacunes are associated with executive dysfunction in cognitively normal elderly. Stroke. 2008;39:397-402

10. Wardlaw JM, Smith C, Dichgans M. Mechanisms of sporadic cerebral small vessel disease: insights from neuroimaging. Lancet Neurol. 2013;12:483-497

11. Baune BT, Roesler A, Knecht S, Berger K. Single and combined effects of cerebral white matter lesions and lacunar infarctions on cognitive function in an elderly population. J Gerontol A Biol Sci Med Sci. 2009;64:118-124

12. Jokinen H, Gouw AA, Madureira S, Ylikoski R, van Straaten EC, van der Flier WM, et al. Incident lacunes influence cognitive decline: the LADIS study. Neurology. 2011;76:1872-1878

13. Henskens LH, Kroon AA, van Oostenbrugge RJ, Gronenschild EH, Hofman PA, Lodder J, et al. Associations of ambulatory blood pressure levels with white matter hyperintensity volumes in hypertensive patients. J Hypertens. 2009;27:1446-1452

14. de Jong G, Kessels F, Lodder J. Two types of lacunar infarcts: further arguments from a study on prognosis. Stroke. 2002;33:2072-2076

15. Fazekas F, Chawluk JB, Alavi A, Hurtig HI, Zimmerman RA. MR signal abnormalities at $1.5 \mathrm{~T}$ in Alzheimer's dementia and normal aging. AJR Am J Roentgenol. 1987;149:351-356

16. Fazekas F, Kleinert R, Offenbacher H, Schmidt R, Kleinert G, Payer F, et al. Pathologic correlates of incidental MRI white matter signal hyperintensities. Neurology. 1993;43:1683-1689

17. Vernooij MW, van der Lugt A, Ikram MA, Wielopolski PA, Niessen WJ, Hofman A, et al. Prevalence and risk factors of cerebral microbleeds: the Rotterdam Scan Study. Neurology. 2008;70:1208-1214

18. Bokura H, Kobayashi S, Yamaguchi S. Distinguishing silent lacunar infarction from enlarged VirchowRobin spaces: a magnetic resonance imaging and pathological study. J Neurol. 1998;245:116-122

19. Brand N, Jolles J. Learning and retrieval rate of words presented auditorily and visually. J Gen Psychol. 1985;112:201-210

20. Golden CJ. Stroop Colour and Word Test. Chicago (Ill): Stoelling; 1978.

21. Reitan R. Trail Making Test: Manual for administration, scoring and interpretation. Bloomington: Indiana University; 1956. 
22. Luteyn F. Een nieuwe verkorte GIT. Dutch J Psychol. 1966;2:675-682

23. Lezak M, Howieson, DB, \& Loring, DW. Neuropsychological assessment New York: Oxford University Press; 2004.

24. Wechsler D. WAIS III, nederlandstalige bewerking: technische handleiding. Lisse: Swets Test Publishers; 2001.

25. Smallwood A, Oulhaj A, Joachim C, Christie S, Sloan C, Smith AD, et al. Cerebral subcortical small vessel disease and its relation to cognition in elderly subjects: a pathological study in the Oxford Project to Investigate Memory and Ageing (OPTIMA) cohort. Neuropathol Appl Neurobiol. 2012;38:337-343

26. Prins ND, van Dijk EJ, den Heijer T, Vermeer SE, Jolles J, Koudstaal PJ, et al. Cerebral small-vessel disease and decline in information processing speed, executive function and memory. Brain. 2005;128:2034-2041 27. Aggarwal NT, Schneider JA, Wilson RS, Beck TL, Evans DA, Carli CD. Characteristics of MR infarcts associated with dementia and cognitive function in the elderly. Neuroepidemiology. 2012;38:41-47

28. Poels MM, Ikram MA, van der Lugt A, Hofman A, Niessen WJ, Krestin GP, et al. Cerebral microbleeds are associated with worse cognitive function: the Rotterdam Scan Study. Neurology. 2012;78:326-333

29. Stehling C, Wersching H, Kloska SP, Kirchhof P, Ring J, Nassenstein I, et al. Detection of asymptomatic cerebral microbleeds: a comparative study at 1.5 and 3.0 T. Acad Radiol. 2008;15:895-900

30. Gottesman RF, Hillis AE. Predictors and assessment of cognitive dysfunction resulting from ischaemic stroke. Lancet Neurol. 2010;9:895-905 
Total burden of CSVD and cognitive function $\mid 135$ 
136 
Chapter 


\section{General discussion and future perspectives}

Cerebral small vessel disease (cSVD) refers to a cluster of pathological mechanisms with varying etiologies that affects the small perforating end-arteries, arterioles, venules and capillaries in the brain ${ }^{1}$. Clinical symptoms of cerebral small vessel disease (cSVD) can be divided in acute symptoms, such as a lacunar stroke syndrome, and subacute symptoms such as cognitive impairment ${ }^{2}$. Hypertension is a major risk factor for $\mathrm{cSVD}^{3}$ and cognitive decline, but the mechanisms underlying hypertension-related cognitive decline are complex and not yet fully understood.

The general aim of this thesis was to explore the association of vascular and brain imaging markers with cognitive function in patients with or at risk for cSVD. Besides the well-known and well-investigated lacunar infarcts and white matter lesions (WMLs) as brain imaging markers of cSVD, brain microbleeds (BMBs) and enlarged perivascular spaces (EPVS) have recently been recognized as markers of $\mathrm{cSVD}^{4,5}$ but their effect on cognitive function in patients with or at risk for cSVD has not been investigated. The effects on cognitive function of certain aspects of vascular function, such as vascular stiffness measured by pulse wave velocity, in cSVD are also largely unknown.

Within the spectrum of vascular diseases, we studied patients at risk for cSVD (with hypertension and congestive heart failure; part I and II respectively) and patients with manifest cSVD (with lacunar stroke; part III). Overall, the studies described in this thesis are based on cross-sectional data, except for some studies in the hypertensive population. These patients participated in a longitudinal study with a brain MRI and pulse wave velocity measurements at baseline and a brain MRI and a neuropsychological assessment at 5-years follow-up.

In this chapter the main results of this thesis are summarized, put into perspective, and implications for future research are discussed. The first part of this general discussion will focus on predictors for cognitive function in patients with or at high risk for cSVD. The second part will focus on interfering factors, which we encountered during studying the association between cSVD and cognitive function, being age and the study population.

\section{PREDICTING COGNITIVE FUNCTION IN PATIENTS WITH OR AT RISK FOR CSVD}

\subsection{Hemodynamic factors}

In chapter 5 we showed that almost $10 \%$ of patients with congestive heart failure (CHF) presented with severe cognitive impairment (SCI), especially those with more severe CHF. Recent studies indicate that autoregulation of cerebral blood flow is not able to protect the brain from hypoperfusion in case of reduced cardiac output or prominent atherosclerosis ${ }^{6}$ and might consequently impair cognitive functioning. Jefferson et $\mathrm{al}^{7}$ suggest this mechanism to be the direct pathway between reduced cardiac output and abnormal brain aging. However, possible intermediate pathways should also be considered as a link between reduced cardiac output and abnormal brain aging. 
There is emerging evidence that aortic stiffness might be considered one of these intermediate pathways. The hemodynamic effects include a loss of windkessel function, which causes an increase of pulsatile energy, and transmission of the increased pulsatile energy into the cerebral microcirculation is facilitated ${ }^{8}$. This will eventually lead to microvascular damage and impaired cognitive function. In chapter 3 we investigated arterial stiffness, a surrogate marker for hypertension, as a predictor for cognitive function in patients with essential hypertension. We found that increased arterial stiffness predicts cognitive function at follow-up, but not independently of age and WML volume. This finding supports the "cerebral microvascular hypothesis" for intellectual deterioration in patients with arterial stiffness ${ }^{9}$. This hypothesis states that microvascular damage such as lacunar infarcts, WMLs and BMBs are caused by high pulsatile pressures and flow in the cerebral microvessels and may in turn affect cognitive function. Our findings also fit with the theoretical model of Jefferson et $\mathrm{al}^{7}$, in which an intermediate pathway exists (in this case arterial stiffness) between reduced cardiac output and abnormal brain aging.

It might be suggested that aortic stiffness is not the only parameter involved in microvascular damage, but also the total cerebral blood flow (tCBF). Van Elderen et $\mathrm{al}^{10}$ found that both aortic stiffness and increased tCBF contributed to white matter atrophy in patients with diabetes mellitus type 1 . tCBF and brain volumes have been associated with each other before ${ }^{11,12}$ and an increased tCBF, particularly in the presence of aortic stiffness, may cause additional pulsatility to penetrate into and affect the microcirculation with subsequent cerebral tissue damage $^{10,13,14}$. Exact pathophysiological mechanisms and causal relationships however remain unknown and need further investigation. Unfortunately we did not include measures of tCBF in our study and as such we were not able to study whether this, possibly in combination with aortic stiffness, would have influenced cognitive function in our hypertensive population.

\subsection{Progression of cSVD}

To reduce the rate of dementia in elderly patients with cardiovascular risk factors it is crucial to identify the factors responsible for the progression towards severe cognitive impairment and decline. cSVD is a frequent finding in older people with cardiovascular risk factors and may contribute to vascular dementia. Our results suggest that progression of cSVD over 5 years predicted cognitive function at 5 years follow up better than cSVD at baseline or cSVD at 5 years follow up (chapter 4). Additionally, patients with large progression of cSVD already showed significant vascular damage at baseline. This is in line with recent results by the LADIS group and implies that once patients reach a certain threshold, they show more progression of cSVD as well as cognitive decline over time. Therefore, it is of great importance to prevent severe cSVD in order to arrest any further progression, and thereby reducing the risk of decreased cognitive functioning and vascular dementia. Although evidence for a beneficial effect of antihypertensive treatment on cSVD progression is inconclusive ${ }^{15}$, it has previously been shown that progression of WMLs was limited in adequately controlled hypertensive patients ${ }^{16,17}$. Others showed that progression of WML load was reduced by active blood pressure lowering in patients with cerebrovascular disease ${ }^{18}$, for whom the greatest 
beneficial effect on WML progression was found in patients with severe WMLs at baseline. An earlier report showed a relative risk reduction of $34 \%$ for dementia and $45 \%$ for cognitive decline in patients with the active treatment, but only in patients with recurrent stroke ${ }^{19}$. In patients without recurrent stroke, no risk reductions were found. Apparently, the impact of a recurrent symptomatic infarct on cognitive function is much larger than the progression of silent WMLs and additional treatment options for the arrest or prevention of progression of silent cSVD markers should be sought.

\section{2a Lessons learned}

* The association between arterial stiffness and cognitive function might be mediated by WMLs.

* Patients with the most microvascular damage at baseline are those who also show the most progression of cSVD over time.

* Progression of cSVD over 5 years predicts cognitive function at 5 years follow up better than cSVD at baseline or cSVD at 5 years follow up

* SCI is a frequent finding in CHF patients and is more often present in patients with more severe CHF.

\section{$1.2 b$ Implications for future research}

One of the limitations of our study concerns the design with the absence of a neuropsychological assessment at baseline (and PWV measurements at follow-up), which prevents statements about causality. Longitudinal studies following increase of arterial stiffness or progression of cSVD and cognitive decline over time are needed to confirm a causal relationship between the two. Since cognitive function varies only little over time, particularly in younger populations, follow-up is suggested to be extended in future studies. Additionally, tCBF could be taken into account and an interaction effect with arterial stiffness on cognitive function could be investigated to provide further clues to the etiology of cognitive deterioration in patients with arterial stiffness.

Regarding CHF, future studies are suggested to investigate possible pathophysiological mechanisms for cognitive impairment in patients with CHF. Measures of brain perfusion and microvascular damage could be taken into account to investigate this in preferably longitudinal follow-up studies. Additionally, elaborate neuropsychological testing is advised to provide insight into specific cognitive (dys)functions in patients with CHF. It would be highly clinically relevant to study whether specific cognitive functions improves when cerebral blood flow is restored after cardiac intervention.

\subsection{Total MRI burden of cSVD}

Regarding EPVS, we demonstrated that an increase in basal ganglia EPVS was associated with a decrease in information processing speed, independent of age and WMLs (chapter 
9). This not only emphasized that specifically EPVS in the basal ganglia are associated with cSVD, but also with cSVD-related decreases in cognitive performance. Regarding BMBs, we found that BMBs are highly prevalent in a cSVD population, but that neither its presence (chapter 8), nor its progression (chapter 4), was associated with any of the cognitive domains, independent of other markers of cSVD. These results suggest that BMBs are, most likely, a marker of cSVD severity, without having a direct and independent effect on cognitive function in this population.

This led us to the question whether studies on single cSVD markers (and its relation to cognition) are of any value, since all these markers are part of the same disease process and correlate so strongly with each other. The present literature mainly focused on the effect of single markers of cSVD on cognitive function and rarely on the combined effect of all neuroimaging markers. In this thesis we made a first attempt to construct a total burden score for cSVD and related this to cognitive function. With this, we tried to capture the overall severity of cSVD, avoiding the focus on direct effects of single MRI markers. We demonstrated that accumulation of the total burden of cSVD, expressed by the co-occurrence of the different MRI markers of cSVD, is associated with decreased cognitive performance (chapter 10). It can be speculated that the co-occurrence of several different lesions represents a more severe stage of cSVD with more subcortical microstructural brain damage, resulting in cognitive dysfunction. Since we also found significant results of an independent variable (increasing blood pressure ${ }^{32}$ ) in relation to an increasing burden of cSVD, as well as significant results of an increasing burden of cSVD with a dependent variable (cognitive function), we feel that this might be an indication of the added value of incorporating multiple markers of cSVD in one variable.

\section{3a Lessons learned}

* BMBs in our population are, most likely, a marker of cSVD severity, without having a direct and independent effect on cognitive function.

* Specifically EPVS in the basal ganglia are associated with cSVD and with cSVDrelated decreases in cognitive performance.

* Accumulation of the total burden of cSVD markers is associated with a decreased performance on tests of information processing speed and overall cognition.

\section{3b Implications for future research}

We made a first attempt to assess the overall burden of cSVD in relation to cognitive function. Longitudinal studies following increase of MRI markers and cognitive decline over time are needed in order to confirm a causal relationship between total burden of cSVD and cognitive function. Additionally, larger and possibly more homogeneous samples need to be studied in order to confirm our results. We used a mixed population of lacunar stroke and hypertensive patients, although both groups are at considerable risk of silent cSVD, most prob- 
ably due to hypertension-related occlusive arteriolosclerosis. The symptomatic stroke could have had a negative impact on cognitive function although we feel that the background silent $\mathrm{cSVD}$ is a more important determinant of cognitive function ${ }^{20}$. Regarding different combinations of cSVD markers, we were not able to compare cognitive function within each category of cSVD due to low frequencies. When higher numbers of patients can be included in future studies, it would be interesting to study whether specific combinations of cSVD markers are associated with decreased cognitive performance.

\section{INTERFERING FACTORS}

\subsection{The effect of population}

The relationship between cSVD and cognitive function is widely studied and has been reported in various populations. Grossly, studies on cSVD can be categorized in population studies, studies on patients with cardiovascular risk factors, studies on patients with cSVD based on neuroimaging and studies on patients with cSVD symptomatology. Dependent on the study population associations between cSVD and cognitive function may vary widely from non-existent to extensive (chapter 2).

Each study population has its advantages and disadvantages and the choice is mainly dependent on the research question. In general, one of the issues is that studies with older patients include survivors, which implies that relatively healthy patients were included ${ }^{21}$. Another issue is the fact of a certain inclusion bias: patients participating in research projects that include a detailed assessment at a hospital tend to be less affected than those who refuse participation ${ }^{21}$. Population studies have the advantage of large numbers of patients, but on the other hand there is also a large heterogeneity in cardiovascular risk factor profiles and higher prevalence of co-morbidities. Additionally, since there is no homogeneity regarding the pathophysiology underlying the cSVD markers, conclusions on a possible relationship between cSVD markers and cognitive function cannot be generalized. In hospital studies, generalizability to the overall population is a problem as well. Generally, hypertension is treated by a general practitioner. More difficult cases, due to for example difficulty of treatment or co-morbidities, are referred to a hospital. Consequently, this may have different implications regarding the relationship with cSVD and cognitive function. Additionally, an underestimation of the effect of hypertension might be present due to more aggressive risk factor management in these patient groups. The RUN-DMC study ${ }^{22}$ suggested that the selection of subjects with cSVD should be based on the more consistent, generalizable features of cSVD, namely neuroimaging. Since the onset of cSVD is often insidious, clinically heterogeneous and often with mild symptoms, the diagnosis of patients with cSVD is often difficult based on clinical symptoms alone. The rationale of the Leukoaraiosis And Disability (LADIS) study ${ }^{23}$ was to include all patients who were incidentally found to have WMLs on MRI or CT, performed for non-specific reasons, in order to reflect the various settings in which patients with WMLs can be encountered. It was suggested that this heterogeneous composition of the sample has the advantage to be better translated to the total population of patients with WMLs. Additionally, 
other causes of leucoencephalopathy, such as inflammatory, infectious and metabolic processes could in this way be included, and not only WMLs of possible microvessel origin. An advantage of including patients in this way is the fact that large numbers of patients can be included for study purposes in a relatively short time period, since one does not have to wait for clinical symptoms to arise. Again, homogeneity regarding the pathophysiology underlying these cSVD markers might be a problem.

Some studies included patients from a memory clinic. Besides the expression of symptomatic cSVD as a lacunar syndrome, it may also express itself as cognitive impairments. Vascular dementia is the second most common form of dementia and the prevalence of cSVD in a memory clinic setting may therefore be relatively high. However, besides cognitive impairments due to cSVD, decreased cognitive function may also be the result of other underlying pathologies, such as Alzheimer's Disease (AD). Due to the underlying pathology, relationships between cSVD and cognition may differ. Results on the relationship between BMBs and cognition, for example, are inconsistent, most probably due to the use of different study populations. Cortically located BMBs have been suggested to be attributable to cerebral amyloid angiopathy ${ }^{24}$, while BMBs in the basal ganglia and thalamus have been specifically linked to hypertensive small vessel vasculopathy ${ }^{4,25,26}$. Therefore, cortical BMBs are expected in patients with $\mathrm{AD}$ and deep BMBs in patients with hypertension or lacunar stroke. Cognitive profiles may consequently be different.

The rationale for choosing our hypertensive and lacunar infarct population to study the association between cSVD and cognitive function is that both populations are at risk for cSVD, most probably due to hypertension-related occlusive arteriolosclerosis. In this way, one can create a sample which shows a high homogeneity regarding cSVD pathophysiology. Although we agree that the symptomatic stroke could have had a negative impact on cognitive function, we feel that the background silent cSVD is a more important determinant of cognitive function ${ }^{20}$.

\subsection{The effect of age}

Although we often found significant associations between cSVD and cognitive function, relationships often disappeared after correction for age. This is a very common and well-known problem in scientific studies on cSVD and cognitive function. Although age is a very important factor for cSVD as well as cognitive function and results often disappear after correction for age, this does not mean that cSVD has no role at all in cognitive function.

Van Boxtel ${ }^{27}$ stated in his thesis that the actual age effect on cognitive function is nothing more than an accumulation of effects of covert (age-related) variables that need to be identified. This implies that the relation between chronological age and cognitive function is mediated by age-related variables that are linked to the chain of neurobiological events that eventually lead to cognitive decline. Figure 1 depicts the relationships between age, the mediator variable and cognitive function. The Venn diagram next to it represents the total proportion of variance in each variable, which, to some extent, may be shared with the other variables. 
Figure 1. Relationship between age, mediator variable and cognition. Adapted from Salthouse ${ }^{28}$
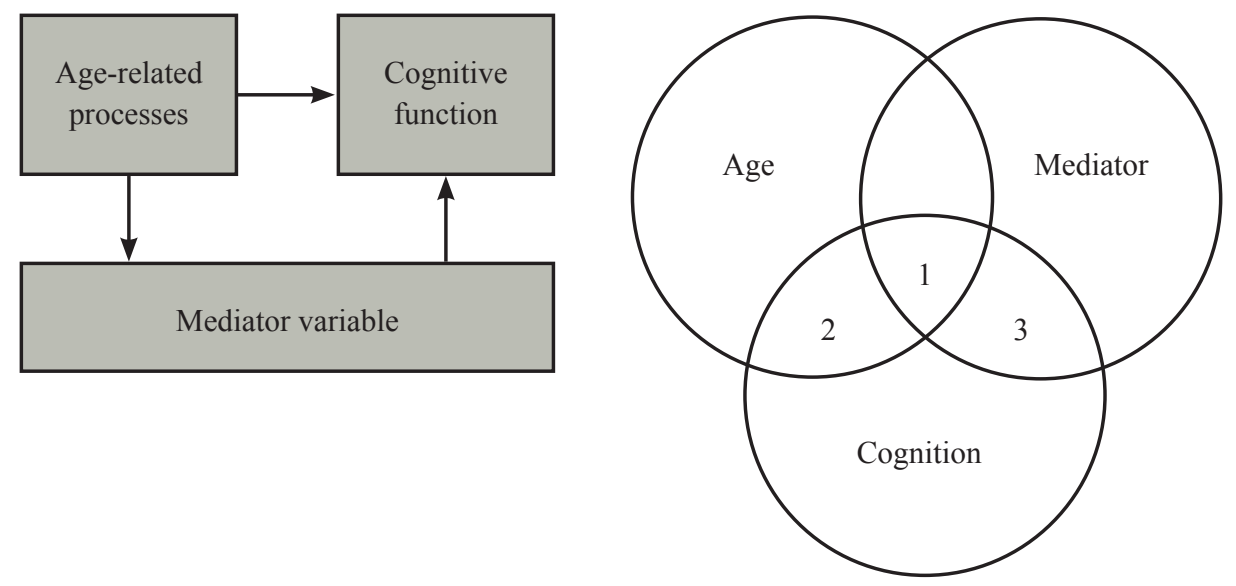

In case of cSVD as the mediator between age and cognition, our results are presented as the combined areas of 1 and 3. However, the independent effect of cSVD on cognitive function is represented by area 3 only. Since our results lost significance after correction for age, area 3 is most probably rather small in comparison to area 1 . This does not mean there is no effect of cSVD on cognitive function, but most probably larger numbers of patients need to be included to find larger independent effects. Additionally, it can be suggested to investigate a birth cohort.

\section{2 a Lessons learned}

* The effect of cSVD on cognitive function is highly dependent on the study population.

* Large numbers of patients need to be included in order to reveal the effects of cSVD on cognitive function, which might otherwise be overshadowed by the effect of age on both cSVD and cognitive function.

\section{2b Future perspectives}

Besides the mentioned interfering factors such as age and population, possible gene-environment interactions can also be studied. General cognitive functioning shows a high heritability $^{29}$, but is also influenced by educational level and adult occupation. The "cognitive reserve theory" states that subjects with a higher cognitive reserve show a greater threshold before clinical deficits appear, or in other words: they show an increased ability to cope with increasing brain damage while still functioning adequately. Childhood cognition, educational attainment and adult occupation are all contributors to cognitive reserve $\mathrm{e}^{30}$.

Regarding genetic heritability, one can focus on genes that might influence cognition or the 
expression of cSVD. CADASIL (Cerebral Autosomal Dominant Arteriopathy with Subcortical Infarcts and Leucoencephalopathy) is the most common form of hereditary stroke disorder, and is caused by a mutation on the Notch3 gene. However, in this case there is no interaction with environment. One of the most well-known genes for cognitive decline, susceptible for interaction with the environment, is the APOE $\mathcal{E} 4$ gene, which increases the risk of lateonset Alzheimer's Disease (AD). However, as opposed to the genes involved in CADASIL, these genes only increase the risk for AD and are not direct causes. Genes involved in cSVD (angiotensin- converting enzyme insertion deletion polymorphisms, endothelial nitric oxide synthase polymorphisms) were also studied, but results are inconsistent and could not be replicated ${ }^{31}$. These kind of studies most probably need very large multi-centred approaches.

\section{CONCLUSION}

In conclusion, we suggest structural changes due to cSVD seen on neuroimaging to play an intermediate role between vascular markers and cognition. These neuroimaging markers do not all have a direct and independent effect on cognitive function, but together are a representative of cSVD severity. For future studies on cognitive function in cSVD, we suggest that all neuroimaging markers should be incorporated in one variable. Age however, is a very important determinant of cSVD and cognition, and it will not be easy to separate its effects. 


\section{References}

1. Pantoni L. Cerebral small vessel disease: from pathogenesis and clinical characteristics to therapeutic challenges. Lancet Neurol. 2010;9:689-701

2. van der Flier WM, van Straaten EC, Barkhof F, Verdelho A, Madureira S, Pantoni L, et al. Small vessel disease and general cognitive function in nondisabled elderly: the LADIS study. Stroke. 2005;36:2116-2120

3. Spence JD. Cerebral consequences of hypertension: where do they lead? J Hyp. 1996;14:S139-145

4. Vernooij MW, van der Lugt A, Ikram MA, Wielopolski PA, Niessen WJ, Hofman A, et al. Prevalence and risk factors of cerebral microbleeds: the Rotterdam Scan Study. Neurology. 2008;70:1208-1214

5. Doubal FN, MacLullich AM, Ferguson KJ, Dennis MS, Wardlaw JM. Enlarged perivascular spaces on MRI are a feature of cerebral small vessel disease. Stroke. 2010;41:450-454

6. Ritz K, van Buchem MA, Daemen MJ. The heart-brain connection: mechanistic insights and models. Neth Heart J. 2013;21:55-57

7. Jefferson AL. Cardiac output as a potential risk factor for abnormal brain aging. J Alzheimers Dis. 2010;20:813-821

8. Mitchell GF, van Buchem MA, Sigurdsson S, Gotal JD, Jonsdottir MK, Kjartansson O, et al. Arterial stiffness, pressure and flow pulsatility and brain structure and function: the Age, Gene/Environment Susceptibility-Reykjavik study. Brain. 2011;134:3398-3407

9. O’Rourke MF. Brain microbleeds, amyloid plaques, intellectual deterioration, and arterial stiffness. Hypertension. 2008;51:e20; author reply e21

10. van Elderen SG, Brandts A, van der Grond J, Westenberg JJ, Kroft LJ, van Buchem MA, et al. Cerebral perfusion and aortic stiffness are independent predictors of white matter brain atrophy in type 1 diabetic patients assessed with magnetic resonance imaging. Diabetes Care. 2011;34:459-463

11. van Es AC, van der Grond J, ten Dam VH, de Craen AJ, Blauw GJ, Westendorp RG, et al. Associations between total cerebral blood flow and age related changes of the brain. PLoS One. 2010;5:e9825

12. Muller M, van der Graaf Y, Visseren FL, Vlek AL, Mali WP, Geerlings MI, et al. Blood pressure, cerebral blood flow, and brain volumes. The SMART-MR study. J Hypertens. 2010;28:1498-1505

13. Henskens LH, Kroon AA, van Oostenbrugge RJ, Gronenschild EH, Fuss-Lejeune MM, Hofman PA, et al. Increased aortic pulse wave velocity is associated with silent cerebral small-vessel disease in hypertensive patients. Hypertension. 2008;52:1120-1126

14. van Elderen SG, Brandts A, Westenberg JJ, van der Grond J, Tamsma JT, van Buchem MA, et al. Aortic stiffness is associated with cardiac function and cerebral small vessel disease in patients with type 1 diabetes mellitus: assessment by magnetic resonance imaging. Eur Radiol. 2010;20:1132-1138

15. Godin O, Tzourio C, Maillard P, Mazoyer B, Dufouil C. Antihypertensive treatment and change in blood pressure are associated with the progression of white matter lesion volumes: the Three-City (3C)-Dijon Magnetic Resonance Imaging Study. Circulation. 2011;123:266-273

16. Dufouil C, de Kersaint-Gilly A, Besancon V, Levy C, Auffray E, Brunnereau L, et al. Longitudinal study of blood pressure and white matter hyperintensities: the EVA MRI Cohort. Neurology. 2001;56:921-926 17. de Leeuw FE, de Groot JC, Oudkerk M, Witteman JC, Hofman A, van Gijn J, et al. Hypertension and cerebral white matter lesions in a prospective cohort study. Brain. 2002;125:765-772

18. Dufouil C, Chalmers J, Coskun O, Besancon V, Bousser MG, Guillon P, et al. Effects of blood pressure lowering on cerebral white matter hyperintensities in patients with stroke: the PROGRESS (Perindopril Protection Against Recurrent Stroke Study) Magnetic Resonance Imaging Substudy. Circulation. 2005;112:1644-1650

19. Tzourio C, Anderson C, Chapman N, Woodward M, Neal B, MacMahon S, et al. Effects of blood pressure lowering with perindopril and indapamide therapy on dementia and cognitive decline in patients with cerebrovascular disease. Arch Intern Med. 2003;163:1069-1075

20. Gottesman RF, Hillis AE. Predictors and assessment of cognitive dysfunction resulting from ischaemic 
stroke. Lancet Neurol. 2010;9:895-905

21. Brands AM, Kessels RP, Hoogma RP, Henselmans JM, van der Beek Boter JW, Kappelle LJ, et al. Cognitive performance, psychological well-being, and brain magnetic resonance imaging in older patients with type 1 diabetes. Diabetes. 2006;55:1800-1806

22. van Norden AG, de Laat KF, Gons RA, van Uden IW, van Dijk EJ, van Oudheusden LJ, et al. Causes and consequences of cerebral small vessel disease. The RUN DMC study: a prospective cohort study. Study rationale and protocol. BMC Neurol. 2011;11:29

23. Pantoni L, Basile AM, Pracucci G, Asplund K, Bogousslavsky J, Chabriat H, et al. Impact of agerelated cerebral white matter changes on the transition to disability -- the LADIS study: rationale, design and methodology. Neuroepidemiology. 2005;24:51-62

24. Mesker DJ, Poels MM, Ikram MA, Vernooij MW, Hofman A, Vrooman HA, et al. Lobar distribution of cerebral microbleeds: the Rotterdam Scan Study. Arch Neurol. 2011;68:656-659

25. Poels MM, Ikram MA, van der Lugt A, Hofman A, Krestin GP, Breteler MM, et al. Incidence of cerebral microbleeds in the general population: the Rotterdam Scan Study. Stroke. 2011;42:656-661

26. Staals J, van Oostenbrugge RJ, Knottnerus IL, Rouhl RP, Henskens LH, Lodder J. Brain microbleeds relate to higher ambulatory blood pressure levels in first-ever lacunar stroke patients. Stroke. 2009;40:3264-3268 27. Van Boxtel MP. Physical health, vascular risk factors, and age-related cognitive decline. Studies into physical determinants of normal cognitive aging. Department of Psychiatry and Neuropsychology. 1997

28. Salthouse TA. Mechanisms of age-cognition relations in adulthood. Hillsdale, NJ: Lawrence Erlbaum; 1992.

29. Swan GE, Carmelli D, Reed T, Harshfield GA, Fabsitz RR, Eslinger PJ. Heritability of cognitive performance in aging twins. The National Heart, Lung, and Blood Institute Twin Study. Arch Neurol. 1990;47:259262

30. Richards M, Sacker A. Lifetime antecedents of cognitive reserve. J Clin Exp Neuropsychol. 2003;25:614-624

31. Markus HS. Genes, endothelial function and cerebral small vessel disease in man. Exp Physiol. 2008;93:121-127

32. Klarenbeek P, Van Oostenbrugge RJ, Rouhl RP, Knottnerus IL, Staals J. Ambulatory blood pressure in patients with lacunar stroke: association with total MRI burden of cerebral small vessel disease. Stroke. 2013;44:2995-2999 
148 
Chapter 


\section{Summary}

Cerebral small vessel disease (cSVD) refers to a cluster of pathological mechanisms with varying etiologies that affects the small perforating end-arteries, arterioles, venules and capillaries in the brain. Manifestations of cSVD can be seen on magnetic resonance imaging and may include small focal areas of infarction (lacunar infarcts), hyperintense areas on T2- weighted and FLAIR images (white matter lesions [WMLs]), small dot-like hemosiderin deposits (brain microbleeds [BMBs]) and enlarged cerebrospinal fluid-filled cavities surrounding the perforating arteries of the brain (enlarged perivascular spaces [EPVS]).

Clinical symptoms of cSVD can be divided in acute symptoms, such as a lacunar stroke syndrome, and subacute symptoms such as cognitive impairment, mood disorders, gait disturbances and urinary symptoms. Most of these subacute symptoms have been explained by a disconnection of prefrontal-subcortical circuits. Regarding cognition this may result in executive dysfunction and slowing of psychomotor speed, but also, though less prominent, memory problems. The general aim of this thesis was to explore the association of vascular and brain imaging markers with cognitive function in patients with or at risk for cerebral small vessel disease. Therefore, we studied three hospital-based populations with an increased risk for cSVD and cognitive impairment: patients with essential hypertension, patients with congestive heart failure and patients with lacunar stroke.

Cerebral small vessel disease is associated with increasing age and vascular risk factors. Its MRI markers may be present in the healthy elderly population, but can also be expected in patients with vascular risk factors that affect the microvasculature, such as hypertension and diabetes, and in patients with clinical manifestations of cSVD, such as lacunar stroke patients. However, patients with large vessel occlusion (cortical stroke) and other cardiovascular diseases, such as coronary artery disease and congestive heart failure (CHF), may also show MRI expressions of cSVD due to cerebral hypoperfusion. Consequently, associations between markers of cSVD and cognitive function have been found in population as well as hospital-based studies. In chapter $\mathbf{2}$ we reviewed the literature for associations between structural cerebrovascular lesions related to cSVD and cognitive function in patient groups with or at risk for cardiovascular disease. We included 50 studies. Results showed associations between WMLs and decreased cognitive function in all patient groups, affecting executive function, information processing speed and memory. Progression of cerebrovascular damage paralleled by cognitive decline was found by some. An increased risk for dementia in those with WMLs was confined to those with symptomatic cardiovascular disease. We suggested that standardization of neuroimaging and neuropsychological assessment might be helpful to compare cSVD and cognitive status across the cardiovascular spectrum.

In this thesis, we further described three hospital-based populations with an increased risk for cSVD and cognitive impairment: patients with essential hypertension, patients with congestive heart failure and patients with lacunar stroke. 


\section{PART I - HYPERTENSION}

Hypertension is a major risk factor for CSVD and cognitive decline, but the mechanisms underlying hypertension-related cognitive decline are complex and not yet fully understood. Earlier we found that $20 \%$ of hypertensive patients showed advanced WMLs and that silent brain infarcts and BMBs were present in 29\% and 15\% respectively. Although hypertension constitutes a major risk factor for cSVD, it cannot account for all the risk of cognitive decline. Therefore, other risk factors need to be investigated in order to disentangle the complex model of the pathogenesis of cSVD-mediated cognitive decline. In chapter 3 we explored a "cerebrovascular mechanism" for decreased cognitive performance in hypertensive patients with arterial stiffness. We included 86 essential hypertensive patients and investigated baseline pulse wave velocity in relation to cognitive function as well as cerebral small vessel disease imaging markers (white matter lesion volume, lacunar infarcts and brain microbleeds) at 5-year follow-up. We found that increased arterial stiffness is a predictor for WML volume progression and that increased arterial stiffness predicts cognitive function at follow-up, but not independently of age and white matter lesion volume. These findings support the "cerebral microvascular hypothesis" for intellectual deterioration in patients with arterial stiffness. We also studied the association of progression of cSVD with cognitive function in hypertensive patients, described in chapter 4. We included 112 essential hypertensive patients and studied cSVD markers (WML volume, lacunar infarcts and BMBs) at baseline and their progression in relation to cognitive function at 5-year follow-up. We found that progression of cSVD over 5 years predicts cognitive function at follow-up, independently of cSVD damage at baseline. Patients with the largest progression of WMLs and progression of lacunar infarcts over 5 years follow-up had worse cognitive function compared to patients with the least or no progression. Our results imply that even only minimal progression of cSVD has consequences for cognitive functioning. Prevention of progression of cSVD is therefore warranted.

\section{PART II - CONGESTIVE HEART FAILURE}

Evidence regarding an association between $\mathrm{CHF}$ and cognitive impairment is increasing and may include up to $50 \%$ of patients with CHF. Cognitive impairment may have significant influence on health outcome in patients with $\mathrm{CHF}$, since they have to adequately manage their medication and diet, as well as to be alert on CHF symptoms. The exact pathophysiological mechanism of cognitive deficits associated with CHF is still unclear. In chapter $\mathbf{5}$ we aimed to assess the prevalence of severe cognitive impairment in elderly patients with CHF, its correlates with $\mathrm{CHF}$ severity, and its effect on morbidity and mortality. In addition, we tested if changes in measures of CHF severity would result in changes of cognitive function. We included 611 patients from the Trial of Intensified versus standard Medical therapy in Elderly patients with Congestive Heart Failure (TIME-CHF) and assessed cognitive function (Hodkinson Abbreviated Mental Test [AMT]) in relation to severity of HF (New York Heart Association [NYHA] class, N-terminal brain natriuretic peptides [NT-proBNP]) at baseline 
and 18 months $(\mathrm{N}=382)$ and effects on hospitalization-free survival and mortality. SCI was present in $9.2 \%$ of patients at baseline, but only $20 \%$ of them had a diagnosis of dementia. The prevalence of SCI remained stable during follow-up. SCI was present at baseline more often in NYHA IV patients compared to NYHA II, but it was not related to NT-proBNP levels. SCI was related to higher mortality, but not hospitalization-free survival. We concluded that SCI is a frequent, but often unrecognized finding in HF patients, but the influence of HF severity and its changes on cognitive function were less than hypothesized.

\section{PART III - LACUNAR STROKE}

We recently found that around 30\% of lacunar stroke patients are vitamin B12 deficient while in the normal elderly population this is only $10-15 \%$. This deficiency was related to the degree of periventricular white matter lesions (pWMLs). WMLs in turn are known to be related to depression, while post-stroke depressive symptoms have been associated with an increased risk of post-stroke fatigue. The prevalence of depression in lacunar stroke patients was found to be $35 \%$. The prevalence of fatigue in these patients is $38 \%$. So far, there are no data available on the relationship between vitamin B12 deficiency and either depression or fatigue in lacunar stroke patients. Besides fatigue and depression, vitamin B12 deficiency was also found to be related to decreased cognitive functioning. Since vitamin B12 deficiency is easily treatable with supplementation, possible effects on cognitive function and post-stroke fatigue and depression may have significant effects on quality of life after lacunar stroke.

In chapter 6 we described levels of fatigue and depression in first-ever lacunar stroke patients with and without vitamin B12 deficiency. In 40 first-ever lacunar stroke patients vitamin B12 levels were determined and self-report questionnaires for fatigue and depression were completed three months after stroke. Lacunar stroke patients with vitamin B12 deficiency reported significantly more fatigue and depressive symptoms than those without. These preliminary results suggested a relationship between vitamin B12 deficiency and increased levels of fatigue and depression in lacunar stroke patients. If these findings could be replicated in a larger and general stroke sample, this would open treatment options and may improve quality of life after stroke. Consequently, in chapter 7, we described the results of a pilot study into the effect of vitamin B12 supplementation on cognitive function and fatigue and depressive symptoms in lacunar stroke patients with vitamin B12 deficiency. We included 14 first-ever lacunar stroke patients with vitamin B12 deficiency who received vitamin B12 supplementation for at least 3 months. Before and after supplementation cognitive function was assessed and self-report questionnaires for fatigue and depression were completed. We found a significant improvement in verbal learning, both on a group as well as on individual level. Although fatigue and depressive symptoms decreased, this did not reach significance. Despite the limitations of this pilot study, the results justify future multi-centre randomized controlled trials to study the effect of vitamin B12 supplementation on cognition, depression and fatigue in lacunar stroke patients.

The relation between lacunar stroke and cognitive function has been well established in the 
present literature and risk factors for decreased cognitive performance or cognitive decline have been widely studied. Brain atrophy, and cSVD markers as WMLs and lacunar infarcts have been suggested as risk factors for decreased cognitive function before. More recently, BMBs and EPVS have also been recognized as markers of cSVD. In chapter 8 we described the presence of BMBs in patients with a high risk for cSVD (essential hypertensive and firstever lacunar stroke patients) and studied associations of presence, number and location of microbleeds with cognitive function, independent of other markers of cSVD. We included 188 patients (112 hypertensive patients and 76 first-ever lacunar stroke patients). We rated the presence and number of BMB and distinguished deep, lobar and infratentorial BMBs. The presence of other markers of cSVD such as (silent) lacunar infarcts and white matter lesions was also rated. BMBs were present in $21 \%$ of our sample. Patients with BMBs significantly more often presented with the other markers of cSVD. The presence of BMBs was not associated with any of the cognitive domains after correction for the other markers of cSVD and age. We concluded that BMBs are highly prevalent in a population with CSVD and co-occur with other markers of cSVD. Instead of an independent relationship, BMBs most likely are a marker of cSVD severity, without having a direct effect on cognitive function in this population.

In chapter 9 we described the relationship between EPVS and cognitive function. Although EPVS have been related to cSVD, its clinical consequences in patients with a high risk for cSVD are unknown. EPVS were rated in the basal ganglia (BG) and centrum semiovale (CSO). We found negative correlations between EPVS in the BG and all cognitive domains, independent of WMLs. After correction for age, results remained significant for information processing speed only. We demonstrated that more BG EPVS were associated with a decrease in information processing speed, independent of age and WMLs. This emphasizes that specifically EPVS in the BG are associated with cSVD, and with cSVD-related decreases in cognition.

The markers of cSVD have all been individually linked to cognitive functioning, often adjusted for each of the other manifestations. However, no data are available on the clinical consequences of the total burden of cSVD, thus the co-occurrence of two or more markers of cSVD. It might be suggested that the combined occurrence is associated with stronger reductions in cognitive function than each of the lesion types alone. In chapter $\mathbf{1 0}$ we investigated whether a higher total burden of cSVD was associated with a decreased performance in cognitive function. We included 189 patients of the above mentioned patient groups and rated the presence of any asymptomatic lacunar infarct, extensive WMLs, any deep BMB, and moderate to extensive EPVS in the basal ganglia. The presence of each marker was summed to an ordinal score between 0 and 4 and we investigated possible associations with domains of cognitive function (memory, executive function, information processing speed and overall cognition). We tested a new approach to capture total brain damage resulting from cSVD and found that accumulation of MRI burden of cSVD is associated with decreased performance on tests of information processing speed and overall cognition, implying that accumulating 
brain damage is accompanied by worse cognitive functioning.

In chapter 11 we discussed the several predicting factors for cognitive function in the patient populations described in this thesis. Additionally, we discussed interfering factors in these studies, such as the effect of population and age. In conclusion, we suggested structural changes due to cSVD seen on neuroimaging to play an intermediate role between vascular markers and cognition. These neuroimaging markers do not all have a direct and independent effect on cognitive function, but together are a representative of cSVD severity. For future studies on cognitive function in cSVD, we suggested that all neuroimaging markers should be incorporated in one variable. Age however, is a very important determinant of cSVD and cognition, and it will not be easy to separate its effects. 


\section{Samenvatting}

Cerebral small vessel disease (cSVD), ziekte van de kleine hersenvaten, verwijst naar een cluster van pathologische mechanismen met verschillende etiologieën, die de kleine perforerende eindarterieën, arteriolen, venulen en capillairen in het brein aantasten. Uitingen van cSVD zijn zichtbaar op MRI en kunnen het volgende omvatten: kleine focale infarceringen (lacunaire infarcten), hyperintense gebieden op T2-gewogen en FLAIR beeldvorming (witte stof afwijkingen [WSAs]), kleine puntvormige hemosiderine-afzettingen (microbloedingen) en verwijde, met hersenvocht gevulde ruimtes, die de perforerende arterieën omgeven (verwijde perivasculaire ruimtes [VPRs]).

Klinische symptomen van cSVD kunnen onderverdeeld worden in acute symptomen zoals een lacunair syndroom, en subacute symptomen zoals cognitieve en stemmingsstoornissen, loopproblematiek en problemen met urineren. De meeste van deze subacute symptomen kunnen verklaard worden door een storing in de verbinding tussen de prefrontale en subcorticale hersengebieden. Wat betreft cognitie kan dit resulteren in executief disfunctioneren, een vertraging in de psychomotore snelheid, maar ook geheugenproblematiek, hoewel de laatste minder voorkomt. Het algemene doel van dit proefschrift was het verkennen van de associatie tussen vasculaire en beeldvormingsmarkers en het cognitief functioneren. Hiervoor hebben we drie ziekenhuispopulaties onderzocht met een verhoogde kans op cSVD en cognitieve stoornissen: patiënten met essentiële hypertensie, patiënten met congestief hartfalen en patiënten met een lacunaire beroerte.

cSVD is geassocieerd met een toenemende leeftijd en vasculaire risicofactoren. De uitingen van cSVD kunnen aanwezig zijn bij een gezonde ouderenpopulatie, maar worden met name verwacht bij patiënten met vasculaire risicofactoren die de microvasculatuur aantasten, zoals diabetes en hypertensie, en bij patiënten met klinische uitingen van cSVD, zoals patiënten met een lacunaire beroerte. Patiënten met een occlusie van de grotere vaten (corticaal infarct) en andere cardiovasculaire aandoeningen, zoals coronair vaatlijden en congestief hartfalen, kunnen echter ook uitingen van cSVD hebben, te wijten aan cerebrale hypoperfusie. Hierdoor kunnen associaties tussen cSVD markers en cognitief functioneren gevonden worden in studies met zowel de gezonde algemene populatie als ziekenhuispopulaties.

In hoofdstuk 2 onderzochten we de literatuur om associaties te vinden tussen structurele cerebrovasculaire lesies te wijten aan cSVD en cognitief functioneren in patiëntgroepen met, of met een hoger risico op, cardiovasculaire ziektes. We includeerden in totaal 50 studies die aan de criteria voldeden. Associaties tussen WSAs en verminderd cognitief functioneren werden gevonden in alle patiëntgroepen, waarbij met name het executief functioneren, informatieverwerkingssnelheid en geheugen aangetast waren. Progressie van cerebrovasculaire schade ging in sommige studies samen met een parallelle cognitieve achteruitgang. Een verhoogd risico op dementie bij patiënten met WSAs leek voorbehouden te zijn aan degenen die al gediagnosticeerd waren met een cardiovasculaire ziekte. We concludeerden uiteindelijk ook dat standaardisatie van beeldvorming en neuropsychologisch onderzoek nuttig zou kun- 
nen zijn om de mate van cSVD en cognitieve status te vergelijken tussen deze groepen van het cardiovasculaire spectrum.

We beschrijven in dit proefschrift drie ziekenhuispopulaties met een verhoogd risico op cSVD en cognitieve stoornissen: patiënten met essentiële hypertensie, patiënten met congestief hartfalen en patiënten met een lacunaire beroerte.

\section{DEEL I - HYPERTENSIE}

Hypertensie is een belangrijke risicofactor voor cSVD en cognitieve stoornissen. De precieze mechanismen die ten grondslag liggen aan deze hypertensie-gerelateerde cognitieve achteruitgang zijn echter nog niet geheel duidelijk. In eerdere studies vonden we dat $20 \%$ van de hypertensieve patiënten uitgebreide WSAs liet zien en dat stille herseninfarcten en microbloedingen aanwezig waren bij resepctievelijk $29 \%$ en $15 \%$ van de populatie. Ondanks dat hypertensie een van de belangrijkste risicofactoren voor cSVD is, kan het niet alle risico op cognitieve stoornissen verklaren. Daarom zullen er andere risicofactoren onderzocht moeten worden om het complexe model van de pathogenese van cSVD-gemedieerde cognitieve achteruitgang te ontrafelen.

In hoofdstuk 3 hebben we een "cerebrovasculair mechanisme" voor verminderd cognitief functioneren onderzocht in hypertensieve patiënten met arteriële stijfheid. We includeerden 86 essentieel hypertensieve patiënten en onderzochten baseline pulse wave velocity (PWV), een maat voor arteriële stijfheid. We relateerden dit aan cognitief functioneren en aan cSVD (volume van WSAs, lacunaire infarcten en microbloedingen), gemeten op de 5-jaars followup. We vonden dat arteriële stijfheid WSA volume kan voorspellen en dat verhoogde arteriële stijfheid een verminderd cognitief functioneren tijdens de follow-up voorspelt, maar niet onafhankelijk van leeftijd en WSA volume. Deze bevindingen ondersteunen de "cerebrale microvasculaire hypothese" om cognitieve achteruitgang bij patiënten met arteriële stijfheid te verklaren.

We onderzochten ook de associatie van progressie van cSVD met cognitief functioneren bij hypertensieve patiënten, beschreven in hoofdstuk 4. We includeerden 112 essentieel hypertensieve patiënten en onderzochten cSVD markers (WSA volume, lacunaire infarcten en microbloedingen) op baseline, evenals hun progressie, en relateerden dit aan cognitief functioneren tijdens de 5-jaarsmeting. We vonden dat progressie van cSVD, gemeten over 5 jaar, cognitief functioneren op de 5-jaarsmeting voorspelt, onafhankelijk van de cSVD schade op baseline. Patiënten met de meeste progressie van WSAs en een vermeerdering van het aantal lacunaire infarcten na 5 jaar presteerden bovendien cognitief slechter dan patiënten met de minste progressie of zonder progressie. Deze resultaten impliceren dat zelfs minimale progressie van cSVD schade consequenties heeft voor het cognitief functioneren. Het voorkomen van progressie van deze schade is daarom van groot belang.

\section{DEEL II - CONGESTIEF HARTFALEN}

Bewijs voor een associatie tussen congestief hartfalen en cognitieve stoornissen neemt toe 
en tot wel $50 \%$ van deze patiënten kunnen last hebben van cognitieve stoornissen. Deze kunnen een zeer belangrijke invloed hebben op de gezondheidsuitkomst van deze patiënten, gezien ze medicatie adequaat moeten beheren en innemen, maar ook alert moeten zijn op symptomen van congestief hartfalen. Het exacte pathofysiologische mechanisme achter de cognitieve stoornissen in deze patiëntengroep is onduidelijk. Het doel van hoofdstuk $\mathbf{5}$ was het vaststellen van de prevalentie van ernstige cognitieve stoornissen bij oudere patiënten met congestief hartfalen. Daarnaast onderzochten we correlaties met de ernst van het hartfalen, en de effecten hiervan op morbiditeit en mortaliteit. Hieraan toegevoegd, waren we ook geïnteresseerd of veranderingen in de ernst van het hartfalen gerelateerd waren aan veranderingen in het cognitief functioneren. We includeerden 611 patiënten van de Trial of Intensified versus Standard Medical therapy in Elderly patients with Congestive Heart Failure (TIME-CHF) en evalueerden het cognitief functioneren (Abbreviated Mental Test) in relatie tot de ernst van het hartfalen (New York heart Association [NYHA] klasse, N-terminal brain natriuretic peptides [NT-proBNP]) op baseline en na 18 maanden $(\mathrm{N}=382)$, en in relatie tot de effecten op ziekenhuisopnamevrije overleving en mortaliteit. Ernstige cognitieve stoornissen kwamen voor bij 9.2\% van de patiënten op baseline, terwijl maar $20 \%$ van hen een diagnose dementie had. De prevalentie van ernstige cognitieve stoornissen bleef stabiel gedurende de follow-up. Ernstige cognitieve stoornissen kwamen vaker voor bij patiënten in NYHA klasse IV dan in NYHA klasse II op baseline, maar waren niet gerelateerd aan NT-proBNP levels. Ernstige cognitieve stoornissen waren gerelateerd aan een hogere mortaliteit, maar niet aan ziekenhuisopnamevrije overleving. We concludeerden dat ernstige cognitieve stoornissen frequent voorkomen in deze groep patiënten met hartfalen, maar vaak niet herkend worden. Desondanks was de invloed van de ernst van het hartfalen op het cognitief functioneren minder dan verwacht.

\section{DEEL III - LACUNAIRE BEROERTE}

Recent vonden we dat ongeveer $30 \%$ van de patiënten met een lacunaire beroerte een vitamine B12 tekort vertoonden, terwijl in de normale oudere populatie dit maar $10-15 \%$ bedraagt. Dit tekort bleek gerelateerd aan de mate van periventriculaire WSAs. WSAs zijn op hun beurt gerelateerd aan depressie, terwijl depressieve symptomen na een beroerte geassocieerd zijn aan een verhoogd risico op vermoeidheid na een beroerte. De prevalentie van depressie bij patiënten met een lacunaire beroerte bedraagt 35\%. De prevalentie van vermoeidheid in deze groep is $38 \%$. Tot nu toe is er niets bekend over de relatie tussen vitamine B12 tekort en depressie of vermoeidheid bij patiënten met een lacunaire beroerte. Naast vermoeidheid en depressie is vitamine B12 tekort ook gerelateerd aan een verminderd cognitief functioneren. Omdat vitamine B12 tekort gemakkelijk te behandelen is met het suppleren ervan, kunnen mogelijk effecten op cognitief functioneren en vermoeidheid en depressie na een beroerte belangrijke effecten hebben op de kwaliteit van leven na een lacunaire beroerte.

In hoofdstuk 6 beschreven we de mate van vermoeidheid en depressie bij patiënten met een lacunaire beroerte met en zonder vitamine B12 tekort. We bepaalden de vitamine B12 spiegel 
bij 40 patiënten met een lacunaire beroerte en lieten hen, drie maanden na de beroerte, vragenlijsten invullen over vermoeidheid en depressie. Patiënten met een vitamine B12 tekort rapporteerden significant vaker depressieve en vermoeidheidsklachten dan degenen zonder tekort. Deze resultaten suggereren een relatie tussen een vitamine B12 tekort en een toegenomen mate van vermoeidheid en depressie bij patiënten met een lacunaire beroerte. Wanneer deze resultaten gerepliceerd kunnen worden in een grotere en algemene populatie met een beroerte, opent dit mogelijkheden voor behandeling en kan het de kwaliteit van leven na een beroerte verbeteren. Hierop aansluitend, beschreven we in hoofdstuk 7 de resultaten van onze pilot studie naar de effecten van vitamine B12 suppletie op cognitief functioneren en depressieve en vermoeidheidsklachten bij patiënten met een lacunaire beroerte en een vitamine B12 tekort. We includeerden 14 patiënten met een lacunaire beroerte en een vitamine B12 tekort. Vitamine B12 suppletie werd gegeven door de huisarts voor tenminste drie maanden. Voor en na deze suppletie stelden we het cognitief functioneren vast en werden vragenlijsten met betrekking tot vermoeidheid en depressie ingevuld. We vonden een significante verbetering van het verbaal leren, zowel op individueel als op groepsniveau. Depressieve en vermoeidheidsklachten namen af, maar niet statistisch significant. Ondanks de beperkingen van deze pilot studie, rechtvaardigen deze resultaten wel toekomstig multi-center gerandomiseerd en gecontroleerd onderzoek om de effecten van vitamine B12 suppletie op het cognitief functioneren, depressie en vermoeidheid te bestuderen in deze groep patiënten.

De relatie tussen een lacunaire beroerte en cognitief functioneren is meermaals bevestigd in de huidige literatuur en ook risicofactoren voor afnemende cognitieve prestaties of cognitieve achteruitgang zijn uitgebreid onderzocht. Atrofie van het brein en cSVD markers zoals WSAs en lacunaire infarcten werden al eerder genoemd als risicofactoren voor een verminderd cognitief functioneren. Naast WSAs en lacunaire infarcten worden nu ook microbloedingen en verwijde perivasculaire ruimtes erkend als markers voor cSVD. In hoofdstuk 8 beschreven we de aanwezigheid van microbloedingen bij patiënten met een verhoogd risico op cSVD (essentiële hypertensiepatiënten en patiënten met een eerste lacunaire beroerte) en we bestudeerden associaties tussen de aanwezigheid, aantal en locatie van microbloedingen en cognitief functioneren, onafhankelijk van de andere markers van cSVD. We includeerden in totaal 188 patiënten (112 hypertensieve patiënten en 76 patiënten met een eerste lacunaire beroerte). We scoorden de aanwezigheid en aantallen microbloedingen en maakten daarin onderscheid tussen diepe, lobaire en infratentoriële microbloedingen. Ook scoorden we de aanwezigheid van andere markers van cSVD zoals (stille) lacunaire infarcten en WSAs. Microbloedingen waren aanwezig bij $21 \%$ van onze populatie. Patiënten met microbloedingen hadden ook significant vaker andere markers van cSVD. De aanwezigheid van microbloedingen was echter niet geassocieerd met een van de cognitieve domeinen na correctie voor de andere cSVD markers en leeftijd. Hieruit concludeerden we dat microbloedingen wel frequent voorkomen in deze populatie met cSVD en vaak samen voorkomen met een van de andere cSVD markers. Maar in plaats van een onafhankelijke relatie, lijken microbloedingen eerder een marker te zijn van de ernst van de cSVD, zonder echt een direct effect te hebben 
op het cognitief functioneren in deze populatie.

In hoofdstuk 9 beschreven we de relatie tussen VPRs en cognitief functioneren. Ondanks dat VPRs eerder al gerelateerd zijn aan cSVD, zijn de klinische consequenties bij patiënten met een verhoogd risico op cSVD onbekend. VPRs werden gescoord in de basale ganglia en centrum semiovale. We vonden negatieve correlaties tussen VPRs in de basale ganglia en het cognitief functioneren op alle domeinen, onafhankelijk van WSAs. Na correctie voor leeftijd waren enkel de resultaten voor informatieverwerkingssnelheid nog statistisch significant. We toonden aan dat meer VPRs in de basale ganglia geassocieerd waren met een afname in informatieverwerkingssnelheid, onafhankelijk van leeftijd en WSAs. Dit benadrukt dat specifiek de VPRs in de basale ganglia geassocieerd zijn met cSVD en cSVD-gerelateerde afnames van het cognitief functioneren.

De markers van cSVD zijn allemaal individueel gelinkt aan cognitief functioneren, zelfs na correctie voor aanwezigheid van elk van de andere manifestaties. Er is echter niets bekend over de klinische consequenties van de totale schade van cSVD, dus het samen voorkomen van twee of meer cSVD markers. Het kan gesuggereerd worden dat het samen voorkomen van markers geassocieerd is met sterkere reducties van het cognitief functioneren dan elk van de lesies alleen. In hoofdstuk 10 onderzochten we of de aanwezigheid van meer uitingen van cSVD geassocieerd was met een verminderde cognitieve prestatie. We includeerden 189 patiënten van de bovengenoemde patiëntgroepen en scoorden de aanwezigheid van een asymptomatisch lacunair infarct, uitgebreide WSAs, een microbloeding, en gematigd tot uitgebreide VPRs in de basale ganglia. De aanwezigheid van elke marker werd uiteindelijk opgeteld tot een ordinale score tussen de 0 en 4 . We bestudeerden associaties tussen deze score en alle cognitieve domeinen (geheugen, executief functioneren, informatieverwerkingssnelheid en algemene cognitie). Hiermee hebben we een nieuwe benadering getest om de totale schade in het brein, te wijten aan cSVD, te inventariseren in 1 variabele. We vonden dat een opeenstapeling van het aantal cSVD markers geassocieerd is met een slechtere prestatie op testen voor informatieverwerkingssnelheid en algemene cognitie. Dit impliceert dat cumulerende hersenschade samengaat met een achteruitgang van het cognitief functioneren.

In hoofdstuk 11 bespreken we de verschillende voorspellende factoren voor het cognitief functioneren van de patiënten populaties die beschreven werden in dit proefschrift. Daarnaast bespreken we interfererende factoren in deze studies, zoals het effect van de onderzochte populatie en het effect van leeftijd. Concluderend stellen we dat structurele veranderingen op beeldvorming, te wijten aan cSVD, een intermediërende rol spelen tussen vasculaire markers en cognitie. Deze cSVD markers hebben niet allemaal een direct en onafhankelijk effect op het cognitief functioneren, maar lijken eerder een maat te zijn voor de ernst van cSVD. We stellen voor om bij toekomstige studies alle markers van cSVD mee te nemen in 1 variabele. Leeftijd blijft echter een erg belangrijke determinant van zowel cSVD als cognitie en het zal moeilijk blijven deze effecten van elkaar te onderscheiden. 
160 


\section{Dankwoord}

Het schrijven van een proefschrift is in vele opzichten een solistisch project. Gelukkig heb ik lang niet alles alleen moeten doen en heb ik het beste en leukste promotieteam dat ik me kon wensen. Daarnaast heb ik veel lieve mensen om me heen gehad die me hierin hebben geholpen en die ervoor zorgden dat ik elke dag weer met veel plezier naar mijn werk ging.

\section{"Jij anders in het midden?"}

Prof. Dr. R.J. van Oostenbrugge, beste Robert. Ik leerde je kennen als de enorm drukke clinicus met de witte broek en doktersjas. Toen Jan ermee stopte en jij mijn dagelijks begeleider werd, was je net hoofd van de afdeling en hoofdopleider geworden en je had ook nog een tiental onderzoekers die je moest begeleiden. Gelukkig vond je tussen al deze werkzaamheden nog tijd om mijn 200 scans te beoordelen, mijn onderzoek en manuscripten te begeleiden en af en toe eens gezellig te komen kletsen. De afgelopen jaren hebben we elkaar steeds beter leren kennen, wat resulteerde in hilarische mails over frauderende psychologen, blondjes en oesters eten met Argentijnse profs. Een korte anekdote na afwijzing van major revisions van mijn review typeert je: "mbt de te bepalen auteursvolgorde: jij in het midden?" $<$ Vandaag vind ik alles goed. Áls het maar gepubliceerd wordt $>$ "heb hier nog wel een paar tissues liggen hoor". Hierna kon ik weer lachen en heb ik het manuscript opnieuw ingestuurd. Tijdens je inauguratie bleek nog eens hoe geliefd en gewaardeerd je wordt. Ik vind het een eer dat ik je promovendus ben en ik hoop dat we nog lang mogen samenwerken, te beginnen met onze gezamenlijke promovenda Renske.

\section{"Consistentie!"}

Dr. A.A. Duits, beste Annelien. Waar begin ik bij jou? Ik heb zoveel aan je te danken. In de eerste plaats deze promotieplek, en nu dankzij onder andere jouw inspanningen ook nog een opleidingsplek. Wauw! Vanaf het eerste moment dat ik solliciteerde voor een stageplek konden we het erg goed vinden, qua interesses binnen de psychologie, maar vooral ook persoonlijk. Jij was de nachtuil en ik het ochtendmens. Vaak stuurde je nog diep in de nacht revisies door van stukken en kon ik hier 's ochtends meteen mee aan de slag. Hoe goed ik het ook probeerde, je kon me toch altijd pakken op punten, komma's en vooral de consistentie. Dit kwam de manuscripten echt ten goede. Ik vind het echt een eer dat je zo je best voor mij hebt gedaan. Ik zal je voor altijd dankbaar zijn!

\section{"Nu kun je zeker weer een paar weken vooruit"}

Dr. J. Staals, beste Julie. Wat een eer dat ik je eerste promovendus ben! Wat was je altijd kritisch, maar dat verwachtte ik ook van je. Hoeveel scans hebben we samen wel niet gezien? Eerst met jou alleen, dan met Robert en dan ook nog eens met zijn driëen. In je onderzoekstijd tijdens je opleiding heb ik je leren kennen als een zeer gefocust iemand. Julie hoorde je werkelijk niet als ze aan het nadenken was. Hierna werd je als neuroloog aangenomen op de afdeling en nu trek je samen met Robert het vasculair wetenschappelijk onderzoek. Dat 
bewonder ik enorm. Het verschil tussen full time onderzoek doen en in de kliniek staan werd wel vaker duidelijk. Als je weer een manuscript van me had gereviseerd, zei je trots: "zo, nu kun je zeker weer een paar weken vooruit." Als ik je dan bij de lunch zag, durfde ik bijna niet te zeggen dat ik je opmerkingen alweer verwerkt had. Een onvergetelijk moment vond ik ook toen we samen een kamer deelden in Londen en tot 1 uur 's nachts een manuscript hebben gereviseerd en analyses hebben uitgevoerd. Bedankt voor alles!

\section{"Nog vragen?"}

Prof. dr. J. Lodder, beste Jan. Ik zal nooit het "sollicitatiegesprek" met je vergeten. Na een half uur monoloog van jouw zijde over het LACI-onderzoek tot dan toe, vroeg je me of ik "nog vragen" had. Vol ongeloof vroeg ik toen of ik was aangenomen. Dat vertrouwen heeft me goed gedaan. Eenmaal gestart kon ik altijd bij je binnenlopen, zodat ik een protocol kon schrijven voor mijn studies van de komende jaren. Helaas kwam het AZM vroegtijdig met een “offer you can't refuse” en stopte je met werken. Ik was een promotieteamlid armer, maar de Belgische Tae Kwondobond een enorme fanatiekeling rijker. Bedankt voor je altijd kritische blik.

Mijn paranimfjes Caroline en Els. Samen zaten we op de onderzoekskamer en we waren "de kleine Belg die in Nederland werkte", "de Nederlander die eigenlijk een Belg was", en de "Nederlander met de Belg die in België ging wonen". Wat hebben we samen een lol gehad. Daarom staan jullie nu naast me. Super veel succes met het afronden van jullie opleiding en natuurlijk jullie eigen boekjes!

Lieve onderzoekers en collega's van de neurovasculaire onderzoeksgroep, Pim, Caroline, Ellen, Miesje, Debbie, Martine, Iris, Annelien, Saartje en Lies. Thanks voor alle lol op de congressen. Ik hoef maar 1 woord te zeggen: Tiger Tiger!

Lieve Anouk. Je bent een prachtmens! Bedankt voor de inclusie van de patiënten en de leuke tijd en mooie gesprekken in Lissabon.

Renske en Eleana, super veel succes met het verderzetten van, onder andere, het cognitief onderzoek binnen de vasculaire neurologie. Jullie maken er vast iets geweldigs van!

Leon Henskens, Bram Kroon en Peter de Leeuw. Bedankt voor het mogen gebruiken van de baseline gegevens van de HYBRiD en het patiëntenbestand. Zonder jullie was dit onderzoek er niet geweest.

Ed Gronenschild. Beste Ed, zonder jouw inzet had ik al mijn MRI's voor niets gemaakt. Super bedankt voor alles en geniet van je pensioen over een tijdje.

Lieve Reinhilde, jij was de kip, ik het konijn. Dankjewel voor alle squash-partijen de afgelo- 
pen 6 jaren. Een vraag rest wel: zouden we meer caloriëen verbrand hebben met squashen of met onze slappe lach op het veld? Helaas heeft het ziekenhuis andere prioriteiten en zullen we het per 1 januari 2014 op een andere plek dan de squashbaan moeten gaan zoeken.

Lieve pap, mam, Myrt, Pleen en Lauraatje. Het is soms lastig om elkaar te zien als je bijna allemaal in een ander land woont, maar wat hebben we het gezellig als we weer samen zijn. Het liefste had ik jullie allemaal dichtbij, maar pap en mam hebben ons te veel reislust meegegeven. Ik hou van jullie en hoop dat jullie er allemaal bij kunnen zijn vandaag.

Alex, lieveke. Om me te plagen heb je me vaker gevraagd of je wel in mijn dankwoord kwam. Nou, bij deze. Eigenlijk hoef ik hier niets te zeggen, dat weet je toch al allemaal. Kus! 
Publications 


\section{Publications}

Huijts, M., Duits, A.A., Van Oostenbrugge, R.J., Kroon, A.A., De Leeuw, P.W., \& Staals, J. (2013) Accumulation of MRI markers of cerebral small vessel disease is associated with cognitive function. A study in first-ever lacunar stroke and hypertensive patients. Frontiers in Aging Neuroscience 5: 72 (IF 5.20)

Pons van Dijk, G., Huijts, M., Lenssen, A.F., Leffers, P., Kingma, H., Lodder, J. Cognition improvement in middle-aged Taekwondo novices. Results from the SEKWONDO study. Frontiers in Aging Neuroscience 5: 74 (IF 5.20)

Huijts, M., Staals, J., \& Duits, A.A. (2013) Letter by Huijts et al regarding article "cerebral microbleeds and cognition in patients with symptomatic small vessel disease". Stroke 44 (6): e69 (IF 6.16)

Huijts, M., Van Oostenbrugge, R.J., Duits, A.A., Burkard, T., Muzzarelli, S., Maeder, M., Schindler, R., Pfisterer, M., \& Brunner-La Rocca, H.P. (2013) Heart failure and cognitive impairment. Results from the Trial of Intensified vs Standard Medical Therapy in Elderly Patients with Congestive Heart Failure (TIME-CHF) randomized trial. European Journal of Heart Failure 15 (6): 699-707 (IF 5.25)

Huijts, M., Van Oostenbrugge, R.J., Rouhl, P.W., Menheere P., \& Duits, A.A. (2013) Effects of vitamin B12 suppletion on cognition, depression and fatigue in patients with lacunar stroke. International Psychogeriatrics 25 (3):508-510 (IF 2.19)

Huijts, M., Duits, A.A., Staals, J., \& Van Oostenbrugge, R.J. (2012) Association of vitamin B12 deficiency with fatigue and depression after lacunar stroke. PLoS ONE 7(1): e30519 (IF 4.09)

Huijts, M., Duits, A.A., \& Van Oostenbrugge, R.J. Cerebral small vessel disease and cognitive function in patients with or at risk for cardiovascular disease.

Huijts, M., Duits, A.A., Staals, J., Kroon, A.A., De Leeuw, P.W., \& Van Oostenbrugge, R.J. Cognitive function and enlarged perivascular spaces in patients with cerebral small vessel disease. Submitted.

Huijts, M., Van Oostenbrugge, R.J., Staals, J., Kroon, A.A., De Leeuw, P.W., \& Duits, A.A. Brain microbleeds are not independently related to cognition in patients with cerebral small vessel disease. Submitted.

Huijts, M., Duits, A.A., Staals, J., Gronenschild, E., Kroon, A.A., De Leeuw, P.W., \& Van Oostenbrugge, R.J. Progression of cerebral small vessel disease predicts cognitive function at follow-up in hypertensive patients. Submitted.

Huijts, M., Staals, J., Duits, A.A., Gronenschild, E., Kroon, A.A., De Leeuw, P.W., \& Van Oostenbrugge, R.J. Arterial stiffness and cognitive function in essential hypertensive patients. Submitted. 


\section{Oral presentations}

Huijts, M., Duits, A.A., Staals, J., \& Van Oostenbrugge, R.J. 7th International Congress on Vascular Dementia. October 2011, Riga, Latvia. Vitamin B12 deficiency in first-ever lacunar stroke patients is associated with post-stroke fatigue and depression.

Huijts, M., Brunner-La Rocca, H.P., Duits, A.A., \& Van Oostenbrugge, R.J. Twenty-first European Stroke Conference. May 2012, Lisbon, Portugal. Stepwise progression of cognitive impairment with advancing stages of heart failure.

Huijts, M., Duits, A.A., Van Oostenbrugge, R.J., Kroon, A.A., De Leeuw, P.W., \& Staals, J. International Neuropsychological Society, Mid-Year Meeting. July 2013, Amsterdam, The Netherlands. The total burden of brain MRI markers of cerebral small vessel disease is associated with cognitive function in patients at risk for cerebral small vessel disease.

\section{Poster presentations}

Huijts, M., Van Oostenbrugge, R.J., Duits, A.A., \& Lodder, J. Nineteenth European Stroke Conference. May 2010, Barcelona, Spain. Worse cognitive performance in lacunar stroke patients than in hypertensive patients is due to more severe white matter lesions, but not to the symptomatic infarct.

Huijts, M., Duits, A.A., Staals, J., \& Van Oostenbrugge, R.J. Twentieth European Stroke Conference. May 2011, Hamburg, Germany. Vitamin B12 deficiency in first-ever lacunar stroke patients is associated with post-stroke fatigue and depression.

Huijts, M., Van Oostenbrugge, R.J., Staals, J., Kroon, A., De Leeuw, P.W., \& Duits, A.A. Twenty-second European Stroke Conference. May 2013, London, United Kingdom. Brain microbleeds are not independently related to cognitive function in patients with a high prevalence of cerebral small vessel disease.

Huijts, M., Duits, A.A., Van Oostenbrugge, R.J., Kroon, A., De Leeuw, P.W., \& Staals, J. Twenty-second European Stroke Conference. May 2013, London, United Kingdom. The total burden of brain MRI markers of cerebral small vessel disease is associated with cognitive function in patients at risk for cerebral small vessel disease. 
170 


\section{Curriculum Vitae}


172 


\section{Curriculum Vitae}

Marjolein Huijts werd geboren op 2 april 1984 in Eindhoven en groeide op in het Brabantse Bladel. In 2002 behaalde zij haar VWO-diploma aan het Pius X College te Bladel. Na uitloting voor geneeskunde vertrok zij in oktober 2002 voor 10 maanden naar Australië om te reizen en werken. In augustus 2003 startte zij met de opleiding Psychologie aan de Universiteit Maastricht. Na een klinische- en onderzoeksstage op de afdeling Medische Psychologie van het Maastrichts Universitair Medisch Centrum (MUMC) rondde zij haar opleiding Psychologie, met de Master Neuropsychologie, in februari 2008 af. Van juni 2008 tot september 2012 werkte zij als promovendus op de afdeling Neurologie van het MUMC onder leiding van Prof. Dr. R.J. van Oostenbrugge, Dr. J. Staals en Dr. A.A. Duits (afdeling Psychiatrie en Psychologie). Hierna werkte ze als psycholoog bij de afdeling Psychiatrie en Psychologie van het MUMC en is ze momenteel werkzaam als psycholoog/ behandelaar bij een tweedelijns verslavingskliniek (Vincere-GGZ) in Sittard. Per 1 januari 2014 zal ze in opleiding zijn tot gezondheidszorgpsycholoog bij de afdeling Psychiatrie en Psychologie van het MUMC.

Marjolein Huijts was born on the 2nd of April 1984 in Eindhoven and grew up in Bladel. She finished secondary school at the Pius X College in Bladel in 2002. When she wasn't allotted a place to study medicine in the Netherlands, she decided to leave for Australia for 10 months in October 2002. In August 2003 she started to study Psychology at Maastricht University. She finished her training in Psychology, with a Master's in Neuropsychology, in February 2008 after a clinical and research internship at the Department of Medical Psychology at the MUMC. From June 2008 until September 2012 she worked as a PhD candidate at the Department of Neurology of the MUMC under supervision of Prof. Dr. R.J. van Oostenbrugge, Dr. J. Staals and Dr. A.A. Duits (Department of Psychiatry and Psychology). Hereafter, she worked as a clinical psychologist at the Department of Psychiatry and Psychology of the MUMC and now works as a clinical psychologist in an addiction care clinic (Vincere-GGZ in Sittard). As of the first of January 2014 she will start her residency in Health Psychology at the department of Psychiatry and Psychology of the MUMC. 
174 
Modern world 
176 


\section{Modern world}

If you would like a digital version (pdf) of this thesis, please scan the following QR-code with your smartphone or tablet or type in the link below.

\section{$\mathrm{PhD}$ thesis}

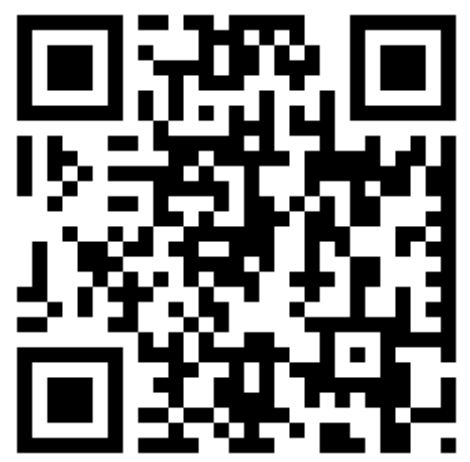

LinkedIn profile

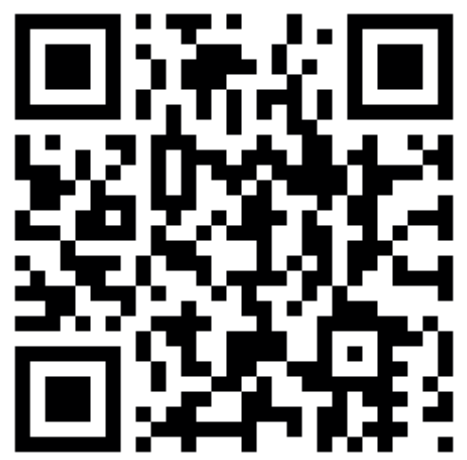

Link: www.proefschriftmarjolein.weebly.com

One can contact the author by email: M.Huijts@mumc.nl 
178 
The cover photo was kindly provided by Robert and Shana ParkeHarrison. It is titled "Guardian" and is one of the photographs within the series of "Burn Season" of "Architect's Brother". The twigs of the "wings" represent the small vessels in the brain.

"Robert and Shana create works in response to the ever-bleakening relationship linking humans, technology, and nature. These works feature an ambiguous narrative that offers insight into the dilemma posed by science and technology's failed promise to fix our problems, provide explanations, and furnish certainty pertaining to the human condition". 